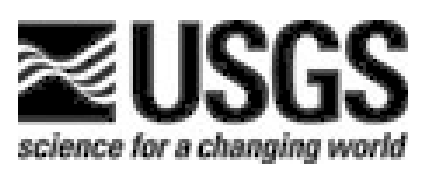

\title{
Lead isotopic analyses of selected soil samples from the USEPA Vasquez Blvd.-I-70 study area, Denver, Colorado
}

\author{
By Daniel M. Unruh ${ }^{1}$
}

Open-File Report 02-321

2002

This report is preliminary and has not been reviewed for conformity with U.S. Geological Survey editorial standards and stratigraphic nomenclature. Any use of trade, product, or firm names is for descriptive purposes only and does not imply endorsement by the U.S. Government

\section{U.S. Department of the Interior \\ U.S. Geological Survey}

${ }^{1} \mathrm{MS}$ 963, Box 25046, Federal Center, Denver, Colorado 80225 


\section{Table of Contents}

Chapter

Introduction

Analytical Procedures

Chemical Procedures

Quality Assurance and Quality Control

Chain of Custody (COC)

Analytical Results and Discussion

Lead Isotopic Compositions

Sources of Lead

Two-Component Mixing

Three-Component Mixing

Focal versus Adjacent Samples

Soils from a Single Property

Conclusions

Suggestions for Future Work

Answers to Questions Posed by USEPA

References cited
Page

5

6

6

6

7

7

7

17

21

25

29

29

35

36

37

38

Appendix 1. Standard analytical procedures for lead isotopic analyses (nitric acid-hydrogen peroxide

digestion) of metal-rich samples.

40

Appendix 2. Quality Assurance and

Quality Control (QA and QC) 43

Reagent Preparations and Analytical Blanks $\quad 43$

Mass Spectrometry Calibrations $\quad 44$

Mass Spectrometry Standards $\quad 45$

Data Reduction $\quad 48$

Duplicate analyses $\quad 50$

Method Determination Limit

(Practical Quantitation Limit) 54 


\section{List of Figures}

Figure 1. ${ }^{206} \mathrm{~Pb} /{ }^{204} \mathrm{~Pb}$ vs. ${ }^{207} \mathrm{~Pb} /{ }^{204} \mathrm{~Pb}$ and ${ }^{206} \mathrm{~Pb} /{ }^{204} \mathrm{~Pb}$ vs. ${ }^{208} \mathrm{~Pb} /{ }^{204} \mathrm{~Pb}$ diagrams for selected soil samples from the Vasquez Blvd.-I70 study area, coded by $\mathrm{Pb}$ concentrations.

Figure 2. ${ }^{206} \mathrm{~Pb} /{ }^{204} \mathrm{~Pb}$ vs. ${ }^{207} \mathrm{~Pb} /{ }^{204} \mathrm{~Pb}$ and ${ }^{206} \mathrm{~Pb} /{ }^{204} \mathrm{~Pb}$ vs. ${ }^{208} \mathrm{~Pb} /{ }^{204} \mathrm{~Pb}$ diagrams for selected soil samples from the Vasquez Blvd.-I70 study area, coded by As concentrations.

Figure 3 As vs. $\mathrm{Pb}$ concentrations for selected samples from the VBI70 study area.

Figure $4 .{ }^{206} \mathrm{~Pb} /{ }^{204} \mathrm{~Pb}$ vs. $\mathrm{Pb}$ concentration $(\mathrm{A})$ and ${ }^{206} \mathrm{~Pb} /{ }^{204} \mathrm{~Pb}$ vs.

$1 / \mathrm{Pb}$ concentration for selected soil samples from the VBI70 study area.

Figure 5. ${ }^{206} \mathrm{~Pb} /{ }^{204} \mathrm{~Pb}$ vs. ${ }^{207} \mathrm{~Pb} /{ }^{204} \mathrm{~Pb}$ and ${ }^{206} \mathrm{~Pb} /{ }^{204} \mathrm{~Pb}$ vs. ${ }^{208} \mathrm{~Pb} /{ }^{204} \mathrm{~Pb}$ diagrams for focal vs. adjacent samples from the VBI70 study area.

Figure $6 .{ }^{206} \mathrm{~Pb} /{ }^{204} \mathrm{~Pb}$ vs. $1 / \mathrm{Pb}$ concentrations for focal vs. adjacent samples from VBI70 study area.

Figure 7. ${ }^{206} \mathrm{~Pb} /{ }^{204} \mathrm{~Pb}$ vs. ${ }^{207} \mathrm{~Pb} /{ }^{204} \mathrm{~Pb}$ and ${ }^{206} \mathrm{~Pb} /{ }^{204} \mathrm{~Pb}$ vs. ${ }^{208} \mathrm{~Pb} /{ }^{204} \mathrm{~Pb}$ diagrams for samples from a single residential property.

Figure $8{ }^{206} \mathrm{~Pb} /{ }^{204} \mathrm{~Pb}$ vs. $1 / \mathrm{Pb}$ concentrations for samples from a single residential property.

Figure A2-1. Percent Standard Error in ${ }^{206} \mathrm{~Pb} /{ }^{204} \mathrm{~Pb}$ vs. ${ }^{204} \mathrm{~Pb}$ beam intensity for seven analyses of NIST standard SRM 981. 


\section{List of Tables}

Table 1. Sample numbers, sample types, and lead and arsenic concentrations in selected samples from the VBI70 study area.

Table 2. Lead isotopic compositions in acid digestions of selected soil samples from the VBI70 study area.

Table 3. Sources of lead in residential samples from the VBI70 study area.

Table 4. Two-component mixing parameters for selected soil samples from VBI70 study area.

Table 5. Three-component mixing calculations for selected soil samples from the VBI70 study area.

Table A2-1. Lead isotopic analyses of NIST standard SRM 981.

Table A2-2. Lead isotopic analyses of NIST standard SRM 982.

Table A2-3. Lead isotopic compositions from replicate runs of Sample 3-15642-B, Vasquez Blvd.-I70 Project.

Table A2-4. Lead isotopic data for replicate acid-digestions of selected soils samples from the Vasquez Blvd.-170 Project.

Table A2-5. Summary of results for determination of the method determination limit (practical quantitation limit). 


\section{Introduction}

Large amounts of arsenic contamination, in excess of $2000 \mathrm{ppm}$, have been found in some residential surface soils in northern Denver, Colorado (USEPA, 1999). Associated with the arsenic are elevated levels of metals such as lead, cadmium and mercury. Potential sources of this contamination include waste from smelters in the area and commercial herbicide containing arsenic trioxide and lead arsenate (USEPA, 1999). As a part of the U.S. Environmental Protection Agency's Vasquez Boulevard-I-70 Project (VBI70 project; USEPA, 1999), lead isotopic analyses of selected soil samples, smelter waste, and a commercial herbicide and a commercial lead arsenate pesticide have been performed in order to constrain the possible sources of elevated lead, and by proxy arsenic, found in these residential soils.

The isotopes of lead can be used as a natural tracer in determining sources of contaminants in soils and stream sediments (e.g. Church and others, 1997; Fey and others, 1999; Unruh and others, 2000). The element lead (Pb) consists of four naturally occurring and stable isotopes, ${ }^{204} \mathrm{~Pb},{ }^{206} \mathrm{~Pb},{ }^{207} \mathrm{~Pb}$, and ${ }^{208} \mathrm{~Pb}$. Three of these, ${ }^{206} \mathrm{~Pb},{ }^{207} \mathrm{~Pb}$, and ${ }^{208} \mathrm{~Pb}$ are radiogenic decay products of naturally occurring ${ }^{238} \mathrm{U},{ }^{235} \mathrm{U}$, and ${ }^{232} \mathrm{Th}$, respectively. Owing to variations among the $\mathrm{U} / \mathrm{Pb}$ and $\mathrm{Th} / \mathrm{Pb}$ elemental abundance ratios among different types of geologic materials, variations in the relative abundances of the $\mathrm{Pb}$ isotopes are produced among different materials during geologic time.

In order for the $\mathrm{Pb}$ isotope method to be useful for determining possible contaminant sources, two important criteria must be met (e.g. Church and others 1997): (1) It must be possible to obtain and measure the $\mathrm{Pb}$ isotopic compositions in all potential contaminant sources and in uncontaminated material and (2) the $\mathrm{Pb}$ isotopic compositions of the potential contaminant sources must be distinctly different from one another and from uncontaminated background. Variations among the $\mathrm{Pb}$ isotopic ratios in selected samples can be correlated with potential sources of $\mathrm{Pb}$ with known isotopic compositions in order to determine the relative contribution of $\mathrm{Pb}$ from a specific source to the sample.

The purpose of this study is to use $\mathrm{Pb}$ isotopic data obtained from a selected subset of samples to determine the $\mathrm{Pb}$ isotopic signatures of uncontaminated soils as well as those of potential sources of contamination. The data will eventually be used in conjunction with other geochemical data to help determine which source or sources of contamination are most likely responsible for the elevated arsenic levels in the residential soils. 


\section{Analytical Procedures}

\section{Chemical Procedures}

Lead isotopic analyses of natural materials are obtained using anion-exchange, solidliquid chromatography and thermal-ionization solid-source mass spectrometry. Samples were received as sieved soils from USEPA. Samples were digested in nitric acid and hydrogen peroxide in accordance with Section 7.2 of method 3050B, EPA SW 846, revision 2 (USEPA, 1992). Ion exchange and mass spectrometry procedures are similar to those reported by Tatsumoto and Unruh (1976) and Fey and others (1999) with minor modifications to accommodate a larger sample size and the metal-rich nature of the samples. A detailed description of the chemical procedures may be found in Appendix 1.

Samples were loaded onto single rhenium filaments using the conventional silica gelphosphoric acid technique (e.g. Tatsumoto and Unruh, 1976). Mass spectrometry was performed using a VG Sector-54, 7-collector, solid source, thermal-ionization mass spectrometer operated in "static" mode. Data were acquired with the "Sector 54, version 3.974" software package provided by the manufacturer of the mass spectrometer. All samples and standards were run using collectors $\mathrm{L} 1, \mathrm{H} 1, \mathrm{H} 2$, and $\mathrm{H} 3$ for ${ }^{204} \mathrm{~Pb},{ }^{206} \mathrm{~Pb},{ }^{207} \mathrm{~Pb}$, and ${ }^{208} \mathrm{~Pb}$, respectively.

\section{Quality Assurance and Quality Control (QA and QC)}

Samples were initially submitted by USEPA to the analyst without context. Although $\mathrm{Pb}$ contents were provided so that the appropriate amount of sample could be processed, the nature of the sample (soil, herbicide, smelter waste, etc.) and the arsenic contents in the samples remained unknown to the analyst until after the first draft of this report was completed. Additional information was then provided so that this report could be completed in a comprehensive manner.

After the first draft of this report was submitted to USEPA for review, fourteen additional residential soils were selected for analyses. Samples were received by the analyst in April and May of 2001. These samples were selected jointly by USEPA and USGS personnel to encompass the complete ranges of lead and arsenic contents within the soils. Included within these additional soils were five samples from a single residential property. These were selected in order to test the validity of simple mixing models.

Quality Assurance and control procedures and results are provided in Appendix 2. The principal source of analytical uncertainty in lead isotopic analyses is from correction for mass fractionation induced during mass spectrometry. Mass fractionation was monitored using NIST 
standard SRM-981 (Cantanzaro and others, 1968; Todt and others, 1993). A second NIST standard, SRM-982 (Cantanzaro and others, 1968; Todt and others, 1993) was measured as a check of the correction procedures (Appendix 2).

Two Pb blanks were determined during the course of this study, one for the acid and hydrogen peroxide digestion procedure alone and one for total chemistry of a $1 \mathrm{ml}$ aliquot from the acid digestion (Appendix 2). The Pb blank for the acid digestion was $0.3 \mathrm{ng}\left(10^{-9} \mathrm{~g}\right)$ and that for the total chemistry was $0.09 \mathrm{ng}$. These values correspond to less than $0.004 \%$ and $0.02 \%$ of the lead in the total samples and solution aliquots, respectively. Consequently, no blank correction was applied to the isotopic data (see Appendix 2).

Three types of replicate samples were analyzed; (1) Blind duplicates submitted by USEPA, (2) Replicate acid-hydrogen peroxide digestions of the same (digestion replicates), and (3) Replicate loads of the same sample from a single chemical procedure (mass spectrometry replicates). Results for the replicate analyses are presented in Table 2, and Appendix 2 (Tables A2-3, and A2-4).

\section{Chain of Custody (COC)}

Samples were handled in accordance with U.S. Geological Survey chain-of-custody procedures (Murphy and others, 1997). Samples were received from the USGS sample control custodian in a sealed box by the analyst and were hand-carried to the laboratory where they remained for the duration of the study. The laboratory is secured with a combination lock with a combination known only to the analyst. Individual samples were enclosed in bags sealed and dated by USEPA. The analyst found all seals to be intact upon receipt.

The mass spectrometer used to acquire data was secured with two padlocks to lock the sample access door. The computer that was used to reduce the data was also secured with a lock supplied by the manufacturer that prevented access to the keyboard. Both the mass spectrometer and computer were kept locked at all times during the study and all keys were retained exclusively by the analyst.

\section{Analytical Results and Discussion}

\section{Lead Isotopic Compositions}

A total of thirty-four selected samples were analyzed for lead isotopic compositions. These included twenty-six residential soils (plus two blind duplicates), one procedural blank, two soils from a local smelter, and one sample of smelter waste from the same smelter. Also analyzed were a sample of "PAX", an arsenic trioxide plus lead arsenate herbicide that was 
commercially available during the 1950's through the early 1970's, and a sample of Acme brand lead arsenate pesticide that was also commercially available during this time frame.

Sample numbers and sample types as well as lead and arsenic concentrations for the samples are summarized in Table 1 (USEPA, written communication, 2000, 2001). Residential soil samples are listed high-As, intermediate-As or low-As and as either "focal" or "adjacent". Focal samples are those that were collected from a specific property, whereas adjacent samples were collected from property adjacent the specific property. Adjacent samples all show relatively low As levels (Table 1).

Lead isotopic data for the samples are shown in Table 2. Each entry represents a separate mass spectrometer run. Entries with identical sample numbers are mass spectrometry replicates measured from a single processed aliquot of sample. Entries with the same sample number but different suffix letters (e.g. 642B-A, 642B-B, 642B-C) are digestion replicates obtained from separate acid and hydrogen peroxide digestions of the sample.

Both the raw data and data corrected for mass fractionation are shown. The precision for the raw data is given as the percent standard error (1 S.E. $\approx 1$ sigma-mean) calculated by the on line data-acquisition software. Analytical uncertainties for the corrected data are shown as absolute values and are calculated at the $95 \%$ confidence interval (C.I., Ludwig, 1994). Weighted mean values, also calculated at the $95 \%$ C.I., are shown for the mass spectrometry replicates and, where appropriate, grand mean values are calculated for each sample from the means of the digestion replicates. The mean values for the individual samples are shown in bold type in Table 2.

The lead isotopic data are summarized on conventional ${ }^{206} \mathrm{~Pb} /{ }^{204} \mathrm{~Pb}$ vs. ${ }^{207} \mathrm{~Pb} /{ }^{204} \mathrm{~Pb}$ and ${ }^{206} \mathrm{~Pb} /{ }^{204} \mathrm{~Pb}$ vs. ${ }^{208} \mathrm{~Pb} /{ }^{204} \mathrm{~Pb}$ diagrams in Figure 1. Each data point represents the mean value for an individual sample (Table 2) and data are coded according to their Pb contents (Table 1). The data yield moderately well correlated linear arrays with $r^{2}=0.854$ and 0.812 for the ${ }^{206} \mathrm{~Pb} /{ }^{204} \mathrm{~Pb}$ vs. ${ }^{207} \mathrm{~Pb} /{ }^{204} \mathrm{~Pb}$ and ${ }^{206} \mathrm{~Pb} /{ }^{204} \mathrm{~Pb}$ vs. ${ }^{208} \mathrm{~Pb} /{ }^{204} \mathrm{~Pb}$ diagrams, respectively (unweighted; $r^{2}$ is defined by the plotting software, Deltagraph 4.0, as the square of the regression correlation coefficient). Also shown by error ellipses in Figure 1 are typical analytical uncertainties for a single mass spectrometer run $\left( \pm 0.09 \%\right.$ for ${ }^{206} \mathrm{~Pb} /{ }^{204} \mathrm{~Pb}, \pm 0.13 \%$ for ${ }^{207} \mathrm{~Pb} /{ }^{204} \mathrm{~Pb}$, and $\pm 0.18 \%$ for ${ }^{208} \mathrm{~Pb} /{ }^{204} \mathrm{~Pb}$ ).

Samples with the lowest $\mathrm{Pb}$ contents are characterized by radiogenic $\mathrm{Pb}\left({ }^{206} \mathrm{~Pb} /{ }^{204} \mathrm{~Pb}>\right.$ 18.4) and slightly elevated ${ }^{208} \mathrm{~Pb} /{ }^{204} \mathrm{~Pb}$ relative to the other samples. Residential soils with the highest $\mathrm{Pb}$ contents form two distinct clusters; one with ${ }^{206} \mathrm{~Pb} /{ }^{204} \mathrm{~Pb}>18.5$ and one with ${ }^{206} \mathrm{~Pb} /{ }^{204} \mathrm{~Pb}<18.0$. The data from the remaining residential soils plot between the extremes defined by the low- $\mathrm{Pb}$ and two high-Pb groups. 
Table 1. Sample numbers, sample types, and lead and arsenic concentrations in selected samples from the VBI70 study.

\begin{tabular}{|c|c|c|c|c|c|}
\hline Sample Number & EPA Code No. & Sample type & Location $^{1}$ & As $\mathrm{ppm}^{2}$ & $\mathrm{~Pb} \mathrm{ppm}$ \\
\hline $3-15639-B$ & 3-15669-R & Acme brand Lead Arsenate & & 273000 & 128000 \\
\hline 3-15641-B & SC-00006 & High-As residential soil & Focal & 836 & 1490 \\
\hline 3-15642-B & SC-00010 & Intermediate As residential & Focal & 173 & 422 \\
\hline $3-15643-B$ & SC-00011 & Smelter Site soil & & 22400 & 4520 \\
\hline 3-15644-B & SC-00017 & Low As residential soil & Adjacent & 9 & 39 \\
\hline 3-15645-B & SC-00018 & Smelter Site soil & & 27200 & 5660 \\
\hline 3-15646-B & SC-00023 & Smelter material & & 7630 & 2160 \\
\hline 3-15647-B & SC-00025 & Low As residential soil & Focal & 24 & 126 \\
\hline $3-15648-B$ & SC-00027 & Intermediate As residential & Focal & 165 & 115 \\
\hline $3-15649-B$ & SC-00039 & Low As residential soil & Focal & 25 & 92 \\
\hline $3-15650-B$ & SC-00046 & High-As residential soil & Focal & 1490 & 1560 \\
\hline 3-15651-B & SC-00046 & Duplicate & & 1490 & 1560 \\
\hline $3-15652-B$ & SC-00048 & High-As residential soil & Adjacent & 35 & 261 \\
\hline 3-15653-B & SC-00065 & Baseline soil & Focal & 7 & 101 \\
\hline 3-15654-B & SC-00065 & Duplicate & & 7 & 101 \\
\hline $3-15655-B$ & SC-00069 & High-As residential soil & Adjacent & 15 & 151 \\
\hline 3-15656-B & SC-00084 & Intermediate As residential & Adjacent & 23 & 175 \\
\hline 3-15657-B & SC-00104 & High-As residential soil & Focal & 1490 & 1140 \\
\hline $3-15658-B$ & SC-00099 & PAX & & 120000 & 24300 \\
\hline 3-15659-B & & Prep. Blank & & n.d. & n.d \\
\hline \multicolumn{6}{|c|}{ Samples received $4 / 01-5 / 01$} \\
\hline $3-13569-B$ & & High-As residential soil & Focal & 1492 & 409 \\
\hline $3-13989-B$ & & High-As residential soil & Focal & 904 & 302 \\
\hline $3-02246-B$ & & Low As residential soil & Focal & $<11$ & 1658 \\
\hline $3-10319-B$ & & Low As residential soil & Focal & 48 & 1469 \\
\hline $3-12524-B$ & & High-As residential soil & Focal & 1135 & 794 \\
\hline $3-12820-B$ & & Intermediate As residential & Focal & 242 & 607 \\
\hline $3-01182-B$ & & Low As residential soil & Focal & 14 & 720 \\
\hline $3-00748-B$ & & Intermediate As residential & Focal & 409 & 633 \\
\hline $3-10740-B$ & & Low As residential soil & Focal & 23 & 984 \\
\hline \multicolumn{6}{|c|}{ Samples from a single residential property } \\
\hline $3-12152-B$ & & Low As residential soil & Focal & $<11$ & 1730 \\
\hline $3-12040-B$ & & Low As residential soil & Focal & $<11$ & 256 \\
\hline $3-12039-B$ & & Low As residential soil & Focal & 15 & 413 \\
\hline $3-12035-B$ & & Low As residential soil & Focal & 26 & 824 \\
\hline 3-12151-B & & Intermediate As residential & Focal & 221 & 540 \\
\hline
\end{tabular}

\footnotetext{
${ }^{1}$ Focal samples are those collected at the site indicted by the sample type. Adjacent samples are those collected adjacent to the indicated sample type.

2 As concentrations provided by USEPA (written communication, 2001).

${ }^{3} \mathrm{~Pb}$ concentrations provided by USEPA (written communication, 2000; 2001).
} 
Table 2. Lead isotopic compositions in acid digestions of selected soils samples from the Vasquez Blvd.-170 Project.

\begin{tabular}{|c|c|c|c|c|c|c|c|c|c|c|c|c|c|}
\hline \multirow[b]{2}{*}{ Lab No/EPA No. ${ }^{3}$} & \multirow[b]{2}{*}{$\mathrm{Pb} \mathrm{ppm}^{4}$} & \multicolumn{7}{|c|}{ Raw Data ${ }^{1}$} & \multicolumn{5}{|c|}{ Corrected for mass fractionation ${ }^{2}$} \\
\hline & & Type & ${ }^{206} \mathrm{~Pb} /{ }^{204} \mathrm{~Pb}$ & \% S.E. & ${ }^{207} \mathrm{~Pb} /{ }^{206} \mathrm{~Pb}$ & $\%$ S.E. ${ }^{2}$ & ${ }^{208} \mathrm{~Pb} /{ }^{206} \mathrm{~Pb}$ & \% S.E. & ${ }^{206} \mathrm{~Pb} /{ }^{204} \mathrm{~Pb}$ & ${ }^{207} \mathrm{~Pb} /{ }^{206} \mathrm{~Pb}$ & ${ }^{208} \mathrm{~Pb} /{ }^{206} \mathrm{~Pb}$ & ${ }^{207} \mathrm{~Pb} /{ }^{204} \mathrm{~Pb}$ & ${ }^{208} \mathrm{~Pb} / 204 \mathrm{~Pb}$ \\
\hline $\begin{array}{l}\text { 3-15639-B } \\
3-15669-B\end{array}$ & & $\mathrm{~Pb}$ Arsenate & & & & & & & & & & & \\
\hline $639 \mathrm{~B}$ & & & 18.0453 & 0.0016 & 0.860891 & 0.0007 & 2.10038 & 0.0010 & $18.075 \pm 0.016$ & $0.86158 \pm 0.00037$ & $2.1037 \pm 0.0018$ & $15.573 \pm 0.021$ & $38.024 \pm 0.067$ \\
\hline $639 \mathrm{~B}$ & & & 18.0497 & 0.0027 & 0.860973 & 0.0010 & 2.10094 & 0.0018 & $18.079 \pm 0.016$ & $0.86166 \pm 0.00037$ & $2.1042 \pm 0.0018$ & $15.578 \pm 0.021$ & $38.043 \pm 0.067$ \\
\hline $639 \mathrm{~B}$ & & & 18.0303 & 0.0020 & 0.860519 & 0.0008 & 2.09888 & 0.0016 & $18.060 \pm 0.016$ & $0.86120 \pm 0.00037$ & $2.1021 \pm 0.0018$ & $15.553 \pm 0.021$ & $37.965 \pm 0.067$ \\
\hline Mean & 128000 & & & & & & & & $18.071 \pm 0.009$ & $0.86148 \pm 0.00044$ & $2.1033 \pm 0.0010$ & $15.568 \pm 0.023$ & $38.009 \pm 0.038$ \\
\hline $\begin{array}{l}\text { 3-15641-B } \\
\text { SC-00006 }\end{array}$ & & Res. Soil & & & & & & & & & & & \\
\hline $641 \mathrm{~B}$ & & & 17.8760 & 0.0030 & 0.867917 & 0.0007 & 2.10752 & 0.0009 & $17.906 \pm 0.016$ & $0.86861 \pm 0.00037$ & $2.1108 \pm 0.0018$ & $15.553 \pm 0.021$ & $37.795 \pm 0.067$ \\
\hline $641 \mathrm{~B}$ & & & 17.8998 & 0.0072 & 0.868367 & 0.0031 & 2.10999 & 0.0064 & $17.929 \pm 0.017$ & $0.86906 \pm 0.00038$ & $2.1133 \pm 0.0019$ & $15.582 \pm 0.021$ & $37.890 \pm 0.067$ \\
\hline $641 \mathrm{~B}$ & & & 17.8656 & 0.0033 & 0.867646 & 0.0008 & 2.10613 & 0.0006 & $17.895 \pm 0.016$ & $0.86834 \pm 0.00037$ & $2.1094 \pm 0.0018$ & $15.539 \pm 0.021$ & $37.748 \pm 0.067$ \\
\hline Mean & 1490 & & & & & & & & $17.910 \pm 0.039$ & $0.86867 \pm 0.00083$ & $2.1112 \pm 0.0046$ & $15.558 \pm 0.050$ & $37.812 \pm 0.163$ \\
\hline $\begin{array}{l}\text { 3-15642-B } \\
\text { SC-00010 }\end{array}$ & & Res. S & & & & & & & & & & & \\
\hline 642B-A & & & 18.2064 & 0.0031 & 0.854041 & 0.0014 & 2.09149 & 0.0024 & $18.236 \pm 0.017$ & $0.85472 \pm 0.00037$ & $2.0947 \pm 0.0018$ & $15.587 \pm 0.021$ & $38.201 \pm 0.067$ \\
\hline 642B-A & & & 18.2260 & 0.0064 & 0.854359 & 0.0023 & 2.09344 & 0.0053 & $18.256 \pm 0.017$ & $0.85504 \pm 0.00037$ & $2.0967 \pm 0.0018$ & $15.610 \pm 0.021$ & $38.278 \pm 0.067$ \\
\hline 642B-A & & & 18.2150 & 0.0093 & 0.854019 & 0.0025 & 2.09192 & 0.0045 & $18.245 \pm 0.017$ & $0.85470 \pm 0.00037$ & $2.0952 \pm 0.0018$ & $15.594 \pm 0.021$ & $38.227 \pm 0.067$ \\
\hline 642B-A & & & 18.2196 & 0.0063 & 0.853997 & 0.0025 & 2.09185 & 0.0054 & $18.250 \pm 0.017$ & $0.85468 \pm 0.00037$ & $2.0951 \pm 0.0018$ & $15.598 \pm 0.021$ & $38.235 \pm 0.067$ \\
\hline 642B-A & & & 18.2284 & 0.0127 & 0.853709 & 0.0028 & 2.09137 & 0.0044 & $18.258 \pm 0.018$ & $0.85439 \pm 0.00038$ & $2.0946 \pm 0.0018$ & $15.600 \pm 0.021$ & $38.245 \pm 0.067$ \\
\hline Mean & & & & & & & & & $18.249 \pm 0.007$ & $0.85471 \pm 0.00021$ & $2.0953 \pm 0.0008$ & $15.598 \pm 0.009$ & $38.237 \pm 0.029$ \\
\hline 642B-B & & & 18.1881 & 0.0041 & 0.854971 & 0.0013 & 2.09284 & 0.0015 & $18.218 \pm 0.017$ & $0.85565 \pm 0.00037$ & $2.0961 \pm 0.0018$ & $15.588 \pm 0.021$ & $38.187 \pm 0.067$ \\
\hline 642B-B & & & 18.2038 & 0.0043 & 0.855349 & 0.0020 & 2.09467 & 0.0043 & $18.234 \pm 0.017$ & $0.85603 \pm 0.00037$ & $2.0979 \pm 0.0018$ & $15.609 \pm 0.021$ & $38.253 \pm 0.067$ \\
\hline 642B-B & & & 18.1755 & 0.0023 & 0.854746 & 0.0010 & 2.09143 & 0.0017 & $18.205 \pm 0.016$ & $0.85543 \pm 0.00037$ & $2.0947 \pm 0.0018$ & $15.573 \pm 0.021$ & $38.135 \pm 0.067$ \\
\hline Mean & & & & & & & & & $18.219 \pm 0.031$ & $0.85570 \pm 0.00065$ & $2.0962 \pm 0.0036$ & $15.590 \pm 0.039$ & $38.191 \pm 0.126$ \\
\hline 642B-C & & & 18.2174 & 0.0016 & 0.854590 & 0.0005 & 2.09349 & 0.0006 & $18.247 \pm 0.016$ & $0.85527 \pm 0.00037$ & $2.0968 \pm 0.0018$ & $15.607 \pm 0.021$ & $38.260 \pm 0.067$ \\
\hline $642 \mathrm{~B}-\mathrm{C}$ & & & 18.2150 & 0.0021 & 0.854463 & 0.0009 & 2.09280 & 0.0018 & $18.245 \pm 0.017$ & $0.85514 \pm 0.00037$ & $2.0961 \pm 0.0018$ & $15.602 \pm 0.021$ & $38.243 \pm 0.067$ \\
\hline 642B-C & & & 18.2080 & 0.0015 & 0.854244 & 0.0006 & 2.09199 & 0.0009 & $18.238 \pm 0.016$ & $0.85492 \pm 0.00037$ & $2.0952 \pm 0.0018$ & $15.592 \pm 0.021$ & $38.213 \pm 0.067$ \\
\hline Mean & & & & & & & & & $18.243 \pm 0.009$ & $0.85511 \pm 0.00021$ & $2.0960 \pm 0.0010$ & $15.600 \pm 0.012$ & $38.237 \pm 0.038$ \\
\hline Mean 642B A-C & 422 & & & & & & & & $18.242 \pm 0.029$ & $0.85509 \pm 0.00094$ & $2.0956 \pm 0.0006$ & $15.599 \pm 0.007$ & $38.235 \pm 0.023$ \\
\hline $\begin{array}{l}3-15643-B \\
\text { SC-00011 }\end{array}$ & & Smelter Soil & & & & & & & & & & & \\
\hline $643 B$ & & & 18.1661 & 0.0023 & 0.855456 & 0.0010 & 2.09202 & 0.0020 & $18.196 \pm 0.016$ & $0.85614 \pm 0.00037$ & $2.0953 \pm 0.0018$ & $15.578 \pm 0.021$ & $38.126 \pm 0.067$ \\
\hline $643 \mathrm{~B}$ & & & 18.1539 & 0.0037 & 0.855205 & 0.0011 & 2.09068 & 0.0019 & $18.184 \pm 0.017$ & $0.85589 \pm 0.00037$ & $2.0939 \pm 0.0018$ & $15.563 \pm 0.021$ & $38.076 \pm 0.067$ \\
\hline Mean & 4520 & & & & & & & & $18.190 \pm 0.011$ & $0.85601 \pm 0.00026$ & $2.0946 \pm 0.0013$ & $15.570 \pm 0.014$ & $38.101 \pm 0.046$ \\
\hline $\begin{array}{l}\text { 3-15644-B } \\
\text { SC-00017 }\end{array}$ & & Res. So & & & & & & & & & & & \\
\hline 644B-A & & & 18.4188 & 0.0026 & 0.844483 & 0.0011 & 2.09277 & 0.0014 & $18.449 \pm 0.017$ & $0.84516 \pm 0.00037$ & $2.0960 \pm 0.0018$ & $15.592 \pm 0.021$ & $38.670 \pm 0.068$ \\
\hline 644B-A & & & 18.4243 & 0.0037 & 0.844582 & 0.0012 & 2.09333 & 0.0027 & $18.455 \pm 0.017$ & $0.84525 \pm 0.00037$ & $2.0966 \pm 0.0018$ & $15.599 \pm 0.021$ & $38.692 \pm 0.068$ \\
\hline Mean & & & & & & & & & $18.452 \pm 0.012$ & $0.84521 \pm 0.00025$ & $2.0963 \pm 0.0013$ & $15.595 \pm 0.014$ & $38.681 \pm 0.046$ \\
\hline 644B-B & & & 18.4670 & 0.0026 & 0.841463 & 0.0010 & 2.09140 & 0.0021 & $18.497 \pm 0.017$ & $0.84213 \pm 0.00036$ & $2.0947 \pm 0.0018$ & $15.577 \pm 0.021$ & $38.746 \pm 0.068$ \\
\hline $\begin{array}{l}\text { 644B-C } \\
\text { Mean 644B A-C }\end{array}$ & 3 & & 18.5792 & 0.0062 & 0.839810 & 0.0025 & 2.10998 & 0.0052 & $\begin{aligned} 18.610 & \pm 0.017 \\
18.52 & \pm 0.20\end{aligned}$ & $\begin{array}{c}0.84048 \pm 0.00037 \\
0.8426 \pm 0.0061\end{array}$ & $\begin{array}{c}2.1133 \pm 0.0019 \\
2.101 \pm 0.023\end{array}$ & $\begin{array}{l}15.641 \pm 0.021 \\
\mathbf{1 5 . 6 0 4} \pm \mathbf{0 . 0 8 0}\end{array}$ & $\begin{aligned} 39.328 & \pm 0.069 \\
38.92 & \pm 0.90\end{aligned}$ \\
\hline
\end{tabular}


Table 2. Contd.

\begin{tabular}{|c|c|c|c|c|c|c|c|c|c|c|c|c|c|}
\hline \multirow{2}{*}{\multicolumn{9}{|c|}{ Raw Data ${ }^{1}$}} & \multirow{2}{*}{\multicolumn{5}{|c|}{ Corrected for mass fractionation ${ }^{2}$}} \\
\hline & & & & & & & & & & & & & \\
\hline Lab No/EPA No. ${ }^{3}$ & $\mathrm{~Pb} \mathrm{ppm}{ }^{4}$ & Type & ${ }^{206} \mathrm{~Pb} /{ }^{204} \mathrm{~Pb}$ & $\%$ S.E. & ${ }^{207} \mathrm{~Pb} /{ }^{206} \mathrm{~Pb}$ & $\%$ S.E. & ${ }^{208} \mathrm{~Pb} / 206 \mathrm{~Pb}$ & $\%$ S.E. & ${ }^{206} \mathrm{~Pb} /{ }^{204} \mathrm{~Pb}$ & ${ }^{207} \mathrm{~Pb} /{ }^{206} \mathrm{~Pb}$ & ${ }^{208} \mathrm{~Pb} /{ }^{206} \mathrm{~Pb}$ & ${ }^{207} \mathrm{~Pb} /{ }^{204} \mathrm{~Pb}$ & ${ }^{208} \mathrm{~Pb} /{ }^{204} \mathrm{~Pb}$ \\
\hline $\begin{array}{l}\text { 3-15645-B } \\
\text { SC-00018 }\end{array}$ & & Smelter Soil & & & & & & & & & & & \\
\hline $645 \mathrm{~B}$ & & & 18.0919 & 0.0022 & 0.857832 & 0.0007 & 2.09510 & 0.0009 & $18.122 \pm 0.016$ & $0.85852 \pm 0.00037$ & $2.0984 \pm 0.0018$ & $15.558 \pm 0.021$ & $38.026 \pm 0.067$ \\
\hline 645B & & & 18.0911 & 0.0027 & 0.857847 & 0.0007 & 2.09515 & 0.0009 & $18.121 \pm 0.016$ & $0.85853 \pm 0.00037$ & $2.0984 \pm 0.0018$ & $15.557 \pm 0.021$ & $38.025 \pm 0.067$ \\
\hline Mean & 5660 & & & & & & & & $18.122 \pm 0.011$ & $0.85852 \pm 0.00026$ & $2.0984 \pm 0.0013$ & $15.557 \pm 0.014$ & $38.026 \pm 0.046$ \\
\hline $\begin{array}{l}\text { 3-15646-B } \\
\text { SC-00023 }\end{array}$ & & $\begin{array}{l}\text { Smelter } \\
\text { Material }\end{array}$ & & & & & & & & & & & \\
\hline $646 \mathrm{~B}$ & & & 18.0984 & 0.0022 & 0.857802 & 0.0007 & 2.09641 & 0.0015 & $18.128 \pm 0.016$ & $0.85849 \pm 0.00037$ & $2.0997 \pm 0.0018$ & $15.563 \pm 0.021$ & $38.063 \pm 0.067$ \\
\hline $646 B$ & & & 18.0898 & 0.0041 & 0.857609 & 0.0009 & 2.09536 & 0.0016 & $18.120 \pm 0.017$ & $0.85829 \pm 0.00037$ & $2.0986 \pm 0.0018$ & $15.552 \pm 0.021$ & $38.026 \pm 0.067$ \\
\hline $646 \mathrm{~B}$ & & & 18.0876 & 0.0058 & 0.857621 & 0.0011 & 2.09541 & 0.0012 & $18.117 \pm 0.017$ & $0.85830 \pm 0.00037$ & $2.0987 \pm 0.0018$ & $15.550 \pm 0.021$ & $38.023 \pm 0.067$ \\
\hline Mean & 2160 & & & & & & & & $18.122 \pm 0.009$ & $0.85836 \pm 0.00021$ & $2.0990 \pm 0.0010$ & $15.555 \pm 0.012$ & $38.037 \pm 0.038$ \\
\hline $\begin{array}{l}\text { 3-15647-B } \\
\text { SC-00025 }\end{array}$ & & Res. Soil & & & & & & & & & & & \\
\hline $647 \mathrm{~B}$ & & & 18.4147 & 0.0019 & 0.845385 & 0.0007 & 2.08550 & 0.0011 & $18.445 \pm 0.017$ & $0.84606 \pm 0.00036$ & $2.0887 \pm 0.0018$ & $15.606 \pm 0.021$ & $38.527 \pm 0.068$ \\
\hline 647B & & & 18.4188 & 0.0034 & 0.845532 & 0.0011 & 2.08635 & 0.0012 & $18.449 \pm 0.017$ & $0.84621 \pm 0.00037$ & $2.0896 \pm 0.0018$ & $15.612 \pm 0.021$ & $38.551 \pm 0.068$ \\
\hline Mean & 126 & & & & & & & & $18.447 \pm 0.012$ & $0.84613 \pm 0.00025$ & $2.0891 \pm 0.0013$ & $15.609 \pm 0.014$ & $38.539 \pm 0.046$ \\
\hline 3-15648-B & & Res. Soil & & & & & & & & & & & \\
\hline SC-00027 & & & & & & & & & & & & & \\
\hline $648 \mathrm{~B}$ & 115 & & 18.3796 & 0.0125 & 0.846401 & 0.0031 & 2.08402 & 0.0059 & $18.410 \pm 0.018$ & $0.84708 \pm 0.00037$ & $2.0873 \pm 0.0018$ & $15.595 \pm 0.021$ & $38.426 \pm 0.068$ \\
\hline $\begin{array}{l}\text { 3-15649-B } \\
\text { SC-00039 }\end{array}$ & & Res. Soil & & & & & & & & & & & \\
\hline $649 \mathrm{~B}$ & & & 18.3648 & 0.0017 & 0.848386 & 0.0006 & 2.09495 & 0.0010 & $18.395 \pm 0.017$ & $0.84906 \pm 0.00037$ & $2.0982 \pm 0.0018$ & $15.610 \pm 0.021$ & $38.597 \pm 0.068$ \\
\hline $649 \mathrm{~B}$ & & & 18.3445 & 0.0034 & 0.847974 & 0.0013 & 2.09255 & 0.0029 & $18.375 \pm 0.017$ & $0.84865 \pm 0.00037$ & $2.0958 \pm 0.0018$ & $15.594 \pm 0.021$ & $38.510 \pm 0.068$ \\
\hline $649 B$ & & & 18.3665 & 0.0038 & 0.848447 & 0.0010 & 2.09514 & 0.0010 & $18.397 \pm 0.017$ & $0.84912 \pm 0.00037$ & $2.0984 \pm 0.0018$ & $15.621 \pm 0.021$ & $38.604 \pm 0.068$ \\
\hline Mean & 92 & & & & & & & & $18.389 \pm 0.024$ & $0.84894 \pm 0.00049$ & $2.0975 \pm 0.0031$ & $15.611 \pm 0.030$ & $38.570 \pm 0.108$ \\
\hline $\begin{array}{l}3-15650-B \\
\text { SC-00046 }\end{array}$ & & Res. Soil & & & & & & & & & & & \\
\hline $650 \mathrm{~B}$ & & & 17.7702 & 0.0018 & 0.873614 & 0.0006 & 2.11319 & 0.0007 & $17.800 \pm 0.016$ & $0.87431 \pm 0.00038$ & $2.1165 \pm 0.0018$ & $15.562 \pm 0.021$ & $37.672 \pm 0.066$ \\
\hline $650 \mathrm{~B}$ & & & 17.7696 & 0.0030 & 0.873548 & 0.0009 & 2.11310 & 0.0013 & $17.799 \pm 0.016$ & $0.87424 \pm 0.00038$ & $2.1164 \pm 0.0018$ & $15.561 \pm 0.021$ & $37.670 \pm 0.066$ \\
\hline $650 \mathrm{~B}$ & & & 17.7741 & 0.0032 & 0.873617 & 0.0012 & 2.11347 & 0.0023 & $17.803 \pm 0.016$ & $0.87431 \pm 0.00038$ & $2.1168 \pm 0.0018$ & $15.566 \pm 0.021$ & $37.686 \pm 0.066$ \\
\hline Mean & 1560 & & & & & & & & $17.801 \pm 0.009$ & $0.87429 \pm 0.00021$ & $2.1166 \pm 0.0010$ & $15.563 \pm 0.012$ & $37.676 \pm 0.038$ \\
\hline $\begin{array}{l}\text { 3-15651-B } \\
\text { SC-00046 DUP }\end{array}$ & & Res. Soil & & & & & & & & & & & \\
\hline $651 \mathrm{~B}$ & & & 17.7556 & 0.0025 & 0.874082 & 0.0012 & 2.11399 & 0.0013 & $17.785 \pm 0.016$ & $0.87478 \pm 0.00038$ & $2.1173 \pm 0.0018$ & $15.558 \pm 0.021$ & $37.656 \pm 0.066$ \\
\hline $651 \mathrm{~B}$ & & & 17.7692 & 0.0070 & 0.874419 & 0.0024 & 2.11596 & 0.0055 & $17.799 \pm 0.017$ & $0.87512 \pm 0.00038$ & $2.1193 \pm 0.0019$ & $15.576 \pm 0.021$ & $37.720 \pm 0.066$ \\
\hline $651 \mathrm{~B}$ & & & 17.7534 & 0.0038 & 0.873984 & 0.0011 & 2.11349 & 0.0016 & $17.783 \pm 0.016$ & $0.87468 \pm 0.00038$ & $2.1168 \pm 0.0018$ & $15.554 \pm 0.021$ & $37.642 \pm 0.066$ \\
\hline Mean & 1560 & & & & & & & & $17.789 \pm 0.009$ & $0.87486 \pm 0.00022$ & $2.1178 \pm 0.0025$ & $15.563 \pm 0.012$ & $36.673 \pm 0.037$ \\
\hline $\begin{array}{l}\text { 3-15652-B } \\
\text { SC-00048 }\end{array}$ & & Res. Soil & & & & & & & & & & & \\
\hline $652 B$ & & & 18.3237 & 0.0018 & 0.849612 & 0.0007 & 2.08176 & 0.0010 & $18.354 \pm 0.017$ & $0.85029 \pm 0.00037$ & $2.0850 \pm 0.0018$ & $15.606 \pm 0.021$ & $38.268 \pm 0.067$ \\
\hline $652 \mathrm{~B}$ & & & 18.3164 & 0.0024 & 0.849428 & 0.0010 & 2.08098 & 0.0021 & $18.347 \pm 0.017$ & $0.85010 \pm 0.00037$ & $2.0842 \pm 0.0018$ & $15.597 \pm 0.021$ & $38.238 \pm 0.067$ \\
\hline Mean & 261 & & & & & & & & $18.351 \pm 0.012$ & $0.85019 \pm 0.00026$ & $2.0846 \pm 0.0013$ & $15.601 \pm 0.014$ & $38.253 \pm 0.046$ \\
\hline
\end{tabular}


Table 2. Contd.

\begin{tabular}{|c|c|c|c|c|c|c|c|c|c|c|c|c|c|}
\hline & \multirow{2}{*}{\multicolumn{7}{|c|}{ Raw Data ${ }^{1}$}} & \multirow{2}{*}{\multicolumn{5}{|c|}{ Corrected for mass fractionation ${ }^{2}$}} \\
\hline & & & & & & & & & & & & & \\
\hline Lab No/EPA No. ${ }^{3}$ & $\mathrm{~Pb} \mathrm{ppm}{ }^{4}$ & Type & ${ }^{206} \mathrm{~Pb} /{ }^{204} \mathrm{~Pb}$ & $\%$ S.E. & ${ }^{207} \mathrm{~Pb} /{ }^{206} \mathrm{~Pb}$ & $\%$ S.E. & ${ }^{208} \mathrm{~Pb} /{ }^{206} \mathrm{~Pb}$ & $\%$ S.E. & ${ }^{206} \mathrm{~Pb} / 204 \mathrm{~Pb}$ & ${ }^{207} \mathrm{~Pb} /{ }^{206} \mathrm{~Pb}$ & ${ }^{208} \mathrm{~Pb} /{ }^{206} \mathrm{~Pb}$ & ${ }^{207} \mathrm{~Pb} / 204 \mathrm{~Pb}$ & ${ }^{208} \mathrm{~Pb} /{ }^{204} \mathrm{~Pb}$ \\
\hline $\begin{array}{l}\text { 3-15653-B } \\
\text { SC-00065 }\end{array}$ & & $\begin{array}{c}\text { Baseline } \\
\text { Soil }\end{array}$ & & & & & & & & & & & \\
\hline $653 \mathrm{~B}$ & & & 18.3800 & 0.0024 & 0.846355 & 0.0007 & 2.08585 & 0.0009 & $18.410 \pm 0.017$ & $0.84703 \pm 0.00037$ & $2.0891 \pm 0.0018$ & $15.594 \pm 0.021$ & $38.461 \pm 0.068$ \\
\hline $653 \mathrm{~B}$ & & & 18.3816 & 0.0032 & 0.846356 & 0.0010 & 2.08571 & 0.0019 & $18.412 \pm 0.017$ & $0.84703 \pm 0.00037$ & $2.0890 \pm 0.0018$ & $15.595 \pm 0.021$ & $38.462 \pm 0.068$ \\
\hline $653 \mathrm{~B}$ & & & 18.3860 & 0.0030 & 0.846417 & 0.0012 & 2.08631 & 0.0026 & $18.416 \pm 0.017$ & $0.84709 \pm 0.00037$ & $2.0896 \pm 0.0018$ & $15.600 \pm 0.021$ & $38.482 \pm 0.068$ \\
\hline Mean & 101 & & & & & & & & $18.413 \pm 0.009$ & $0.84705 \pm 0.00020$ & $2.0892 \pm 0.0010$ & $15.596 \pm 0.012$ & $38.468 \pm 0.038$ \\
\hline 3-15654-B & & Baseline & & & & & & & & & & & \\
\hline SC-00065 DUP & & Soil & & & & & & & & & & & \\
\hline 654B-A & & & 18.8272 & 0.0048 & 0.827089 & 0.0022 & 2.04638 & 0.0049 & $18.858 \pm 0.017$ & $0.82775 \pm 0.00036$ & $2.0496 \pm 0.0018$ & $15.610 \pm 0.021$ & $38.651 \pm 0.068$ \\
\hline 654B-A & & & 18.8467 & 0.0029 & 0.827383 & 0.0008 & 2.04795 & 0.0014 & $18.878 \pm 0.017$ & $0.82804 \pm 0.00036$ & $2.0511 \pm 0.0018$ & $15.632 \pm 0.021$ & $38.721 \pm 0.068$ \\
\hline 654B-A & & & 18.8414 & 0.0026 & 0.827372 & 0.0013 & 2.04786 & 0.0025 & $18.872 \pm 0.017$ & $0.82803 \pm 0.00036$ & $2.0511 \pm 0.0018$ & $15.627 \pm 0.021$ & $38.708 \pm 0.068$ \\
\hline Mean & & & & & & & & & $18.869 \pm 0.010$ & $0.82794 \pm 0.00021$ & $2.0506 \pm 0.0010$ & $15.623 \pm 0.012$ & $38.693 \pm 0.039$ \\
\hline $654 \mathrm{~B}-\mathrm{B}$ & & & 18.4285 & 0.0045 & 0.844454 & 0.0012 & 2.08549 & 0.0018 & $18.459 \pm 0.017$ & $0.84513 \pm 0.00037$ & $2.0887 \pm 0.0018$ & $15.600 \pm 0.021$ & $38.556 \pm 0.068$ \\
\hline 654B-C & & & 18.4232 & 0.0075 & 0.845692 & 0.0014 & 2.08653 & 0.0012 & $18.454 \pm 0.017$ & $0.84637 \pm 0.00037$ & $2.0898 \pm 0.0018$ & $15.619 \pm 0.021$ & $38.564 \pm 0.068$ \\
\hline 654B-D & & & 18.4659 & 0.0029 & 0.843491 & 0.0011 & 2.08544 & 0.0018 & $18.496 \pm 0.017$ & $0.84416 \pm 0.00036$ & $2.0887 \pm 0.0018$ & $15.614 \pm 0.021$ & $38.633 \pm 0.068$ \\
\hline 654B-E & & & 18.3547 & 0.0023 & 0.847687 & 0.0008 & 2.08618 & 0.0016 & $18.385 \pm 0.017$ & $0.84836 \pm 0.00037$ & $2.0894 \pm 0.0018$ & $15.597 \pm 0.021$ & $38.414 \pm 0.068$ \\
\hline 654B-F & & & 18.4291 & 0.0016 & 0.844134 & 0.0008 & 2.08531 & 0.0015 & $18.460 \pm 0.017$ & $0.84481 \pm 0.00036$ & $2.0886 \pm 0.0018$ & $15.595 \pm 0.021$ & $38.554 \pm 0.068$ \\
\hline Mean 654B B-F & 101 & & & & & & & & $18.451 \pm 0.050$ & $0.8458 \pm 0.0020$ & $2.0890 \pm 0.0008$ & $15.605 \pm 0.009$ & $38.544 \pm 0.096$ \\
\hline 3-15655-B & & Res. Soil & & & & & & & & & & & \\
\hline SC-00069 & & & & & & & & & & & & & \\
\hline 655B-A & & & 18.2694 & 0.0018 & 0.851880 & 0.0007 & 2.08647 & 0.0014 & $18.300 \pm 0.017$ & $0.85256 \pm 0.00037$ & $2.0897 \pm 0.0018$ & $15.601 \pm 0.021$ & $38.241 \pm 0.067$ \\
\hline $655 B-A$ & & & 18.2648 & 0.0017 & 0.851734 & 0.0004 & 2.08594 & 0.0010 & $18.295 \pm 0.017$ & $0.85241 \pm 0.00037$ & $2.0892 \pm 0.0018$ & $15.595 \pm 0.021$ & $38.222 \pm 0.067$ \\
\hline Mean & & & & & & & & & $18.297 \pm 0.011$ & $0.85249 \pm 0.00026$ & $2.0894 \pm 0.0013$ & $15.598 \pm 0.014$ & $38.231 \pm 0.046$ \\
\hline 655B-B & & & 18.2823 & 0.0025 & 0.850617 & 0.0006 & 2.08327 & 0.0015 & $18.312 \pm 0.017$ & $0.85129 \pm 0.00037$ & $2.0865 \pm 0.0018$ & $15.589 \pm 0.021$ & $38.209 \pm 0.067$ \\
\hline Mean 655B A-B & 151 & & & & & & & & $18.303 \pm 0.073$ & $0.8519 \pm 0.0073$ & $2.088 \pm 0.017$ & $15.595 \pm 0.011$ & $38.224 \pm 0.037$ \\
\hline 3-15656-B & & Res. Soil & & & & & & & & & & & \\
\hline SC-00084 & & & & & & & & & & & & & \\
\hline 656B-A & & & 18.4515 & 0.0035 & 0.844073 & 0.0017 & 2.06797 & 0.0035 & $18.482 \pm 0.017$ & $0.84475 \pm 0.00037$ & $2.0712 \pm 0.0018$ & $15.613 \pm 0.021$ & $38.280 \pm 0.067$ \\
\hline 656B-A & & & 18.4479 & 0.0024 & 0.844073 & 0.0008 & 2.06751 & 0.0018 & $18.478 \pm 0.017$ & $0.84475 \pm 0.00036$ & $2.0707 \pm 0.0018$ & $15.609 \pm 0.021$ & $38.264 \pm 0.067$ \\
\hline 656B-A & & & 18.4502 & 0.0032 & 0.844119 & 0.0011 & 2.06803 & 0.0011 & $18.481 \pm 0.017$ & $0.84479 \pm 0.00036$ & $2.0713 \pm 0.0018$ & $15.612 \pm 0.021$ & $38.278 \pm 0.067$ \\
\hline Mean & & & & & & & & & $18.480 \pm 0.010$ & $0.84476 \pm 0.00020$ & $2.0711 \pm 0.0010$ & $15.611 \pm 0.012$ & $38.274 \pm 0.038$ \\
\hline 656B-B & & & 17.9549 & 0.0021 & 0.864978 & 0.0008 & 2.09423 & 0.0015 & $17.985 \pm 0.016$ & $0.86567 \pm 0.00037$ & $2.0975 \pm 0.0018$ & $15.569 \pm 0.021$ & $37.722 \pm 0.067$ \\
\hline 656B-C & & & 18.5411 & 0.0042 & 0.840091 & 0.0019 & 2.06893 & 0.0041 & $18.572 \pm 0.017$ & $0.84076 \pm 0.00037$ & $2.0722 \pm 0.0018$ & $15.614 \pm 0.021$ & $38.483 \pm 0.068$ \\
\hline 656B-D & & & 18.3719 & 0.0029 & 0.846875 & 0.0013 & 2.06935 & 0.0027 & $18.402 \pm 0.017$ & $0.84755 \pm 0.00037$ & $2.0726 \pm 0.0018$ & $15.597 \pm 0.021$ & $38.140 \pm 0.067$ \\
\hline 656B-E & & & 18.3958 & 0.0036 & 0.845958 & 0.0014 & 2.06725 & 0.0028 & $18.426 \pm 0.017$ & $0.84663 \pm 0.00037$ & $2.0705 \pm 0.0018$ & $15.600 \pm 0.021$ & $38.151 \pm 0.067$ \\
\hline Mean 656B A, C-E & 175 & & & & & & & & $18.47 \pm 0.12$ & $0.8449 \pm 0.0042$ & $2.0714 \pm 0.0007$ & $15.607 \pm 0.008$ & $38.26 \pm 0.25$ \\
\hline
\end{tabular}


Table 2. Contd.

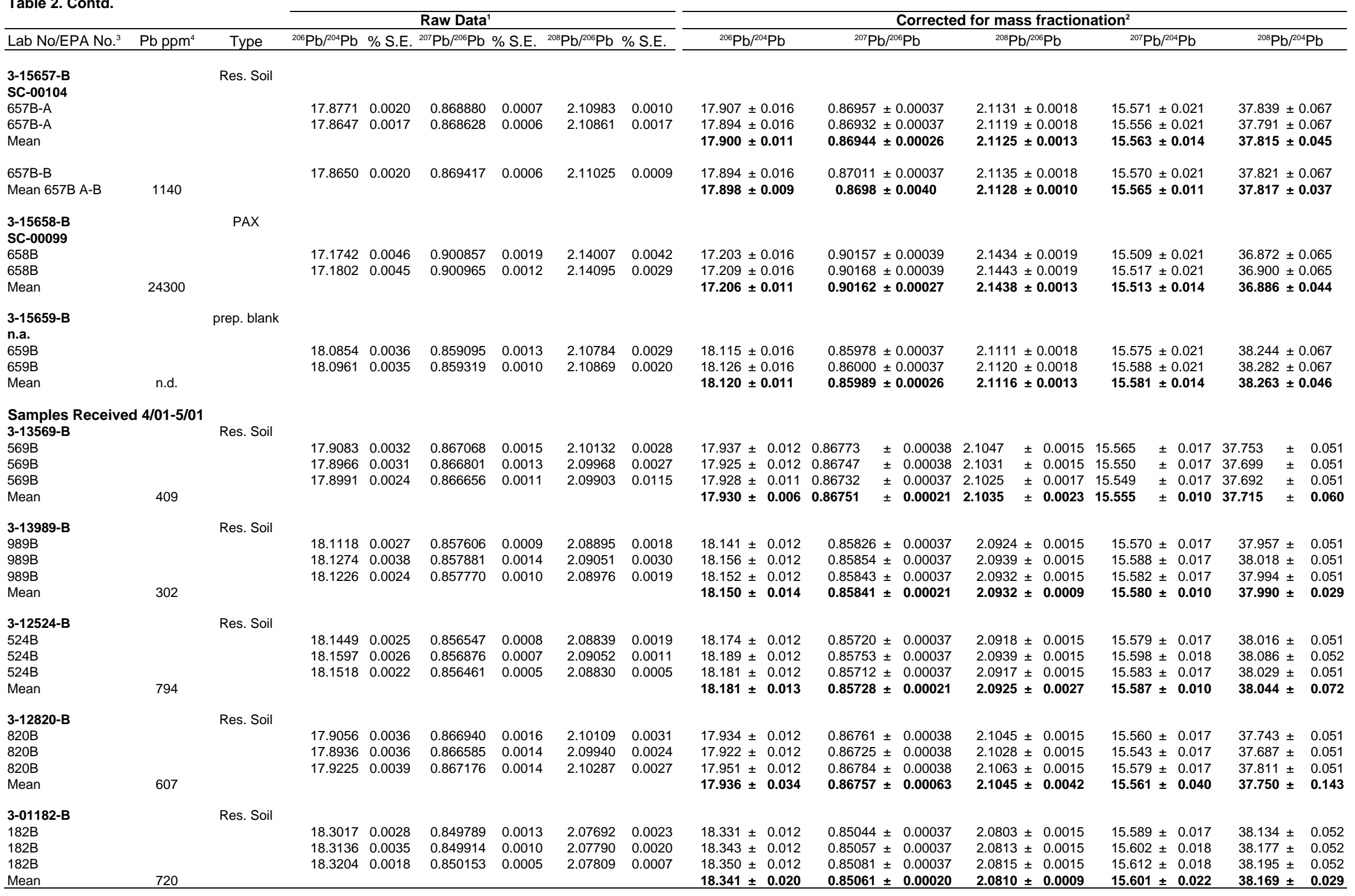


Table 2. Contd.

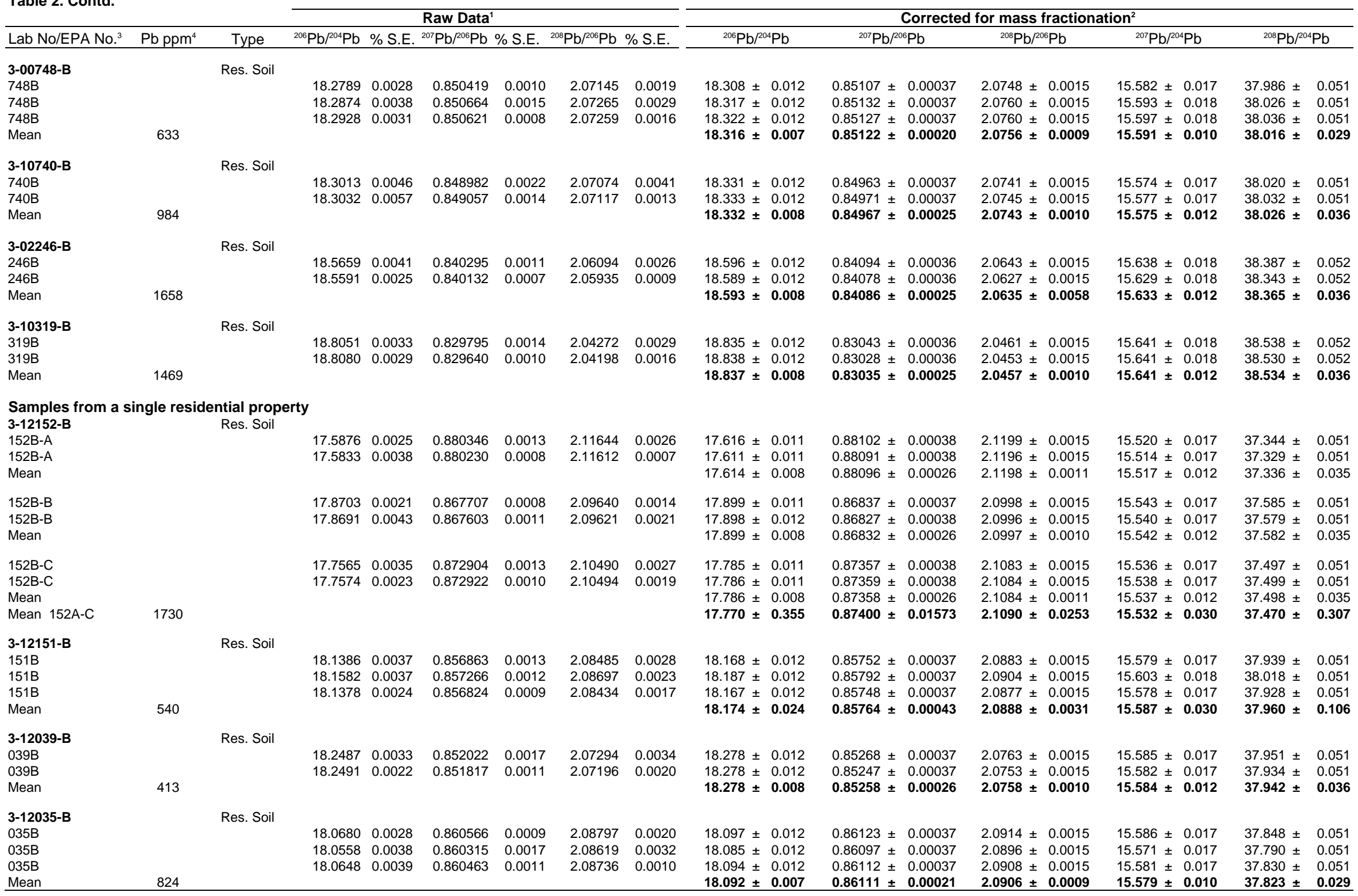


Table 2. Contd.

Raw Data

Corrected for mass fractionation ${ }^{2}$

\begin{tabular}{|c|c|c|c|c|c|c|c|c|c|c|c|c|c|c|}
\hline & & \multicolumn{7}{|c|}{ Raw Data ${ }^{1}$} & \multicolumn{6}{|c|}{ Corrected for mass fractionation ${ }^{2}$} \\
\hline Lab No/EPA No. ${ }^{3}$ & $\mathrm{~Pb} \mathrm{ppm}^{4}$ & Type & ${ }^{206} \mathrm{~Pb} /{ }^{204} \mathrm{~Pb}$ & $\%$ S.E. & ${ }^{207} \mathrm{~Pb} /{ }^{206} \mathrm{~Pb}$ & $\%$ S.E. & ${ }^{208} \mathrm{~Pb} /{ }^{206} \mathrm{~Pb}$ & $\%$ S.E. & ${ }^{206} \mathrm{~Pb} /{ }^{204} \mathrm{~Pb}$ & ${ }^{207} \mathrm{~Pb} /{ }^{206} \mathrm{~Pb}$ & ${ }^{208} \mathrm{~Pb} /{ }^{206} \mathrm{~Pb}$ & ${ }^{207} \mathrm{~Pb} /{ }^{204} \mathrm{~Pb}$ & ${ }^{208} \mathrm{~Pb} /{ }^{204} \mathrm{~F}$ & \\
\hline $3-120$ & & $\mathrm{R}$ & & & & & & & & & & & & \\
\hline 040B & & & 18.4208 & 0.0050 & 0.845624 & 0.0020 & 2.06295 & 0.0044 & $18.450 \pm 0.012$ & $0.84627 \pm 0.00037$ & $2.0663 \pm 0.0015$ & 0.018 & $38.124 \pm$ & 0.052 \\
\hline 040B & & & 18.4169 & 0.0032 & 0.845433 & 0.0010 & 2.06280 & 0.0016 & $18.446 \pm 0.012$ & $0.84608 \pm 0.00$ & $2.0662 \pm 0.0015$ & $15.607 \pm 0.018$ & $38.113 \pm$ & 0.052 \\
\hline Mean & 256 & & & & & & & & $18.448 \pm 0.008$ & $0.84617 \pm 0.00025$ & $2.0662 \pm 0.0010$ & $15.611 \pm 0.012$ & $38.118 \pm$ & 0.036 \\
\hline
\end{tabular}

1 Uncertainties are in percent and represent one standard error ( $\approx 1$ sigma mean).

2 Corrected for mass fractionation based on analyses of NIST standard SRM 981 (Table A1). Uncertainties are absolute and are at the 95\% confidence interval (Ludwig, 1980; 1994).

3 Individual mass spectrometer runs are listed separately under the same lab sample number. Separate acid-digestions of the same sample are listed as "-A" through "-F".

$4 \mathrm{~Pb}$ concentrations provided by USEPA from acid digestions of splits of the samples. 

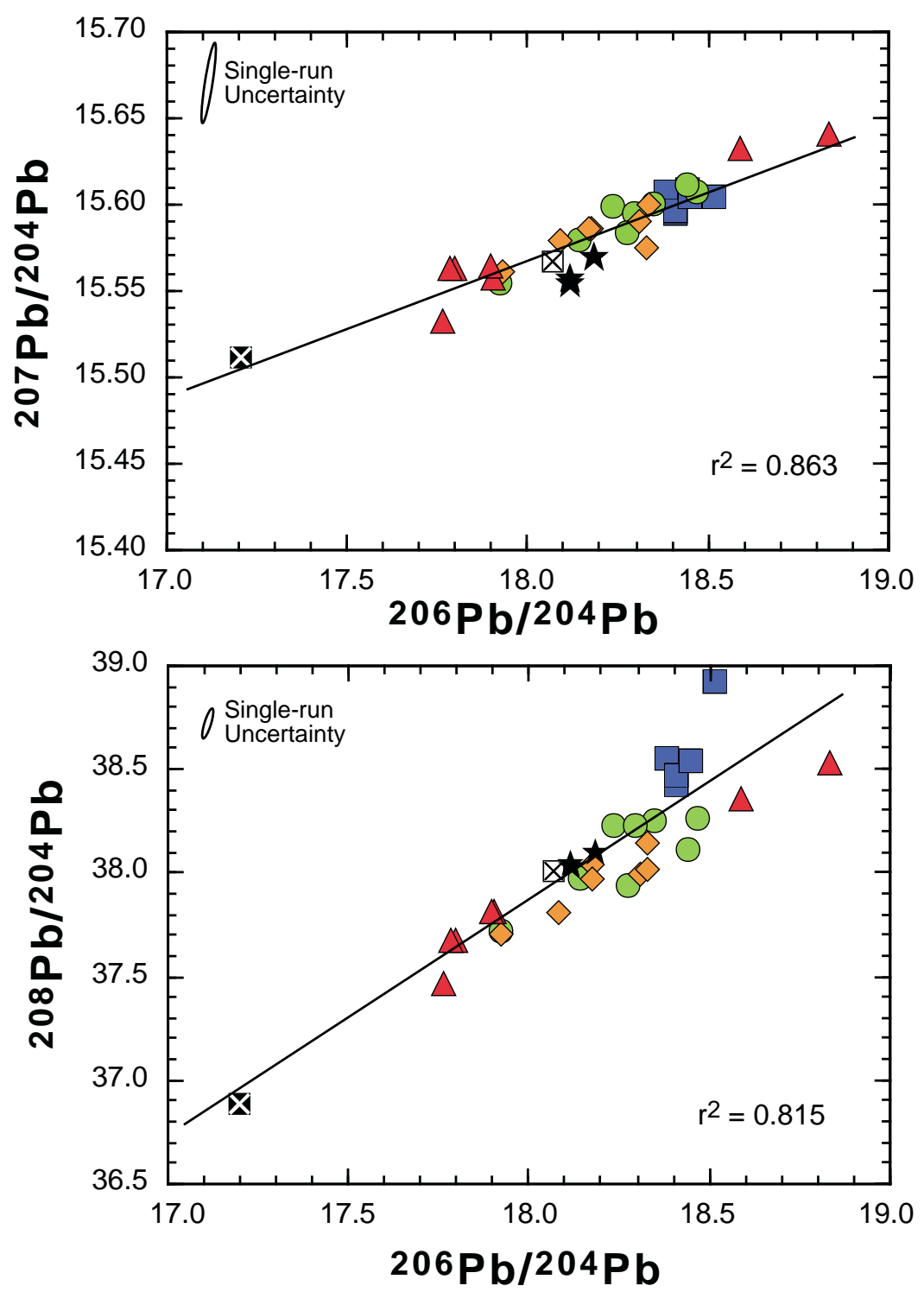

\begin{tabular}{|lll|}
\hline & Nominal Range & Actual Range \\
$\square$ & $\mathrm{Pb}<150 \mathrm{ppm}$ & $(39-126 \mathrm{ppm})$ \\
$\bigcirc \mathrm{Pb}=150-500 \mathrm{ppm}$ & $(151-422 \mathrm{ppm})$ \\
$\diamond \mathrm{Pb}=500-1000 \mathrm{ppm}$ & $(540-984 \mathrm{ppm})$ \\
$\triangle$ & $\mathrm{Pb}>1000 \mathrm{ppm}$ & $(1140-1730 \mathrm{ppm})$ \\
$\star$ & Smelter materials & \\
$\mathbf{X}$ PAX & \\
$\square$ & Acme Pb-Arsenate & \\
\hline
\end{tabular}

Figure 1. ${ }^{206} \mathrm{~Pb} / 204 \mathrm{~Pb}$ vs. ${ }^{207} \mathrm{~Pb} / 204 \mathrm{~Pb}$ and ${ }^{206} \mathrm{~Pb} / 204 \mathrm{~Pb}$ vs. ${ }^{208} \mathrm{~Pb} / 204 \mathrm{~Pb}$ diagrams for selected soil samples from the Vasquez Blvd.-170 study area, coded by $\mathrm{Pb}$ concentrations. Data are from Table 2 and represent the mean values for individual samples. Best fit lines (unweighted) through the data yield $\mathrm{r}^{2}$ values (square of the regression correlation coefficients) of 0.863 and 0.815 for ${ }^{206} \mathrm{~Pb} / 204 \mathrm{~Pb}$ vs. ${ }^{207} \mathrm{~Pb} / 204 \mathrm{~Pb}$ and ${ }^{206 \mathrm{~Pb}} / 204 \mathrm{~Pb}$ vs. $208 \mathrm{~Pb} / 204 \mathrm{~Pb}$, respectively. Also shown is the typical uncertainty (95\% C.I.) for and individual mass spectrometer run. 
Lead isotopic data for the Acme lead arsenate, smelter soils, and smelter waste are very similar to one another and to some of the residential soils. On the other hand, the sample of PAX has a unique and nonradiogenic $\left(l o w{ }^{206} \mathrm{~Pb} /{ }^{204} \mathrm{~Pb}\right.$ ) lead isotopic composition with ${ }^{206} \mathrm{~Pb} /{ }^{204} \mathrm{~Pb}=17.21$.

The $\mathrm{Pb}$ isotopic compositions presented in Figure 1 are also shown in Figure 2, but the data points are coded based on As concentrations. Low-As samples are generally the most radiogenic with ${ }^{206} \mathrm{~Pb} /{ }^{204} \mathrm{~Pb}>18.25$ (two exceptions, both from the same residential property). High-As samples show two distinct groups; one with ${ }^{206} \mathrm{~Pb} /{ }^{204} \mathrm{~Pb}<17.9$, and one with ${ }^{206} \mathrm{~Pb} /{ }^{204} \mathrm{~Pb}=18.15-18.18$. Comparison of Figures 1 and 2 reveals that the soils with high $\mathrm{Pb}$ and $\mathrm{As}$ are characterized by ${ }^{206} \mathrm{~Pb} /{ }^{204} \mathrm{~Pb}<17.9$, whereas the samples with radiogenic $\mathrm{Pb}$ and slightly-elevated ${ }^{208} \mathrm{~Pb} /{ }^{204} \mathrm{~Pb}$ are low in both $\mathrm{Pb}$ and $\mathrm{As}$.

Isotopic compositions in most of the high-As and high-Pb samples are less radiogenic than the smelter material, Acme $\mathrm{Pb}$ arsenate, or the low-As and low-Pb soils (baseline soils). Consequently, these soils must have a component of PAX (or some similar, but as yet unidentified material) within them. However, the isotopic data for the three contaminants and the residential soils are nearly colinear. Consequently, from the lead isotopic data alone it is not possible to determine whether the $\mathrm{Pb}$ in the high- $\mathrm{As}$, high- $\mathrm{Pb}$ soils is a simple mixture of $\mathrm{PAX}$ and baseline soil or whether the other contaminants are also present.

\section{Sources of Lead}

Lead and As concentrations of the residential soils, coded according to their ${ }^{206} \mathrm{~Pb} /{ }^{204} \mathrm{~Pb}$ values, are shown in Figure 3. Shown for comparison are data from a selected number of other residential soils within the study area that were not analyzed for $\mathrm{Pb}$ isotopic compositions. Uncontaminated or least-contaminated samples, represented by the cluster of points with low As and $\mathrm{Pb}$, have ${ }^{208} \mathrm{~Pb} /{ }^{204} \mathrm{~Pb}=18.3->18.5$, although the majority of the samples have ${ }^{208} \mathrm{~Pb} /{ }^{204} \mathrm{~Pb}=18.4-18.5$. The samples highest in As $(>1200 \mathrm{ppm})$ are characterized by ${ }^{208} \mathrm{~Pb} /{ }^{204} \mathrm{~Pb}<18.0$, even though $\mathrm{Pb}$ contents vary from 400 to over $1500 \mathrm{ppm}$. As mentioned above, samples with the highest $\mathrm{Pb}$ contents fall into two groups; one with ${ }^{208} \mathrm{~Pb} /{ }^{204} \mathrm{~Pb}>18.5$ and one with ${ }^{208} \mathrm{~Pb} /{ }^{204} \mathrm{~Pb}<18.0$. Both isotopic groups are found among low-As-residential soils (lower right in Figure 3). These results indicate that there are at least two high- $\mathrm{Pb}$, low-As contaminants present in these soils.

Lead isotopic compositions, represented by ${ }^{206} \mathrm{~Pb} /{ }^{204} \mathrm{~Pb}$, are shown as a function of $\mathrm{Pb}$ concentration in Figure 4. Six lead sources are represented as summarized in Table 3. The uncontaminated or least-contaminated end member is defined by the low-As and low- $\mathrm{Pb}$ samples. This component with ${ }^{206} \mathrm{~Pb} /{ }^{204} \mathrm{~Pb}=18.48$ and $\mathrm{Pb}=70 \mathrm{ppm}$ is represented by the means of the baseline soil sample, SC-00065, and the lowest-Pb sample, SC-00017. 

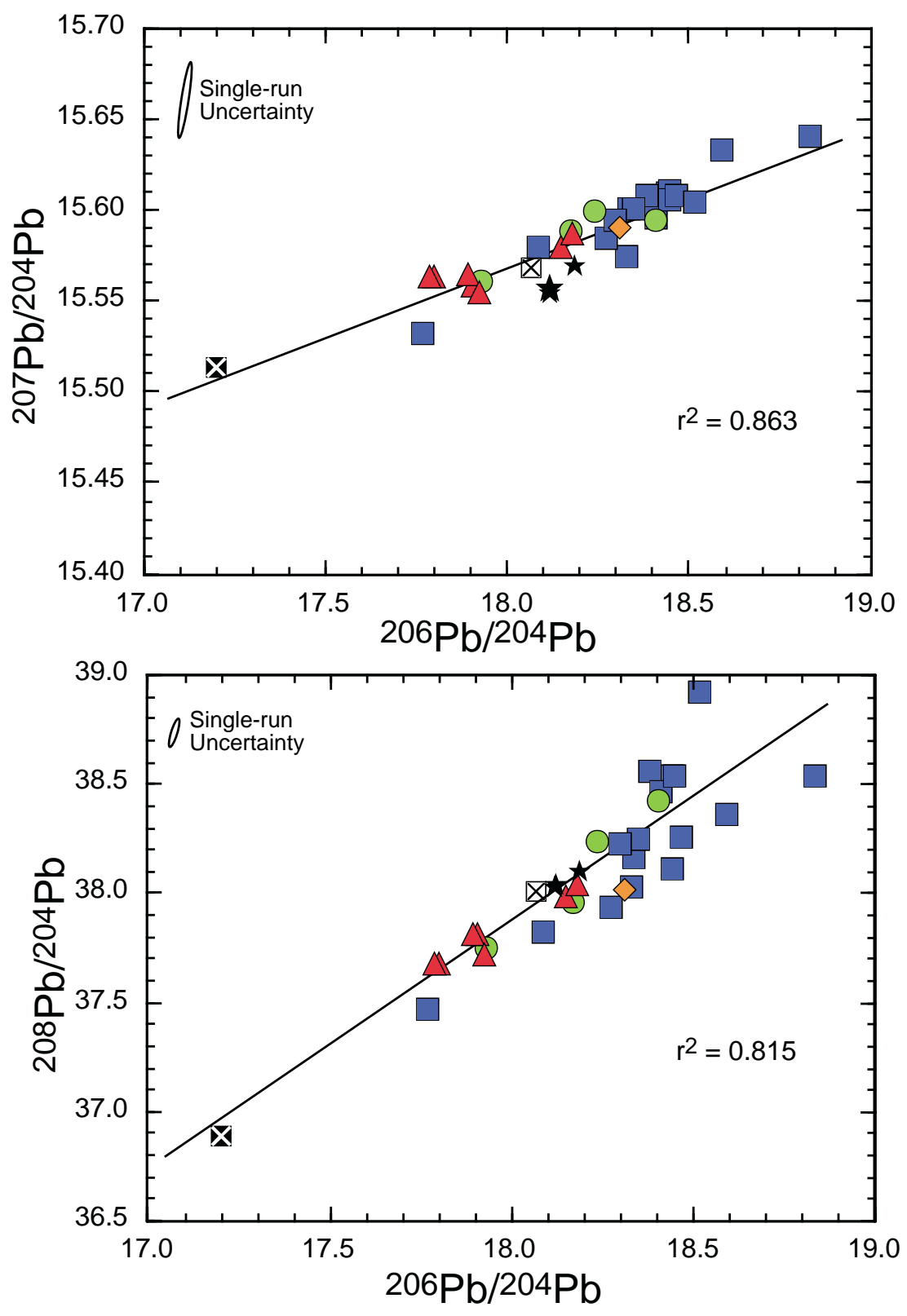

\begin{tabular}{|lll|}
\hline & Nominal Range & Actual Range \\
As $<50 \mathrm{ppm}$ & $(<11-48 \mathrm{ppm})$ \\
$\bigcirc$ As $=50-250 \mathrm{ppm}$ & $(165-242 \mathrm{ppm})$ \\
$\diamond$ As $=250-500 \mathrm{ppm}$ & $(409 \mathrm{ppm})$ \\
$\triangle$ As $>500 \mathrm{ppm}$ & $(830-1492 \mathrm{ppm})$ \\
$\star$ Smelter materials & \\
$\mathbf{X}$ PAX & \\
$\square$ Acme Pb-Arsenate & \\
\hline
\end{tabular}

Figure 2. ${ }^{206} \mathrm{~Pb} / 204 \mathrm{~Pb}$ vs. ${ }^{207} \mathrm{~Pb} / 204 \mathrm{~Pb}$ and ${ }^{206} \mathrm{~Pb} / 204 \mathrm{~Pb}$ vs. ${ }^{208} \mathrm{~Pb} / 204 \mathrm{~Pb}$ diagrams for selected soil samples from the Vasquez Blvd.-170 study area, coded by As concentrations. Data are from Table 2 and represent the mean values for individual samples. Also shown are the typical uncertainty ( $95 \%$ C.I.) for and individual mass spectrometer run and best-fit lines through all of the data. 

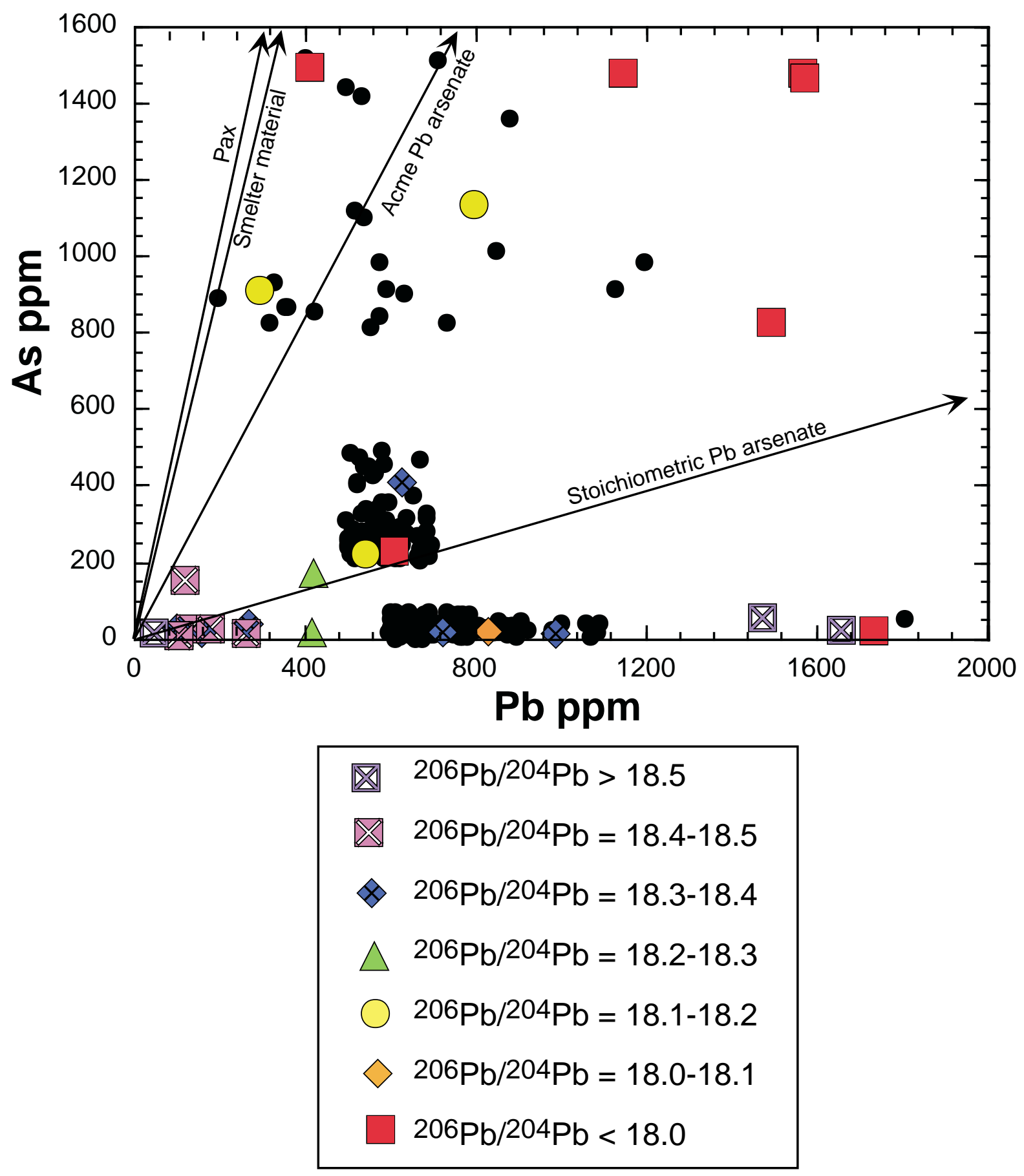

Figure 3. As vs. Pb concentrations for selected samples from the VBI70 study area. Samples are coded according to their ${ }^{206} \mathrm{~Pb} / 204 \mathrm{~Pb}$ values. Also shown by the small filled circles are data from samples not analyzed for $\mathrm{Pb}$ isotopic compositions? Vectors for PAX, smelter soils and materials, Acme lead arsenate, and stoichiometric $\mathrm{Pb}$ arsenate $\left(\mathrm{PbAsO}_{4}\right)$, which are all off the scale of the diagram, are also shown. 
Table 3. Summary of identified Pb sources in the VBI70 study area.

\begin{tabular}{|c|c|c|c|c|c|c|}
\hline Sample & Type & $\mathrm{Pb}$ ppm & As ppm & ${ }^{206} \mathrm{~Pb} /{ }^{204} \mathrm{~Pb}$ & ${ }^{207} \mathrm{~Pb} /{ }^{204} \mathrm{~Pb}$ & ${ }^{208} \mathrm{~Pb} /{ }^{204} \mathrm{~Pb}$ \\
\hline \multicolumn{7}{|l|}{ Baseline } \\
\hline Mean $^{1}$ & res soils. & 70 & 8 & 18.476 & 15.604 & 38.732 \\
\hline \multicolumn{7}{|c|}{ High-As contaminants } \\
\hline 3-15639-B & Acme $\mathrm{Pb}$-Arsenate & 128000 & 273000 & 18.071 & 15.568 & 38.009 \\
\hline 3-15658-B & PAX & 24300 & 120000 & 17.206 & 15.513 & 36.886 \\
\hline 3-15643-B & Smelter-soil & 4520 & 22400 & 18.190 & 15.570 & 38.101 \\
\hline 3-15645-B & Smelter-soil & 5660 & 27200 & 18.122 & 15.557 & 38.026 \\
\hline $3-15646-B$ & Smelter-material & 2160 & 7630 & 18.121 & 15.554 & 38.035 \\
\hline Mean smelte & materials \& soils & 4113 & 19077 & 18.144 & 15.560 & 38.054 \\
\hline \multicolumn{7}{|c|}{ Low-As contaminants ${ }^{2}$} \\
\hline $3-10319-B$ & res. soil & 1469 & 48 & 18.837 & 15.641 & 38.534 \\
\hline 3-12152-B & res. soil & 1730 & $<11$ & 17.770 & 15.532 & 37.470 \\
\hline
\end{tabular}

${ }^{1}$ Mean of soils $3-15644-B$ and $3-15654-B$

${ }^{2}$ The residential soils with highest lead contents are used to approximate the contaminants. The true contaminant should have higher $\mathrm{Pb}$ concentrations and slightly different lead isotopic values. 
The data for the PAX sample represent one possible contaminant with ${ }^{206} \mathrm{~Pb} /{ }^{204} \mathrm{~Pb}=$ 17.21 and $\mathrm{Pb}=24300 \mathrm{ppm}$. A second contaminant is represented by the lead arsenate sample with ${ }^{206} \mathrm{~Pb} /{ }^{204} \mathrm{~Pb}=18.07$ and $\mathrm{Pb}=128000 \mathrm{ppm}$. The smelter soils with ${ }^{206} \mathrm{~Pb} /{ }^{204} \mathrm{~Pb}$ $\approx 18.12-18.19$ and $\mathrm{Pb} \approx 2160-5600 \mathrm{ppm}$ represent a third contaminant source. Each of these three sources represents a potential As as well as $\mathrm{Pb}$ contaminant.

Two additional contaminants are approximated by residential soils 3-10319-B and 312152-B. These sources appear to represent $\mathrm{Pb}$ contamination, but not As. Because these soils are likely mixtures of contaminant and baseline material, the actual $\mathrm{Pb}$ concentrations in the true contaminants are probably higher than in the soils and the $\mathrm{Pb}$ isotopic compositions more extreme $\left({ }^{206} \mathrm{~Pb} /{ }^{204} \mathrm{~Pb} \geq 18.84\right.$ and $\leq 17.77$ for $3-10319-\mathrm{B}$ and $3-12152-\mathrm{B}$, respectively). Another high- $\mathrm{Pb}$ sample with ${ }^{206} \mathrm{~Pb} /{ }^{204} \mathrm{~Pb}=18.6$ may reflect yet another $\mathrm{Pb}$ contaminant or a mixture of $\mathrm{Pb}$ contaminants.

\section{Two-Component Mixing}

Calculated bulk-mixing curves between average baseline and each of the fivecontaminant sources are shown for reference in Figure 4A. The bulk mixing curves are calculated from the following two-component bulk-mixing equations (Faure, 1977):

$$
\begin{gathered}
C_{M}=C_{C}{ }^{*}(X)+C_{B}{ }^{*}(1-X) \\
R_{M}=\left[R_{C}{ }^{*} C_{C}{ }^{*}(X)+R_{B}{ }^{*} C_{B}{ }^{*}(1-X)\right] / C_{M}
\end{gathered}
$$

where $C_{C}$, and $C_{B}$ are the concentrations of an element, in this case lead, in the contaminant (C) and baseline (B); $C_{M}$ is the concentration of the element in the mixture (a contaminated soil sample), and $X$ is the weight fraction of contaminant source $A$ in the mixture (where $0 \leq X \leq 1$ ). $R_{A}, R_{B}$, and $R_{M}$ are the isotopic ratios (in this case ${ }^{206} \mathrm{~Pb} /{ }^{204} \mathrm{~Pb}$ ) in the contaminant source, baseline, and mixture, respectively. The percent contamination is $100^{*} X$. The weight fraction of an element in a soil, $X_{C}$, derived from the contaminant is calculated from $X$ in the following manner (Church and others, 2002):

$$
\mathrm{X}_{\mathrm{C}}=\mathrm{X}^{*} \mathrm{C}_{\mathrm{C}} / \mathrm{C}_{\mathrm{M}}
$$

By combining equations (1) and (2) and eliminating $X$, the following expression is obtained (Faure, 1977):

$$
R_{M}=\left[C_{C}{ }^{*} C_{B}{ }^{*}\left(R_{C}-R_{B}\right)\right] /\left[C_{M}{ }^{*}\left(C_{C}-C_{B}\right)\right]+\left(C_{C}{ }^{*} R_{A}-C_{B}{ }^{*} R_{B}\right) /\left(C_{C}-C_{B}\right)
$$



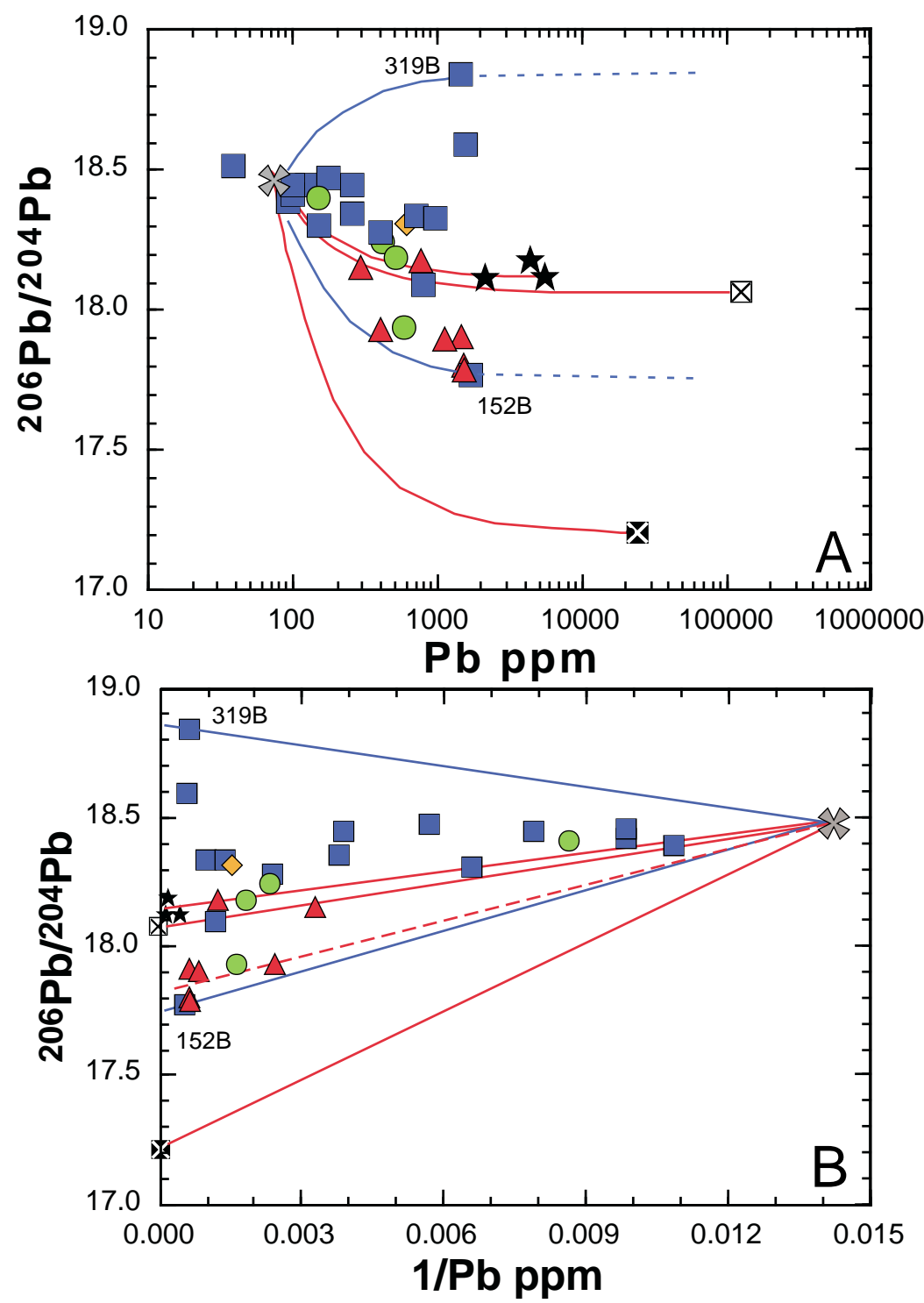

\begin{tabular}{|c|c|c|}
\hline & Nominal Range & Actual Range \\
\hline$\square$ & As $<50 \mathrm{ppm}$ & $(<11-48$ ppm $)$ \\
\hline 0 & $A s=50-250 \mathrm{ppm}$ & $(165-242 \mathrm{ppm})$ \\
\hline$\diamond$ & $A s=250-500 \mathrm{ppm}$ & (409 ppm) \\
\hline$\triangle$ & As $>500 \mathrm{ppm}$ & (830-1492 ppm) \\
\hline$\star$ & Smelter materials & \\
\hline $\mathbf{X}$ & PAX & \\
\hline$凶$ & Acme $\mathrm{Pb}$-Arsenate & \\
\hline 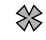 & Av. Baseline & \\
\hline & \multicolumn{2}{|c|}{ High-As high-Pb source } \\
\hline 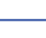 & Low-As high-Pb so & \\
\hline
\end{tabular}

Figure 4. (A) ${ }^{206} \mathrm{~Pb} / 204 \mathrm{~Pb}$ vs. $\mathrm{Pb}$ concentration and (B) ${ }^{206} \mathrm{~Pb} / 204 \mathrm{~Pb}$ vs. $1 / \mathrm{Pb}$ concentration for selected soil samples from the VBI70 study area. Data are from Table 2 and represent the grand means of data from individual samples (bold type in Table 2). An average baseline value (cross, ${ }^{206} \mathrm{~Pb} / 204 \mathrm{~Pb}=18.48, \mathrm{~Pb}=70 \mathrm{ppm}$ ) is estimated from data for samples 3-15654-B and 3-15644-B. Bulk-mixing curves (lines in Figure 4B) between average baseline and PAX, smelter soil, Acme lead arsenate, soil 3-10319-B (319B), and soil 3-12152-B (152B) are shown for reference. The broken line in Figure 4B represents a hypothetical mixing line between average baseline and $\mathrm{ab}+\mathrm{As}$ source with $206 \mathrm{~Pb} / 204 \mathrm{~Pb} \quad 17.8$. 
This equation is of the general form:

$$
R_{M}=a / C_{M}+b
$$

which is the form for a hyperbolic curve when $R_{M}$ is plotted as a function of $C_{M}$ (a and b are constants dependent upon the values of $C_{C}, C_{B}, R_{C}$, and $R_{B}$ ). The mixing hyperbole is converted to a straight line if $R_{M}$ is plotted as a function of $\left(1 / C_{M}\right)$ as is shown in Figure $4 B$.

Four points regarding Figure 4 are worthy of mention. (1) The bulk mixing curves for Acme lead arsenate and average smelter material are nearly superimposed upon one another. This means that the $\mathrm{Pb}$ data are not able to resolve contamination from these two sources. (2) Most of the low-As samples plot above the mixing curves for lead arsenate and smelter material. This observation coupled with the fact that these samples show a wide range in lead contents indicates that $\mathrm{Pb}$ contamination from a source or sources with radiogenic $\mathrm{Pb}$ $\left({ }^{206} \mathrm{~Pb} /{ }^{204} \mathrm{~Pb}>18.2\right)$ is common among the low-As soils. One might reasonably conclude that this contamination is also present among the higher-As soils as well, but may be masked by other contaminants. (3) The data for many of the high-As residential samples plot between the $\mathrm{PAX}$ and lead arsenate - smelter material mixing curves. This suggests that the $\mathrm{Pb}$ in these samples was derived from at least three sources: baseline, PAX and at least one other contaminant source. Alternatively, the results may indicate the presence of another contaminant with ${ }^{206} \mathrm{~Pb} /{ }^{204} \mathrm{~Pb} \approx 17.8$, similar to soil 3-12152-B, but with high $\mathrm{As}$ as well as $\mathrm{Pb}$ (broken red line in Figure 4B). (4) Finally, data for two of the high-As soils (3-13989-B and 3-12524-B) as well as three of the intermediate-As soils (3-15648-B, 3-15642-B, and 3-12151-B) plot on or near the mixing lines (Figure 4B) between baseline and smelter material or lead arsenate. This suggests that lead arsenate or smelter material may represent the principal contaminant in these samples. However, if multiple contaminants are involved, then the position of these data relative to the lead arsenate and smelter material mixing curves may be fortuitous.

In a situation involving two-component-mixing, the weight fraction of contaminant $(X)$ can be semi-independently calculated from both equations 1 and 2 (equations 1 and 2 are not totally independent because the concentration data are used in both equations). The weight fraction of contaminant $\mathrm{Pb}, \mathrm{X}_{\mathrm{Pb}}$, in a sample can also be estimated using the $\mathrm{Pb}$ isotopic compositions alone (Church and others, 1997; 2002) as follows:

$$
X_{P b}=\left(R_{M}-R_{B}\right) /\left(R_{C}-R_{B}\right)
$$


Table 4. Two-component mixing parameters for selected soil samples from the VBI70 study area.

\begin{tabular}{|c|c|c|c|c|c|c|c|c|c|c|}
\hline Components & Sample & Pb ppm & As ppm & ${ }^{206} \mathrm{~Pb} /{ }^{204} \mathrm{~Pb}$ & $\mathbf{X}_{\mathrm{c}} \mathbf{P b}^{1}$ & $\mathrm{X}_{\mathrm{Pb}}{ }^{2}$ & $\mathrm{XPb}(1)^{3}$ & $\mathrm{X} \mathrm{Pb}(2)^{4}$ & $\mathrm{XPb}(6)^{5}$ & X As $(1)^{3}$ \\
\hline $\begin{array}{l}\text { Acme } \mathrm{Pb} \text { arsenate } \\
\text { and average baseline }\end{array}$ & $\begin{array}{l}3-13989-B \\
3-12524-B \\
3-15648-B \\
3-15642-B \\
3-12151-B\end{array}$ & $\begin{array}{l}302 \\
794 \\
115 \\
422 \\
540\end{array}$ & $\begin{array}{r}904 \\
1135 \\
165 \\
173 \\
221\end{array}$ & $\begin{array}{l}\mathbf{1 8 . 1 5 0} \\
\mathbf{1 8 . 1 8 1} \\
18.410 \\
18.242 \\
18.174\end{array}$ & $\begin{array}{l}0.769 \\
0.912 \\
0.392 \\
0.835 \\
0.871\end{array}$ & $\begin{array}{l}0.805 \\
0.728 \\
0.163 \\
0.578 \\
0.746\end{array}$ & $\begin{array}{l}\mathbf{0 . 0 0 1 8} \\
\mathbf{0 . 0 0 5 7} \\
0.0004 \\
0.0028 \\
0.0037\end{array}$ & $\begin{array}{l}0.0018 \\
0.0057 \\
0.0004 \\
0.0028 \\
0.0037\end{array}$ & $\begin{array}{l}0.0019 \\
0.0045 \\
0.0002 \\
0.0019 \\
0.0032\end{array}$ & $\begin{array}{l}0.0033 \\
0.0041 \\
0.0006 \\
0.0006 \\
0.0008\end{array}$ \\
\hline $\begin{array}{l}\text { Average smelter material } \\
\text { and average baseline }\end{array}$ & $\begin{array}{l}3-13989-B \\
3-12524-B \\
3-15648-B \\
3-15642-B \\
3-12151-B\end{array}$ & $\begin{array}{l}302 \\
794 \\
115 \\
422 \\
540\end{array}$ & $\begin{array}{r}904 \\
1135 \\
165 \\
173 \\
221\end{array}$ & $\begin{array}{l}\mathbf{1 8 . 1 5 0} \\
18.181 \\
\mathbf{1 8 . 4 1 0} \\
18.242 \\
18.174\end{array}$ & $\begin{array}{l}0.782 \\
0.928 \\
0.398 \\
0.849 \\
0.885\end{array}$ & $\begin{array}{l}0.982 \\
0.889 \\
0.199 \\
0.705 \\
0.910\end{array}$ & $\begin{array}{l}0.0574 \\
0.1791 \\
\mathbf{0 . 0 1 1 1} \\
0.0871 \\
0.1163\end{array}$ & $\begin{array}{l}0.0571 \\
0.1792 \\
0.0112 \\
0.0873 \\
0.1162\end{array}$ & $\begin{array}{l}0.0721 \\
0.1715 \\
0.0056 \\
0.0723 \\
0.1194\end{array}$ & $\begin{array}{l}0.0470 \\
0.0591 \\
0.0082 \\
0.0087 \\
0.0112\end{array}$ \\
\hline
\end{tabular}

${ }^{1}$ Weight fraction of contaminant $\mathrm{Pb}$ in the soil calculated from $\mathrm{Pb}$ concentrations using equation (3).

${ }^{2}$ Weight fraction of contaminant $\mathrm{Pb}$ in the soil calculated from $\mathrm{Pb}$ isotopic compositions using equation (5).

${ }^{3}$ Weight fraction of contaminant in the soil calculated from $\mathrm{Pb}$ or As concentrations using equation (1).

${ }^{4}$ Weight fraction of contaminant in the soil calculated from equation (2).

${ }^{5}$ Weight fraction of contaminant in the soil calculated from equation (6). 
The weight fraction of contaminant, $\mathrm{X}$, can then be calculated from $\mathrm{X}_{\mathrm{Pb}}$ and the $\mathrm{Pb}$ concentrations in the contaminant and soil in the following manner:

$$
\mathrm{X}=\mathrm{X}_{\mathrm{Pb}}{ }^{*} \mathrm{C}_{\mathrm{M}} / \mathrm{C}_{\mathrm{C}}
$$

Equations (3) and (5) provide two independent methods of estimating the relative amount of contaminant $\mathrm{Pb}$ within a soil, one based solely on the $\mathrm{Pb}$ concentrations (3), and one based exclusively on the $\mathrm{Pb}$ isotopic compositions (5). Equation (6) also provides another semi-independent method of estimating the relative amount of contaminant in a soil. The As concentration data can also be used in equation (1) to provide an independent check of the calculations.

Two-component mixing calculations for the five soils mentioned above, that plot near the baseline- $\mathrm{Pb}$ arsenate or smelter material mixing curves, are presented in Table 4. Two sets of calculations have been made for mixing between baseline and lead arsenate and between baseline and average smelter material. It should be emphasized that these calculations represent possible solutions only. Independent verification from geochemical analyses and speciation studies are also required in order to determine whether these possible solutions are in fact reasonable. Calculations in Table 4 are highlighted in bold type when agreement among the three calculations was within a factor of 2 (arbitrary).

Data for the two high-As samples are consistent contamination of baseline soil with $0.2-$ $0.6 \%$ acme lead arsenate. One of these samples, $3-13989-B$ is also consistent with contamination of baseline soil with 5-6\% smelter material. Calculations for the intermediate-As sample 3-15648-B are also consistent with a small amount of contamination from either $\mathrm{Pb}$ arsenate or smelter material. Internally consistent results were not obtained for the other samples.

\section{Three-Component Mixing}

As mentioned above four of the six high-As samples (samples 3-15650-B and 315651-B are duplicate splits of the same soil) and one of the intermediate-As soils plot between the three high-As mixing curves in Figure 4. Although these samples plot close to the mixing curve for baseline and soil 3-12152-B, this soil can not represent the only contaminant in these samples because soil 3-12152-B has low As. Barring the existence of an unidentified high-As contaminant with ${ }^{206} \mathrm{~Pb} /{ }^{204} \mathrm{~Pb} \approx 17.8$, the $\mathrm{Pb}$ data for these samples must reflect contamination from more than one source.

If two contaminant sources are involved then a three-component mixing model may be employed where 


$$
\begin{gathered}
\mathrm{C}_{\mathrm{M}}=\mathrm{C}_{\mathrm{C} 1}{ }^{*}(\mathrm{X})+\mathrm{C}_{\mathrm{C} 2}{ }^{*}(\mathrm{Y})+\mathrm{C}_{\mathrm{B}}{ }^{*}(1-\mathrm{X}-\mathrm{Y}) \\
\mathrm{R}_{\mathrm{M}}=\left[\mathrm{R}_{\mathrm{C} 1}{ }^{*} \mathrm{C}_{\mathrm{C} 1}{ }^{*}(\mathrm{X})+\mathrm{R}_{\mathrm{C} 2}{ }^{*} \mathrm{C}_{\mathrm{C} 2}{ }^{*}(\mathrm{Y})+\mathrm{R}_{\mathrm{B}}{ }^{*} \mathrm{C}_{\mathrm{B}}{ }^{*}(1-\mathrm{X}-\mathrm{Y})\right] / \mathrm{C}_{\mathrm{M}}
\end{gathered}
$$

where $\mathrm{X}$ and $\mathrm{Y}$ are the weight fractions of contaminants $\mathrm{C} 1$ and $\mathrm{C} 2$, respectively. Equations 7 and 8 may be combined to solve for both $X$ and $Y$. If more than two contaminant sources are involved, then additional data are required in order to obtain unique solutions.

Three-component mixing calculations for all six high-As and all five intermediate-As soils are summarized in Table 5. All calculations are made assuming the soils are mixtures of baseline material and two contaminants. The requirements for selecting pairs of contaminants are (1) that one of the contaminants must have nonradiogenic $\mathrm{Pb}$ (either PAX or soil 3-12152$\mathrm{B}$; this requirement is strictly valid only for those soils having ${ }^{206} \mathrm{~Pb} /{ }^{204} \mathrm{~Pb}<18.08$ ) and (2) that at least one of the contaminants must have high As (either PAX, lead arsenate, or smelter material). Using these criteria, 5 different situations are allowed (Table 5). Weight fractions of the two contaminants were calculated using the $\mathrm{Pb}$ concentration and $\mathrm{Pb}$ isotopic data in equations 4 and 5 . Arsenic contents were calculated from these proportions and arsenic contents of the contaminants using equation 4 . The calculated arsenic contents are compared to the measured As in the soils in Table 5. Calculations highlighted in bold are for calculated As contents that are within a factor of 2 of the measured values. Once again, the calculations only indicate possible solutions which must be used in conjunction with other evidence.

Consistent results were not obtained. Data for some samples (e.g. 3-13569-B and 313989-B) have multiple solutions whereas data for other samples (3-15650-B and 3-00748B) yield no satisfactory solutions. If taken at face value, the data in Table 5 suggest that the As and $\mathrm{Pb}$ contamination in each residential property is derived from a unique set of circumstances.

The calculations in Tables 4 and 5 are complicated by several factors. First, the proportions of lead and arsenic currently present in the soils may be different from those in the potential sources as a result of preferential dissolution of specific chemical phases from the soils (J. Drexler, oral communication, 2001). Second, the smelter soils present today may have different chemical and isotopic signatures from soils present in the past. This is particularly true of the smelter in question, which switched from arsenic to cadmium refining during the late 1920 's. It should also be noted that two other smelters were at one time present in this general area, but samples from these smelters are not available. Finally, the samples of PAX and lead arsenate represent only two of several similar compounds that might have been commercially available during the middle $20^{\text {th }}$ century. The proportions of lead and arsenic as well as the lead isotopic signatures of this other material, or of the PAX and Acme lead arsenate for that 
Table 5. Three-component mixing calculations for selected resedential soils from the VBI70 study area. ${ }^{1}$

\begin{tabular}{|c|c|c|c|c|c|c|}
\hline Sample & Pb ppm & ${ }^{206} \mathrm{~Pb} /{ }^{204} \mathrm{~Pb}$ & $\%$ Cont. $\mathbf{C}_{1}{ }^{2}$ & $\%$ Cont. $\mathbf{C}_{2}{ }^{3}$ & Calc. As ppm ${ }^{4}$ & Meas. As ppm \\
\hline \multicolumn{7}{|c|}{ Contaminants: $\mathrm{Pax}$ and $\mathrm{Acme} \mathrm{Pb}$ arsenate } \\
\hline & $\mathrm{Pb} \mathrm{ppm}$ & ${ }^{206} \mathrm{~Pb} /{ }^{204} \mathrm{~Pb}$ & $\%$ PAX & $\%$ Acme & Calc. As ppm & Meas. As ppm \\
\hline 3-15641-B & 1490 & 17.910 & 1.27 & 0.87 & 3908 & 836 \\
\hline 3-15650-B & 1560 & 17.801 & 2.13 & 0.76 & 4645 & 1490 \\
\hline 3-15657-B & 1140 & 17.898 & 1.07 & 0.63 & 3023 & 1490 \\
\hline 3-13569-B & 409 & 17.930 & 0.41 & 0.19 & 1010 & 1492 \\
\hline 3-13989-B & 302 & 18.150 & 0.02 & 0.18 & 517 & 904 \\
\hline 3-12524-B & 794 & 18.181 & -0.28 & 0.62 & 1361 & 1135 \\
\hline 3-15648-B & 115 & 18.410 & -0.05 & 0.04 & 70 & 165 \\
\hline 3-15642-B & 422 & 18.242 & -0.21 & 0.31 & 617 & 173 \\
\hline $3-12820-B$ & 607 & 17.936 & 0.52 & 0.32 & 1511 & 242 \\
\hline 3-12151-B & 540 & 18.174 & -0.13 & 0.39 & 922 & 221 \\
\hline 3-00748-B & 633 & 18.316 & -0.60 & 0.55 & 798 & 409 \\
\hline
\end{tabular}

Contaminants: Pax and average smelter material

\begin{tabular}{lrrrrrr} 
& $\mathrm{Pb} \mathrm{ppm}$ & ${ }^{206} \mathrm{~Pb} /{ }^{204} \mathrm{~Pb}$ & $\% \mathrm{PAX}$ & $\%$ smelter & Calc. As ppm & Meas. As ppm \\
\cline { 2 - 7 } 3-15641-B & 1490 & 17.910 & 1.60 & 25.51 & 6797 & 836 \\
$3-15650-\mathrm{B}$ & 1560 & 17.801 & 2.42 & 22.33 & 7174 & 1490 \\
$3-15657-\mathrm{B}$ & 1140 & 17.898 & 1.31 & 18.60 & 5130 & 1490 \\
$\mathbf{3}-13569-\mathrm{B}$ & $\mathbf{4 0 9}$ & $\mathbf{1 7 . 9 3 0}$ & $\mathbf{0 . 4 8}$ & $\mathbf{5 . 5 1}$ & $\mathbf{1 6 3 4}$ & $\mathbf{1 4 9 2}$ \\
$\mathbf{3}-13989-\mathrm{B}$ & $\mathbf{3 0 2}$ & $\mathbf{1 8 . 1 5 0}$ & $\mathbf{0 . 0 9}$ & $\mathbf{5 . 2 1}$ & $\mathbf{1 1 0 7}$ & $\mathbf{9 0 4}$ \\
$3-12524-\mathrm{B}$ & 794 & 18.181 & -0.05 & 18.18 & 3420 & 1135 \\
$\mathbf{3}-15648-\mathrm{B}$ & $\mathbf{1 1 5}$ & $\mathbf{1 8 . 4 1 0}$ & $\mathbf{- 0 . 0 3}$ & $\mathbf{1 . 3 1}$ & $\mathbf{2 1 8}$ & $\mathbf{1 6 5}$ \\
$3-15642-\mathrm{B}$ & 422 & 18.242 & -0.09 & 9.24 & 1663 & 173 \\
$3-12820-\mathrm{B}$ & 607 & 17.936 & 0.65 & 9.41 & 2578 & 242 \\
$3-12151-\mathrm{B}$ & 540 & 18.174 & 0.02 & 11.51 & 226 & 221 \\
$3-00748-\mathrm{B}$ & 633 & 18.316 & -0.39 & 16.27 & 2641 & 409
\end{tabular}

Contaminants: soil 3-12152-B and Acme lead arsenate

\begin{tabular}{lrrrrrr} 
& $\mathrm{Pb} \mathrm{ppm}$ & ${ }^{206} \mathrm{~Pb} /{ }^{204} \mathrm{~Pb}$ & $\% 152-\mathrm{B}$ & $\%$ Acme & Calc. As ppm & Meas. As ppm \\
\cline { 2 - 7 } 3-15641-B & $\mathbf{1 4 9 0}$ & $\mathbf{1 7 . 9 1 0}$ & $\mathbf{4 8 . 8 3}$ & $\mathbf{0 . 4 8}$ & $\mathbf{1 3 1 0}$ & $\mathbf{8 3 6}$ \\
$3-15650-\mathrm{B}$ & 1560 & 17.801 & 81.87 & 0.10 & 289 & 1490 \\
$3-15657-\mathrm{B}$ & 1140 & 17.898 & 41.07 & 0.30 & 837 & 1490 \\
$3-13569-\mathrm{B}$ & 409 & 17.930 & 15.66 & 0.06 & 177 & 1492 \\
$\mathbf{3}-13989-\mathrm{B}$ & $\mathbf{3 0 2}$ & $\mathbf{1 8 . 1 5 0}$ & $\mathbf{0 . 8 1}$ & $\mathbf{0 . 1 7}$ & $\mathbf{4 7 4}$ & $\mathbf{9 0 4}$ \\
$3-12524-\mathrm{B}$ & 794 & 18.181 & -10.78 & 0.71 & 1935 & 1135 \\
$3-15648-\mathrm{B}$ & 115 & 18.410 & -1.94 & 0.06 & 173 & 165 \\
$3-15642-\mathrm{B}$ & 422 & 18.242 & -8.00 & 0.38 & 1042 & 173 \\
3-12820-B & 607 & $\mathbf{1 7 . 9 3 6}$ & $\mathbf{2 0 . 0 8}$ & $\mathbf{0 . 1 6}$ & $\mathbf{4 4 3}$ & $\mathbf{2 4 2}$ \\
$3-12151-\mathrm{B}$ & 540 & 18.174 & -4.99 & 0.43 & 1188 & 221 \\
$3-00748-\mathrm{B}$ & 633 & 18.316 & -23.12 & 0.74 & 2028 & 409 \\
\hline
\end{tabular}


Table 5. Cont'd.

\begin{tabular}{lllllll}
\hline Sample & $\mathrm{Pb} \mathrm{ppm}$ & ${ }^{206} \mathrm{~Pb} /{ }^{204} \mathrm{~Pb}$ & $\%$ Cont. $\mathrm{C}_{1}{ }^{2}$ & $\%$ Cont. $\mathrm{C}_{2}{ }^{3}$ & Calc. As ppm & Meas. As ppm \\
\hline
\end{tabular}

Contaminants: Soil $12152-\mathrm{B}$ and average smelter material

\begin{tabular}{lrrrrrr} 
& $\mathrm{Pb} \mathrm{ppm}$ & ${ }^{206} \mathrm{~Pb} /{ }^{204} \mathrm{~Pb}$ & $\% 152-\mathrm{B}$ & \% smelter & Calc. As ppm & Meas. As ppm \\
\cline { 2 - 6 } 3-15641-B & 1490 & 17.910 & 55.05 & 12.52 & 2396 & 836 \\
$3-15650-\mathrm{B}$ & 1560 & 17.801 & 83.21 & 2.69 & 523 & 1490 \\
$\mathbf{3}-15657-\mathrm{B}$ & $\mathbf{1 1 4 0}$ & $\mathbf{1 7 . 8 9 8}$ & $\mathbf{4 5 . 0 3}$ & $\mathbf{7 . 9 8}$ & $\mathbf{1 5 3 0}$ & $\mathbf{1 4 9 0}$ \\
$3-13569-\mathrm{B}$ & 409 & 17.930 & 16.47 & 1.62 & 318 & 1492 \\
$\mathbf{3 - 1 3 9 8 9 - B}$ & $\mathbf{3 0 2}$ & $\mathbf{1 8 . 1 5 0}$ & $\mathbf{3 . 0 4}$ & $\mathbf{4 . 4 9}$ & $\mathbf{8 6 4}$ & $\mathbf{9 0 4}$ \\
$3-12524-\mathrm{B}$ & 794 & 18.181 & -1.56 & 18.55 & 3545 & 1135 \\
$3-15648-\mathrm{B}$ & 115 & 18.410 & -1.15 & 1.59 & 310 & 165 \\
$3-15642-\mathrm{B}$ & 422 & 18.242 & -3.05 & 9.96 & 1907 & 173 \\
$3-12820-\mathrm{B}$ & 607 & 17.936 & 22.16 & 4.18 & 806 & 242 \\
$3-12151-\mathrm{B}$ & 540 & 18.174 & 0.66 & 11.36 & 2173 & 221 \\
$3-00748-\mathrm{B}$ & 633 & 18.316 & -13.45 & 19.45 & 3716 & 409
\end{tabular}

Contaminants: PAX and soil 3-10319-B

\begin{tabular}{lrrrrrr} 
& $\mathrm{Pb} \mathrm{ppm}$ & ${ }^{206} \mathrm{~Pb} /{ }^{204} \mathrm{~Pb}$ & $\% \mathrm{PAX}$ & $\% 319-\mathrm{B}$ & Calc. As ppm & Meas. As ppm \\
\cline { 2 - 6 } $3-15641-\mathrm{B}$ & 1490 & 17.910 & 3.45 & 41.75 & 4165 & 836 \\
$3-15650-\mathrm{B}$ & 1560 & 17.801 & 4.04 & 36.54 & 4870 & 1490 \\
$3-15657-\mathrm{B}$ & 1140 & 17.898 & 2.66 & 30.44 & 3210 & 1490 \\
$\mathbf{3 - 1 3 5 6 9 - B}$ & $\mathbf{4 0 9}$ & $\mathbf{1 7 . 9 3 0}$ & $\mathbf{0 . 8 8}$ & $\mathbf{9 . 0 2}$ & $\mathbf{1 0 6 6}$ & $\mathbf{1 4 9 2}$ \\
$\mathbf{3 - 1 3 9 8 9 - B}$ & $\mathbf{3 0 2}$ & $\mathbf{1 8 . 1 5 0}$ & $\mathbf{0 . 4 7}$ & $\mathbf{8 . 5 2}$ & $\mathbf{5 7 0}$ & $\mathbf{9 0 4}$ \\
$\mathbf{3 - 1 2 5 2 4 - B}$ & $\mathbf{7 9 4}$ & $\mathbf{1 8 . 1 8 1}$ & $\mathbf{1 . 2 7}$ & $\mathbf{2 9 . 7 5}$ & $\mathbf{1 5 4 4}$ & $\mathbf{1 1 3 5}$ \\
$\mathbf{3 - 1 5 6 4 8 - B}$ & $\mathbf{1 1 5}$ & $\mathbf{1 8 . 4 1 0}$ & $\mathbf{0 . 0 6}$ & $\mathbf{2 . 1 5}$ & $\mathbf{8 3}$ & $\mathbf{1 6 5}$ \\
3-15642-B & 422 & 18.242 & 0.58 & 15.12 & 710 & 173 \\
$3-12820-\mathrm{B}$ & 607 & 17.936 & 1.33 & 15.40 & 1606 & 242 \\
$3-12151-\mathrm{B}$ & 540 & 18.174 & 0.85 & 18.84 & 1038 & 221 \\
3-00748-B & 633 & 18.316 & 0.79 & 26.63 & 962 & 409 \\
\hline
\end{tabular}

${ }^{1}$ Calculations in bold represent agreement to within a factor of 2 for calculated vs. measured As contents. and no significant significant negative contribution from one of the contaminant sources.

${ }^{2} X\left({ }^{*} 100\right)$ calculated from simultaneous solutions of equations 7 and 8.

${ }^{3} Y\left({ }^{*} 100\right)$ calculated from simultaneous solutions of equations 7 and 8.

${ }^{4}$ As concentration calculated from equation 7 and $X$ and $Y$ values calculated for $\mathrm{Pb}$. 
matter, may have been different from those observed in the existing samples depending upon the sources of lead used in the manufacture of the products.

\section{Focal versus Adjacent Samples}

Samples of residential soils adjacent to high- and intermediate-As soils have been analyzed (Table 1) in order to determine whether significant migration of $\mathrm{Pb}$ or As from the high-As properties has occurred. All of the adjacent samples analyzed in this study have $<50$ ppm As (Table 1) which suggests that As migration to surrounding properties has been minimal.

$\mathrm{Pb}$ isotopic compositions of the soil samples, this time coded by sample type, are shown in Figure 5. Low-As focal samples, which show large variations in Pb contents (Table 1), span almost the entire range of isotopic values found within the residential soils. The single low-As adjacent sample analyzed has the highest ${ }^{208} \mathrm{~Pb} /{ }^{204} \mathrm{~Pb}$ and among the highest ${ }^{206} \mathrm{~Pb} /{ }^{204} \mathrm{~Pb}$. Data for the two high-As adjacent samples and the single intermediate-As adjacent samples are well within the range observed for other low-As (focal) samples, although the ${ }^{206} \mathrm{~Pb} /{ }^{204} \mathrm{~Pb}$ values for the high-As adjacent samples are slightly less radiogenic than those in the low-As and intermediate-As adjacent samples.

Lead contents of the high-As adjacent samples are significantly higher than baseline values (150-260 ppm versus $\approx 70 \mathrm{ppm}$; Tables 1 and 3 ), but are well within the range of other low-As samples (Figure 6). However, the ${ }^{206} \mathrm{~Pb} /{ }^{204} \mathrm{~Pb}$ values in these two samples appear to be slightly lower than in other low-As samples with similar Pb contents. The data are therefore consistent with the interpretation that some migration of non-radiogenic $\mathrm{Pb}$ has occurred from the high-As properties to the surrounding properties.

\section{Samples from a Single Property}

Five samples, 3-12152-B, 3-12151-B, 3-12040-B, 3-12039-B, and 3-12035-B (Table 2), were collected from a single residential property in order to look at mixing relationships within a geographically restricted area. The samples show a wide range in $\mathrm{Pb}$ contents, 256-1730 ppm Pb. Four of the five samples have As $<50 \mathrm{ppm}$, but sample 312151-B has 221 ppm As. Sample 3-12152-B represents the low-As contaminant source with nonradiogenic $\mathrm{Pb}$ (Table 3).

Lead isotopic data for the five sediments are highly correlated with $r^{2}$ values of 0.947 and 0.961 for the ${ }^{206} \mathrm{~Pb} /{ }^{204} \mathrm{~Pb}$ vs. ${ }^{207} \mathrm{~Pb} /{ }^{204} \mathrm{~Pb}$ and ${ }^{206} \mathrm{~Pb} /{ }^{204} \mathrm{~Pb}$ vs. ${ }^{208} \mathrm{~Pb} /{ }^{204} \mathrm{~Pb}$ diagrams, respectively (Figure 7). The high degree of correlation suggests that the data are best 

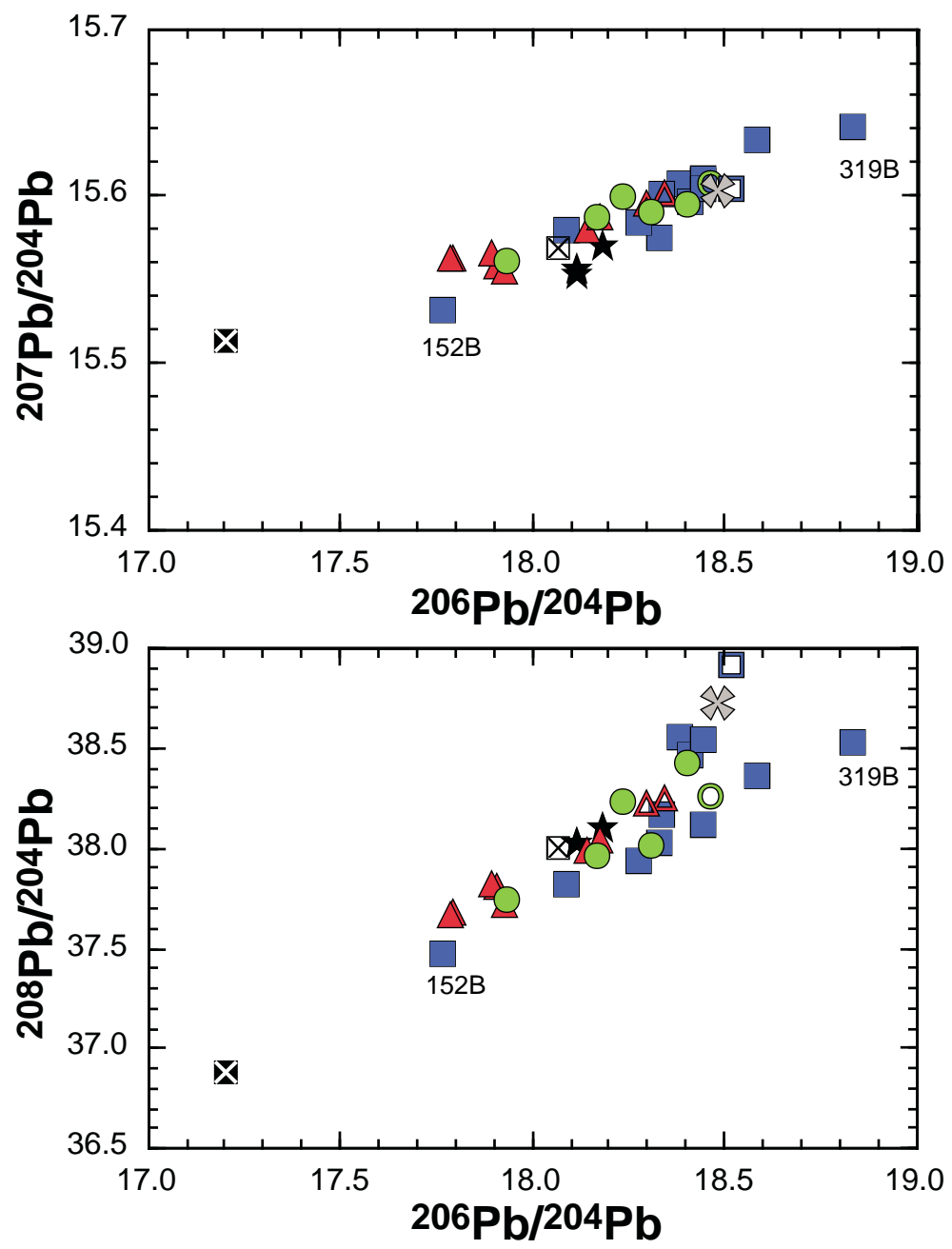

\begin{tabular}{|c|c|}
\hline$\triangle$ & High-As focal \\
\hline$\Delta$ & High-As adjacent \\
\hline O & Intermediate-As focal \\
\hline (0) & Intermediate-As adjacent \\
\hline$\square$ & Low-As focal \\
\hline$\square$ & Low-As adjacent \\
\hline 新 & Average baseline \\
\hline $\mathbf{X}$ & PAX \\
\hline 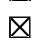 & Acme lead arsenate \\
\hline$\star$ & Smelter materials \\
\hline
\end{tabular}

Figure 5. ${ }^{206} \mathrm{~Pb} / 204 \mathrm{~Pb}$ vs. ${ }^{207} \mathrm{~Pb} / 204 \mathrm{~Pb}$ and ${ }^{206} \mathrm{~Pb} / 204 \mathrm{~Pb}$ vs. ${ }^{208} \mathrm{~Pb} / 204 \mathrm{~Pb}$ diagrams for focal vs. adjacent samples from the VBI70 study area. Samples are coded by As concentrations. Focal samples are shown by filled symbols and adjacent samples by open symbols. 


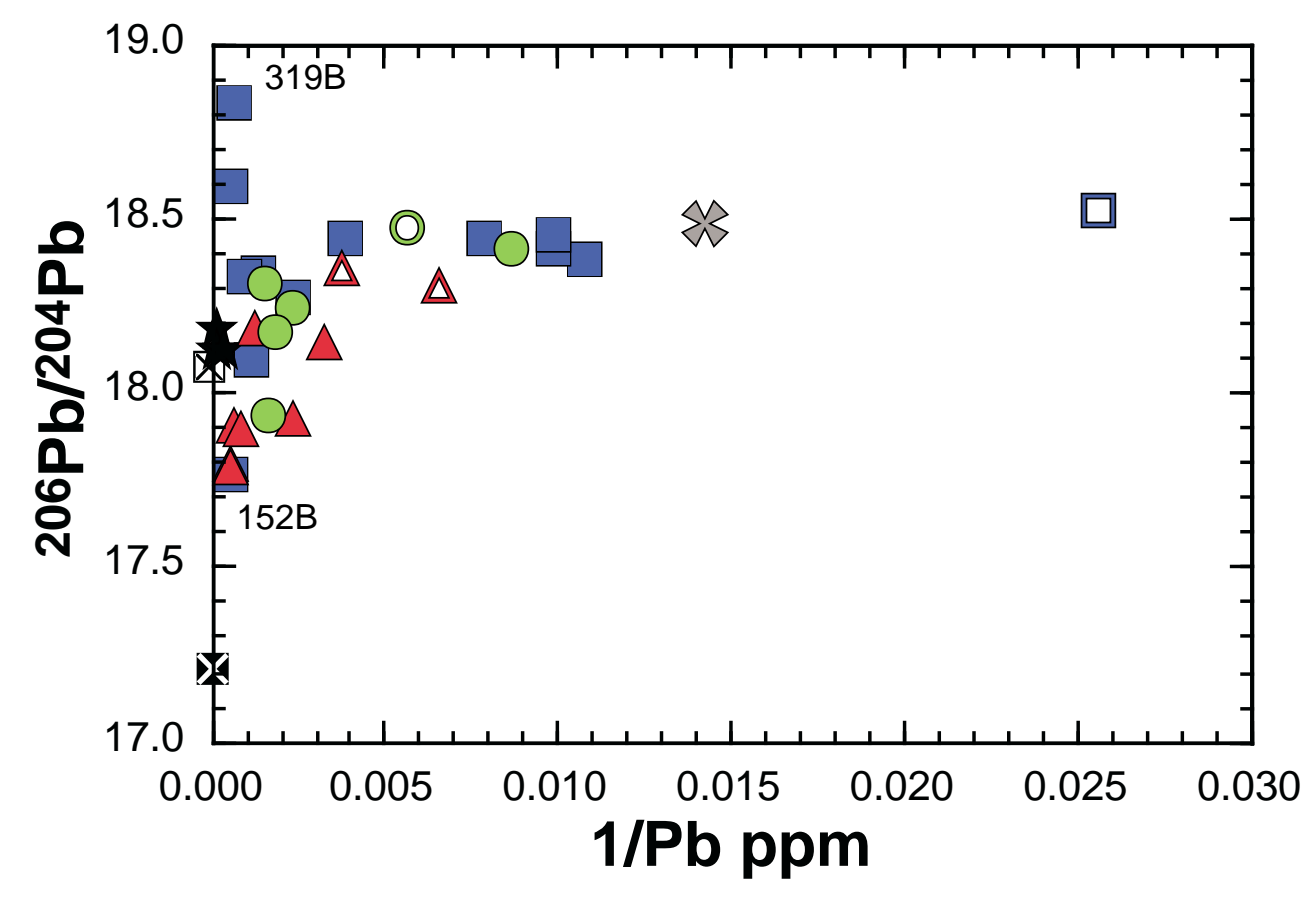

\begin{tabular}{|ll|}
\hline$\triangle$ & High-As focal \\
$\Delta$ & High-As adjacent \\
$\bigcirc$ & Intermediate-As focal \\
0 & Intermediate-As adjacent \\
$\square$ & Low-As focal \\
$\square$ & Low-As adjacent \\
$\square$ & Average baseline \\
$\mathbf{X}$ & PAX \\
$\square$ & Acme lead arsenate \\
$\star$ & Smelter materials \\
\hline
\end{tabular}

Figure 6. ${ }^{206} \mathrm{~Pb} / 204 \mathrm{~Pb}$ vs. $1 / \mathrm{Pb}$ concentrations for focal vs. adjacent samples from VBI70 study area. Samples are coded by As concentrations. 
explained in terms of mixing between two components. However, the best-fit line on the ${ }^{206} \mathrm{~Pb} /{ }^{204} \mathrm{~Pb}$ vs. ${ }^{208} \mathrm{~Pb} /{ }^{204} \mathrm{~Pb}$ diagram does not pass through the average baseline value.

The ${ }^{206} \mathrm{~Pb} /{ }^{204} \mathrm{~Pb}$ values are shown as a function of $\mathrm{Pb}$ contents $(1 / \mathrm{Pb})$ in Figure 8 . The data are moderately well correlated with $r^{2}=0.884$, but there is obvious scatter about the bestfit line, and the best-fit line passes nowhere near the average baseline value. The results again suggest that there are at least two $\mathrm{Pb}$ components in these soils. One of the components has isotopic characteristics similar to soils $3-12152-\mathrm{B}\left({ }^{206} \mathrm{~Pb} /{ }^{204} \mathrm{~Pb} \approx 17.8, \mathrm{~Pb} \geq 1730 \mathrm{ppm}\right)$. The other has ${ }^{206} \mathrm{~Pb} /{ }^{204} \mathrm{~Pb} \geq 18.45$ but $\mathrm{Pb} \leq 256 \mathrm{ppm}$.

The high lead component is clearly a contaminant, but the nature of the other end member is somewhat problematic. The trend may suggest that baseline isotopic ratios in this soil are much more radiogenic than in other low-As soils (the baseline values lie on the upper right extension of the mixing line in Figure 8).

Another way in which low-Pb end-member could be explained is that this end member is a mixture between baseline $\mathrm{Pb}$ and a second contaminant with radiogenic $\mathrm{Pb}$. If the two contaminants (i.e. those represented by soils $3-12152-\mathrm{B}$ and $3-10319-\mathrm{B}$ ) were randomly distributed within the soils at this property, then a linear trend in Figure 8 would not be expected. The data would simply fall anywhere within an envelope defined by average baseline and soils 3-12152-B and 3-10319-B. The fact that a scattered linear trend does exist may suggest that variable amounts of contamination from the source represented by soil 312152-B were superimposed onto a soil that was more or less uniformly contaminated by the radiogenic $-\mathrm{Pb}$ contaminant.

The presence of two contaminants is consistent with the results from multiple aciddigestions of sample 3-12152-B (Tables 2 and A2-4). There is more isotopic variation among the replicate digestions than is easily accounted for if only a single contaminant is involved. The isotopic variation may suggest that one of the contaminants is not being totally dissolved by the acid-digestion procedure or that one of the contaminants is heterogeneously distributed within the soil at a scale comparable to the sample sizes.

The elevated As content found in sample 3-12151-B is not accounted for by either of the scenarios outlined above. This sample is intermediate in terms of both $\mathrm{Pb}$ contents and isotopic compositions, but has As contents almost an order of magnitude higher than in any of the other soils from this property. These observations suggest that yet another contaminant is present in this soil. Although the nature of this contaminant can not be determined, it must have very high $\mathrm{As} / \mathrm{Pb}$ such that addition of this material does not significantly affect relationships between $\mathrm{Pb}$ concentrations and $\mathrm{Pb}$ isotopic compositions in Figure 8.

The results from soils from this property and the fact that there is such a large range in $\mathrm{Pb}$ contents among low-As soils in general (Figure 4) clearly indicate that the $\mathrm{Pb}$ and $\mathrm{As}$ 

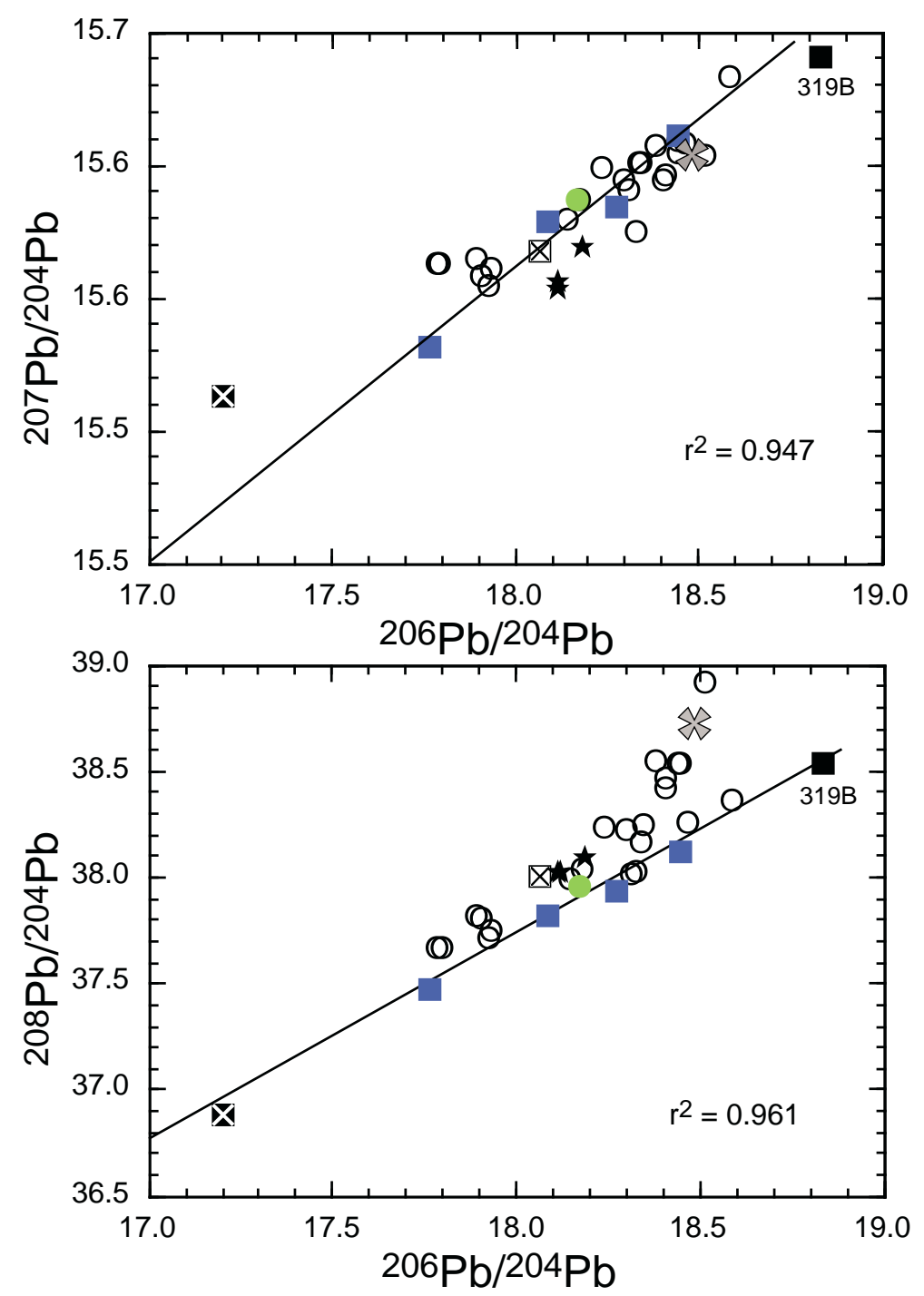

\begin{tabular}{|c|c|c|}
\hline $\begin{array}{l}\square \\
\bigcirc\end{array}$ & $\begin{array}{l}\text { Nominal Range } \\
\text { As }<50 \mathrm{ppm} \\
\text { As }=50-250 \mathrm{ppm}\end{array}$ & $\begin{array}{l}\text { Actual Range } \\
\text { (<11-26 ppm) } \\
(221 \mathrm{ppm})\end{array}$ \\
\hline [ & \multicolumn{2}{|c|}{ High-Pb soil 3-10319-B } \\
\hline$\star$ & \multicolumn{2}{|l|}{ Smelter materials } \\
\hline $\mathbf{X}$ & \multicolumn{2}{|l|}{ PAX } \\
\hline$\nabla$ & \multicolumn{2}{|l|}{ Acme Pb-Arsenate } \\
\hline$\Leftrightarrow$ & \multicolumn{2}{|l|}{ Av. Baseline } \\
\hline
\end{tabular}

Figure 7. ${ }^{206} \mathrm{~Pb} / 204 \mathrm{~Pb}$ vs. ${ }^{207} \mathrm{~Pb} / 204 \mathrm{~Pb}$ and ${ }^{206} \mathrm{~Pb} / 204 \mathrm{~Pb}$ vs. ${ }^{208} \mathrm{~Pb} / 204 \mathrm{~Pb}$ diagrams for samples from a single residential property. Samples from the property are coded by As concentrations. Other samples from the VBI70 study area are shown for reference by open circles. Best-fit lines through the five points yield good linear arrays with $\mathrm{r}^{2}=0.947$ and 0.961 for ${ }^{206} \mathrm{~Pb} / 204 \mathrm{~Pb}$ vs. ${ }^{207} \mathrm{~Pb} / 204 \mathrm{~Pb}$ and ${ }^{206} \mathrm{~Pb} / 204 \mathrm{~Pb}$ vs. ${ }^{208} \mathrm{~Pb} / 204 \mathrm{~Pb}$ diagrams, respectively. 


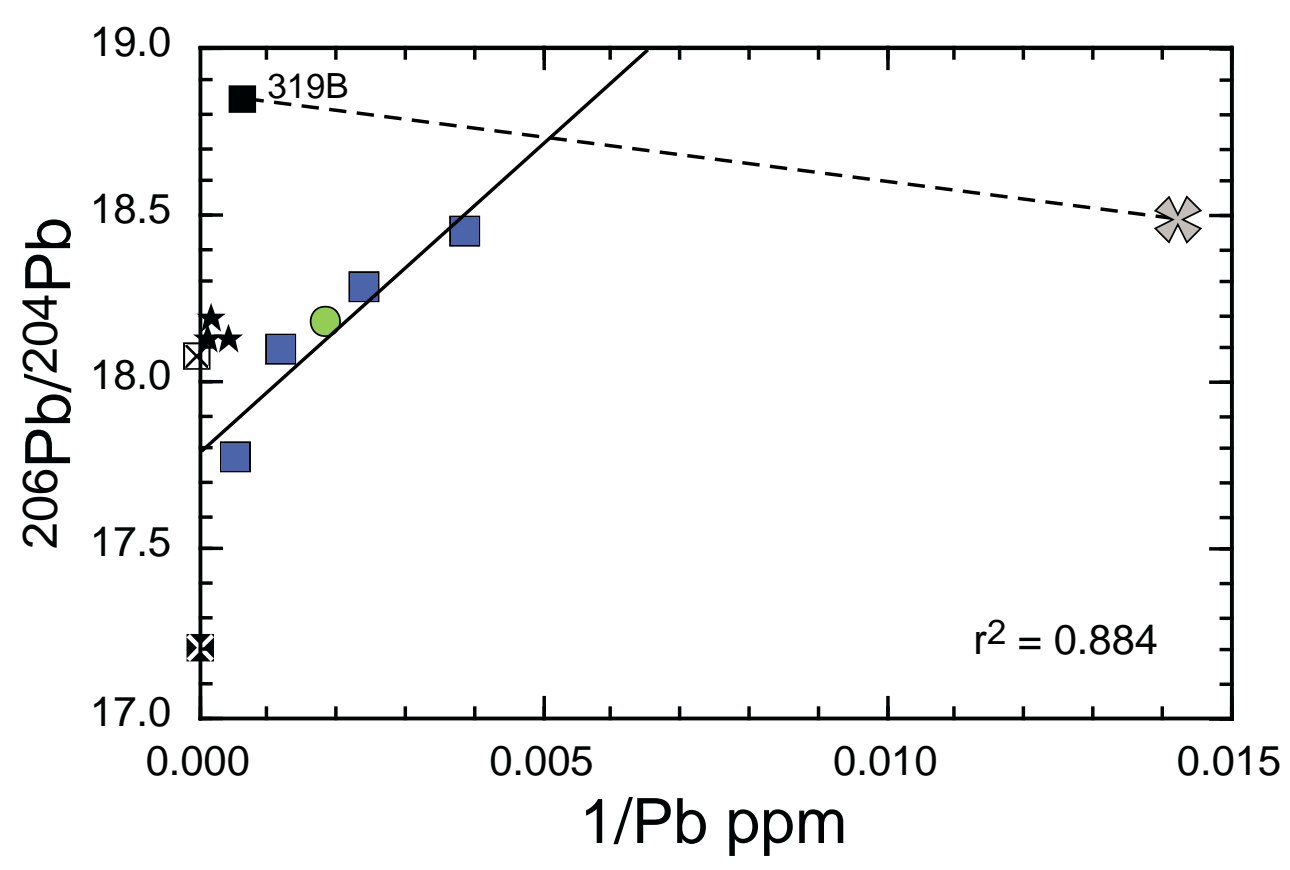

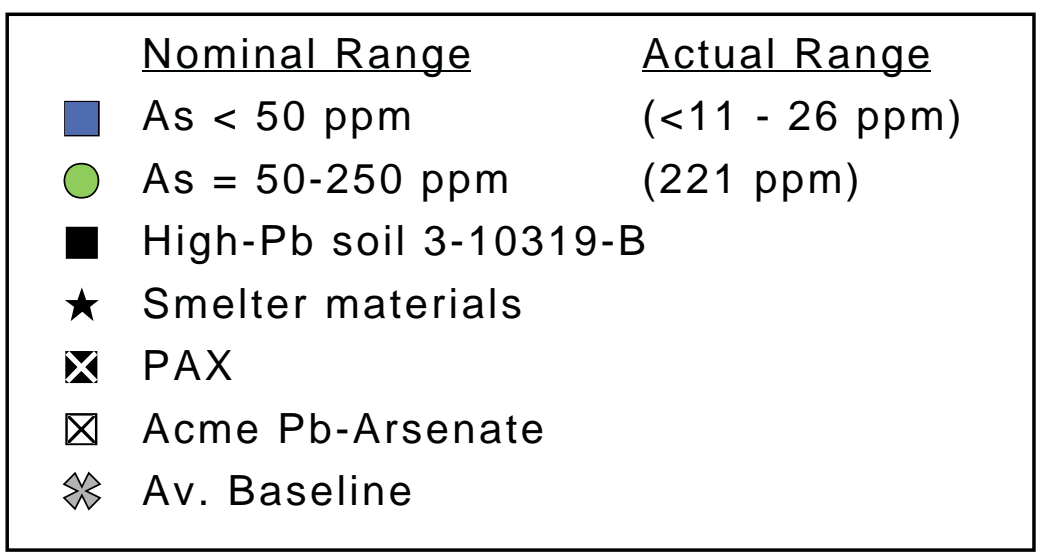

Figure $8 .{ }^{206} \mathrm{~Pb} / 204 \mathrm{~Pb}$ vs. $1 / \mathrm{Pb}$ concentrations for samples from a single residential property. Samples from the property are coded by As concentrations. The five points determine a moderately well correlated linear array with $r^{2}=0.884$. The broken line represents mixing between average baseline soil and soil 310319-B (319B). 
contamination in the soils are not entirely related to the same sources. However, the absence or at least paucity of high-As, low-Pb soils within the sample set (Figure 1), the nonradiogenic character of the $\mathrm{Pb}$ in many of the high-As samples, and the presence of significant amounts of $\mathrm{Pb}$ arsenate in many of the soils (Laboratory for Environmental and Geochemical Studies, 2001) suggest that there are high-Pb+As sources responsible for much of the As contamination in these soils. Identification of the exact number and nature of the contaminants within these soils must await detailed studies of individual properties.

\section{Conclusions}

(1) At least six potential sources of lead have been found in selected soil samples from the Vasquez Blvd.-I70 study area based on the relationships between the isotopic compositions and $\mathrm{Pb}$ concentrations in the soils: (1) an average "baseline" soil with ${ }^{206} \mathrm{~Pb} /{ }^{204} \mathrm{~Pb}$ $\approx 18.48$ and $\mathrm{Pb} \approx 70 \mathrm{ppm}$, (2) smelter soil and waste with ${ }^{206} \mathrm{~Pb} /{ }^{204} \mathrm{~Pb}=18.12-18.19$ and $\mathrm{Pb}$ $=2100-5600$ ppm, (3) PAX, a commercial herbicide, with ${ }^{206} \mathrm{~Pb} /{ }^{204} \mathrm{~Pb}=17.2$ and $\mathrm{Pb}=24300$ ppm, (4) Acme brand lead arsenate pesticide with ${ }^{206} \mathrm{~Pb} /{ }^{204} \mathrm{~Pb}=18.07$ and $\mathrm{Pb}=128000$ ppm, (5) an unidentified contaminant with ${ }^{206} \mathrm{~Pb} /{ }^{204} \mathrm{~Pb} \geq 18.8$ inferred from residential soil 310319-B, and (6) an unidentified contaminant with ${ }^{206} \mathrm{~Pb} /{ }^{204} \mathrm{~Pb} \leq 17.8$ inferred from residential soil 3-12152-B. Sources 2,3, and 4 are $\mathrm{Pb}$ and As contaminants whereas sources 5 and 6 appear to be $\mathrm{Pb}$ contaminants only.

(2) The isotopic compositions of the smelter materials and the Acme lead arsenate are similar enough that it is not possible to distinguish between these two sources as potential $\mathrm{Pb}$ contaminants.

(3) The $\mathrm{Pb}$ isotopic data for two of the high-As soils (3-13989-B and 3-12524-B) are consistent with the interpretation that they represent contamination of average baseline soil with small amounts of either Acme lead arsenate or smelter material. Confirmation of this interpretation must await detailed geochemical analyses and speciation studies of these soils.

(4) The other high-As soils (3-15641, 3-15650-B, 3-15657-B, and 3-13569-B) and one intermediate-As soil $(3-12820)$ have ${ }^{206} \mathrm{~Pb} /{ }^{204} \mathrm{~Pb}$ values lower than those found in either the smelter materials or Acme lead arsenate. These samples must have within them a component of PAX (or a similarly nonradiogenic $\mathrm{Pb}$-rich material). However, the $\mathrm{Pb}$ data for these samples cannot be explained by simple two-component mixing involving contamination of baseline soil with PAX. These data may reflect the presence of more than one $\mathrm{Pb}$ 
contaminant or the presence of an as yet unidentified $\mathrm{Pb}$ and As contaminant with ${ }^{206} \mathrm{~Pb} /{ }^{204} \mathrm{~Pb} \approx$ 17.8.

(5) The $\mathrm{Pb}$ and As data for the intermediate- and high-As soils are reasonably consistent with three-component mixing models involving baseline soil and two contaminants (Table 5). However, different contaminants are required for each of the soils and unique solutions were not obtained for most of the soils. The presence of smelter material or Acme lead arsenate in these soils are neither eliminated nor required by the calculations.

(6) Low-As soils show a wide range in Pb concentrations (39-1730 ppm) and isotopic compositions $\left({ }^{206} \mathrm{~Pb} /{ }^{204} \mathrm{~Pb}=17.8-18.8\right)$. These results clearly indicate that $\mathrm{Pb}$ and $\mathrm{As}$ contamination is at least partially decoupled within these soils. Furthermore, if such large and variable amounts of $\mathrm{Pb}$-only contamination are found in the low-As samples, one might logically conclude that this type of $\mathrm{Pb}$-only contamination is also present in intermediate- and high-As soils. If true, then the two-component mixing calculations involving average baseline $\mathrm{Pb}$ would not necessarily be valid.

(7) Analyses of soils adjacent to high-As soils are consistent with some migration of $\mathrm{Pb}$ from the high-As, high-Pb soils to the surrounding properties. However, given the wide variation in $\mathrm{Pb}$ contents and isotopic compositions found among low As focal soils, the evidence for $\mathrm{Pb}$ migration should be regarded as tentative.

(8) Analyses of five soils from a single residential property confirm the complex nature of the contamination in these soils. The $\mathrm{Pb}$ concentration and isotopic data require either the presence of two $\mathrm{Pb}$ contaminants or a single contaminant and unusual "baseline" with an elevated $\mathrm{Pb}$ concentration and/or ${ }^{206} \mathrm{~Pb} /{ }^{204} \mathrm{~Pb}$. In addition a third contaminant with high $\mathrm{As}$ and low $\mathrm{Pb}$ is required to account for the As content in one of the five soils from this property.

\section{Suggestions for Future Work}

Based upon the preceding discussion, it is quite evident that $\mathrm{Pb}$ and $\mathrm{As}$ contamination in these soils is a complex issue. In some instances $\mathrm{Pb}$ and As contamination appear unrelated whereas in other instances there is good evidence for a single principal $\mathrm{Pb}$ and As contaminant. Furthermore, at least 5 potential $\mathrm{Pb}$ contaminants and three potential As contaminants have been identified. Although the presence of PAX in four of the 6 high-As samples is indicated by the data, unique solutions could not be obtained regarding the involvement of other potential $\mathrm{Pb}$ and As sources.

Detailed studies of soils from individual properties, such as that represented by Figures 7 and 8 should be performed. This procedure is based on the assumption that individual 
properties would represent less complex systems than the study area as a whole. That is, only a restricted number of contaminants would be present at any one property. Five to six samples would generally be required and the samples would have to show a significant range in $\mathrm{Pb}$ (and ideally $\mathrm{As}$ ) concentrations. Ideally, $\mathrm{Pb}$ and As contents should show a good correlation among the soils from a single property. The $\mathrm{Pb}$ data for each individual property would be plotted as in Figures 4, 6, and 8 and the data evaluated as outlined below.

(1) The data define no linear trend on a plot of ${ }^{206} \mathrm{~Pb} /{ }^{204} \mathrm{~Pb}$ vs. $1 / \mathrm{Pb} \mathrm{ppm}$. This would mean that multiple $\mathrm{Pb}$ contaminants are present and are not homogeneously distributed within the soils. In this situation it may not be possible to use $\mathrm{Pb}$ isotopic data to identify the source(s) of As or $\mathrm{Pb}$ contamination.

(2) The data define a linear trend, but there is no correlation with As contents in the samples. This is the situation observed for the samples in Figure 8 and would indicate that $\mathrm{Pb}$ and $\mathrm{As}$ are derived from separate sources. The $\mathrm{Pb}$ isotopic data for these samples would therefore not be a valid tool for evaluating the source of the As contamination. However, the intersection of the mixing trend with the $\mathrm{Y}$-axis would define the ${ }^{206} \mathrm{~Pb} /{ }^{204} \mathrm{~Pb}$ of one of the $\mathrm{Pb}$ contaminants.

(3) The data define a linear trend with at least moderately good correlation with As contents. A single source for $\mathrm{Pb}$ and $\mathrm{As}$ contamination would be suggested. The $\mathrm{y}$-axis intercept of the mixing trend defines the ${ }^{206} \mathrm{~Pb} /{ }^{204} \mathrm{~Pb}$ of the $\mathrm{Pb}$ and As contaminant in this soil.

\section{Answers to Specific Questions Posed by USEPA}

Question 1. Do the isotopic ratios for lead in residential site soils depend on the level of either arsenic or lead present in the sample? If so, what are the characteristic ratios for high-lead or arsenic samples compared to low-lead or arsenic samples?

Answer. Soils with high $\mathrm{Pb}$ contents show isotopic values that span the entire range of those observed within the soils with ${ }^{206} \mathrm{~Pb} /{ }^{204} \mathrm{~Pb} \approx 17.8-18.8$. Low- $\mathrm{Pb}$ soils show a much more restricted range with ${ }^{206} \mathrm{~Pb} / 204 \mathrm{~Pb} \approx 18.3-18.5$.

Four of six high-As samples have ${ }^{206} \mathrm{~Pb} /{ }^{204} \mathrm{~Pb}<18.0$ whereas two other high-As samples have ${ }^{206} \mathrm{~Pb} /{ }^{204} \mathrm{~Pb} \approx 18.1-18.2$. All high-As samples analyzed are also high in $\mathrm{Pb}$. 
With two exceptions (both from the same residential property), low As soils are characterized by ${ }^{206} \mathrm{~Pb} /{ }^{204} \mathrm{~Pb}>18.3$.

Question 2. Do the isotopic ratios observed in residential site soils resemble one or more of the potential source materials (Globe soils, PAX, lead arsenate pesticide)? If so, how does this depend on lead or arsenic level in the residential soil?

Answer. Four of six high-As samples have lower ${ }^{206} \mathrm{~Pb} /{ }^{204} \mathrm{~Pb}$ than found in any of the identified contaminants except PAX. Two high-As samples have ${ }^{206} \mathrm{~Pb} /{ }^{204} \mathrm{~Pb}$ similar to smelter material and Acme lead arsenate. Low-As and low-Pb soils have $\mathrm{Pb}$ isotopic values similar to baseline values.

Question 3. Does this approach allow you to identify one or more of the potential source materials as being more likely for the observed contamination in site soils than the other potential source materials?

Answer. Four of six high-As samples must have some PAX or isotopically similar material within them. Specific sources could not be identified for the other two high-As samples. The presence of smelter material or Acme lead arsenate is neither required nor eliminated by the $\mathrm{Pb}$ isotopic data in any of the soils.

\section{References cited:}

Cantanzaro, E.J., Murphy, T.J., Shields, W.R., and Garner, E.L., 1968, Absolute isotopic abundance ratios of Common, Equal Atom, and Radiogenic lead isotopic standards: Journal of research of the national bureau of standards, v. 72A, p. 261-267.

Church, S.E., Kimball, B.A., Fey, D.L., Ferderer, D.A., Yager, T.J., and Vaughn, R.B., 1997, Source, transport, and partitioning of metals between water, colloids, and bed sediments of the Animas River, Colorado: U.S. Geological Survey Open-File Report 97-151, 135pp.

Fey, D.L., Unruh, D.M., and Church, S.E., 1999, Chemical data and lead isotopic compositions in stream-sediment samples from the Boulder River Watershed, Jefferson County, Montana: U. S. Geological Survey Open File Report 99-575, 147 pp.

Faure, G., 1977, Principles of Isotope Geology, John Wiley \& Sons, New York, 464pp. Laboratory for Environmental and Geological Studies, 2001, Extended laboratory report, VBI70 project, Denver, Colorado: Department of Geological Sciences, University of Colorado Administrative Report. 
Ludwig, K.R., 1980, Calculation of uncertainties of U-Pb isotope data: Earth and Planetary Science Letters, v. 46, p. 212-220.

Ludwig, K.R., 1994, Isoplot: a plotting and regression program for radiogenic-isotope data: U.S. Geological Survey Open-File Report 91-445, version 2.75, October, 1994, 45pp.

Murphy, C., Briggs, P., Adrian, B., Wilson, S., Hageman, P., and , P., 1997, Chain of Custody-Recommendations for acceptance and analysis of evidentiary geochemical samples: U.S. Geological Survey Circular 1138, 26 pp.

Tatsumoto, M. and Unruh, D.M., 1976, KREEP basalt age: Grain by grain U-Th-Pb systematics study of the quartz monzodiorite clast 15405,88: Proceedings of the $7^{\text {th }}$ Lunar Science Conference, p. 2107-2129.

Todt, W., Cliff, R.A., Hanser, A., and Hofmann, 1993, Re-calibration of NBS lead standards using a ${ }^{202} \mathrm{~Pb}-{ }^{205} \mathrm{~Pb}$ double spike: Abstracts presented to the $7^{\text {th }}$ meeting of the European Union of Geosciences, p. 396.

Unruh, D.M., Fey, D.L., and Church, S.E., 2000, Chemical data and lead isotopic compositions of geochemical baseline samples from streambed sediments and smelter slag, lead isotopic compositions in fluvial tailings, and dendrochronology results from the Boulder River Watershed, Jefferson County, Montana: U. S. Geological Survey Open-File Report 000038, 75pp.

U. S. Environmental Protection Agency, 1992, EPA SW 846 Method 3050B, Revision 2, December, 1996.

U. S. Environmental Protection Agency, 1999, Project plan for the Vasquez Boulevard \& I 70 site, Denver, Colorado, pilot scale soil characterization study (Sept. 9, 1999).

Vandecasteele, C. and Block, C.B., 1993, Modern Methods for Trace Element Determination: Wiley and Sons Ltd., U.K., 330 pp. 


\section{Appendix 1. Standard analytical procedures for lead isotopic analyses (nitric acid- hydrogen peroxide digestion) of metal-rich samples.}

\section{A. Acid digestion}

1. Samples are digested in accordance with Section 7.2 of method 3050B, EPA SW 846, revision 2 (12/96), with minor modifications to accommodate smaller sample sizes.

Although the $\mathrm{Pb}$ isotopic analyses would require sample sizes of only a few milligrams for most samples, sample sizes of approximately $50 \mathrm{mg}$ to $200 \mathrm{mg}$ are digested in order to ensure that they are representative of the bulk sample.

2. 2 to $3 \mathrm{ml}$ of $1: 1$ nitric acid $\left(\mathrm{HNO}_{3}\right)$ are added to the sample in a PFA-teflon, screw-cap container. The sample is heated to near boiling for 15 minutes in the closed container. The sample is allowed to cool, and $1 \mathrm{ml}$ of concentrated $\mathrm{HNO}_{3}$ is added. If brown fumes are observed, another $1 \mathrm{ml}$ of $\mathrm{HNO}_{3}$ is added and the procedure repeated until fuming is no longer observed. The solution is then heated to near boiling for approximately 2 hours in the closed container.

3. The sample is allowed to cool and $1 \mathrm{ml}$ of water and $1 \mathrm{ml}$ of $30 \%$ hydrogen peroxide $\left(\mathrm{H}_{2} \mathrm{O}_{2}\right)$ are added to the sample. Additional $\mathrm{H}_{2} \mathrm{O}_{2}$ is added in 0.1 -ml increments until either strong effervescence subsides or until the general sample appearance remains unchanged.

4. The sample is heated to just below boiling for approximately two hours in the closed container.

5. The sample is allowed to cool and is diluted to $15 \mathrm{ml}$ with deionized water. The sample is centrifuged and the supernatant transferred to an HDPE bottle.

6. A lead blank of $0.3 \mathrm{ng}\left(10^{-9} \mathrm{~g}\right)$ was obtained for this procedure.

B. Ion Exchange Chromatography

1. An aliquot of the solution, corresponding to approximately $0.5 \mathrm{ug}$ of $\mathrm{Pb}$ based on preliminary estimates of the $\mathrm{Pb}$ concentration provided by the submitter, is transferred to a teflon beaker and evaporated to dryness

2. 1-2 $\mathrm{ml}$ of $6 \mathrm{M}$ hydrochloric acid $(\mathrm{HCl})$ is added to the sample and again evaporated to dryness. Then $0.5-1 \mathrm{ml}$ of $1.0-1.2 \mathrm{~N}$ hydrobromic acid $(\mathrm{HBr})$ is added to the sample and is warmed gently for 5-10 minutes.

3. The sample is allowed to cool, centrifuged, and the supernatant is loaded onto an anion-exchange column (0.8-1.0 ml resin volume) using Dowex AG1-X8 anion exchange resin.

4. The column is washed with $1.0-1.2 \mathrm{~N} \mathrm{HBr}$ and water. 
5. The $\mathrm{Pb}$ is eluted from the column with $6-8 \mathrm{~N} \mathrm{HCl}$.

6. The sample is evaporated to dryness and $\approx 0.25 \mathrm{ml}$ of $1.2 \mathrm{~N} \mathrm{HBr}$ is added.

7. The sample is loaded onto a second anion exchange column (AG1-X8 resin) with a resin volume of $0.1-0.2 \mathrm{ml}$.

8. The column is washed with $1.0-1.2 \mathrm{~N} \mathrm{HBr}$ and water.

9. Lead is eluted from the column with dilute $(\leq 1 \mathrm{M})$ Nitric Acid.

10. $2-3$ drops of dilute $(0.25-0.5 \%)$ phosphoric acid are added to the sample and it is evaporated to dryness.

11. Samples are then ready to be loaded onto filaments for mass spectrometry.

12. A Pb blank of $0.09 \mathrm{ng}$ was obtained for this procedure.

\section{Mass spectrometry}

Data for samples and standards run during this study were acquired using the following procedure:

1. Aliquots of the samples were loaded onto rhenium filaments with colloidal silica gel and loaded into the mass spectrometer. Sample filaments were heated to 2.3-2.4 amp.

a. During the initial stages of the study approximately $1 / 3$ of the sample was loaded onto the filament. However, this produced an ion-beam intensity of $>10^{-10} \mathrm{Amp}$ for ${ }^{208} \mathrm{~Pb}$, the maximum measurable signal. Consequently, approximately $1 / 2$ -

$1 / 3$ of this amount was loaded for subsequent analyses.

2. The temperature of the filament was adjusted to $1250^{\circ} \mathrm{C} \pm 5 \%\left(1187-1313^{\circ} \mathrm{C}\right)$.

a. The temperature was determined by the data-acquisition software from a pyrometer supplied with the mass spectrometer. These temperatures may be $\approx 120^{\circ} \mathrm{C}$ lower than the true filament temperatures as determined by other pyrometers.

3. The beam was centered and focussed using the most intense peak, ${ }^{208} \mathrm{~Pb}$. In most instances the initial current was less than $1250^{\circ} \mathrm{C}$ so that samples were run at the lower end of the temperature window. In many instances, $\mathrm{a}^{208} \mathrm{~Pb}$ intensity of $>10^{-10}$ amp, the maximum signal allowed, was obtained. The filament current was then decreased until appropriate beam intensity was achieved.

4. Isotopic data for all samples and standards are obtained using " $\mathrm{L} 1, \mathrm{H} 1, \mathrm{H} 2$, and H3" collectors for ${ }^{204} \mathrm{~Pb},{ }^{206} \mathrm{~Pb},{ }^{207} \mathrm{~Pb}$, and ${ }^{208} \mathrm{~Pb}$, respectively. Data are acquired in "static" mode using on line software designed by the manufacturer. Each run consisted of 4 
blocks of 12 data cycles. All peaks in each data cycle are measured simultaneously with 5 to 8 one-second integrations per cycle. Baselines at the half-mass positions are measured at the beginning and end of each block. The software provided by the manufacturer (Sector 54-relase 3.974) calculates a running average and statistical data. 


\section{Appendix 2. Quality Assurance and Quality Control (QA and QC)}

\section{Reagent Preparations and Analytical Blanks}

Nitric, Hydrochloric and Hydrobromic acids are purified by sub-boiling distillation within the analyst's laboratory from commercially available reagent grade acids. Dilute acids are prepared by titration of the distilled concentrated acid followed by dilution with the appropriate calculated amount of deionized water for the desired final concentration.

Deionized water is prepared from filtered tap water by passing it through two mixedbed resin filters, an activated charcoal filter, and a "Milli-Q plus" commercial deionizing system. Measured $\mathrm{Pb}$ blanks for the purified acids and water are typically in the range of $0.001-0.01$ ppb $\left(10^{-9} \mathrm{~g} / \mathrm{g}\right)$.

Phosphoric acid is diluted from commercial analytical grade acid with deionized water. Hydrogen peroxide is commercial reagent grade material. Ion-exchange resin is commercially available analytical grade anion exchange resin

Reagents are considered acceptable if the overall chemical procedure blank is less than the amount required to alter the lead isotopic composition $\left({ }^{206} \mathrm{~Pb} /{ }^{204} \mathrm{~Pb}\right)$ of the sample by more than the maximum allowable 1 sigma-mean $(0.05 \%)$. If the total blank exceeds specifications, then work is halted and each of the component reagents is checked to determine the source of $\mathrm{Pb}$ in the blank. Samples processed with the unacceptable blank are discarded and the analyses repeated when the problem has been corrected. Data obtained from samples run under conditions of an unacceptable blank are deemed unusable.

The maximum allowable blank is calculated based on the $\mathrm{Pb}$ isotopic differences between the samples and the blank. The maximum blank is calculated to be that amount which when added to the sample will change the isotopic composition of the sample by no more than the target 1 sigma-mean precision. For example, the target precision for ${ }^{206} \mathrm{~Pb} /{ }^{204} \mathrm{~Pb}$ is $0.05 \%$. If the sample ${ }^{206} \mathrm{~Pb} /{ }^{204} \mathrm{~Pb}$ were 17.0 , then the maximum blank contribution would have no more than a $0.05 \%$ effect on the ${ }^{206} \mathrm{~Pb} /{ }^{204} \mathrm{~Pb}$ of the sample, or an effect of 0.0085 absolute. With a blank ${ }^{206} \mathrm{~Pb} /{ }^{204} \mathrm{~Pb}$ of 19.0 , the maximum $\mathrm{Pb}$ mass allowable in the blank for 0.5 ug of sample lead can be calculated in the following manner:

$$
\left(0.5^{*} 17.0+X^{*} 19.0\right) /(0.5+X)=17.0085
$$

Where $\mathrm{x}$ is the maximum blank in ug. 
Solving for $\mathrm{x}=0.0021 \mathrm{ug}(2.1 \mathrm{ng})$ or $0.4 \%$ of the sample $\mathrm{Pb}$. If the ${ }^{206} \mathrm{~Pb} /{ }^{204} \mathrm{~Pb}$ of the sample is closer to that of the blank, then the maximum allowable blank increases, for example to $4.5 \mathrm{ng}$ for a sample ${ }^{206} \mathrm{~Pb} /{ }^{204} \mathrm{~Pb}=18.0$.

Because samples were aliquotted after acid-hydrogen peroxide digestion, it is necessary to evaluate the $\mathrm{Pb}$ blank in both the digestion procedure and the total chemical procedure in order to ensure that the $\mathrm{Pb}$ blank does not exceed specifications at any stage of the overall procedure. A Pb blank of $0.3 \mathrm{ng}\left(10^{-9} \mathrm{~g}\right)$ was obtained for the acid and hydrogen peroxide digestion procedure (procedure " $A$ " in Appendix 1). The minimum amount of $\mathrm{Pb}$ present in any of the acid digestions (sample 3-15644-B) was approximately 9 ug. Thus the blank contribution was less than $0.004 \%$.

A total-chemistry blank was processed in the same manner as the samples. A 1-ml aliquot from the digestion procedure was processed through ion-exchange chemistry (procedure " $\mathrm{B}$ " in Appendix 1). Therefore, this blank is a measure of both the Pb contributions from the acid digestion to a sample aliquot as well as the subsequent chemical procedures applied to the aliquot. A total-chemistry blank of $0.09 \mathrm{ng}$ was obtained. The average amount of sample lead processed through chemistry was $0.5 \mathrm{ug}$ so that the blank contribution was less than $0.02 \%$. Consequently both blanks were well within specifications and no blank correction was applied to the isotopic data.

\section{Mass Spectrometry Calibrations.}

$\mathrm{Pb}$ isotopic data are acquired using a VG-Sector 54, 7-collector, thermal ionization mass spectrometer. Up to twenty samples may be loaded into the mass spectrometer at a time. The positions of the individual samples on the turret are recorded in the mass spectrometer logbook and the software supplied by the manufacturer keeps track of the turret. A turret of samples will normally consist of at least two primary standards (NIST SRM-981) which are used to monitor mass fractionation induced by the mass spectrometry, a second primary standard (NIST SRM 982), and seventeen unknown samples. Data are collected using "static" mode (each isotope is measured simultaneously on a separate collector). At least one SRM 981 standard is run at the beginning, and the other at the end of the analyses of the unknowns.

At the beginning of each group of analyses or daily when a set of analyses requires more than one day to complete, the collector gains are calibrated using a computerized subroutine supplied by the manufacturer of the Mass Spectrometer.

Should the gain calibrations not be of acceptable precision based on print out from the calibration sub-routine, the following steps are taken: (1) the calibration is repeated. (2) If the second calibration also fails, the electronics to the mass spectrometer are shut off, and the software rebooted. The electronics are then turned back on and the calibration repeated. (3) If 
the third calibration also fails, step (2) is repeated. (4) If the $4^{\text {th }}$ calibration fails, then all work is stopped until a qualified electronics technician is able to examine and correct the problem.

\section{Mass Spectrometry Standards}

Analyses of NIST standard SRM 981 (Cantanzaro and others, 1968; Todt and others, 1993) are used to monitor mass fractionation during mass spectrometry. At least two standards are loaded into the mass spectrometer for each batch of samples (at least $10 \%$ of the runs are primary standards). Analyses of NIST standard SRM 982 (Cantanzaro and others, 1968; Todt and others, 1993) are also used to check the mass fractionation corrections (at least 1 in 20 or $5 \%$ ).

Data are acquired at filament temperatures of approximately $1150-1350 \mathrm{C}$, as determined by the pyrometer supplied with the mass spectrometer (Unruh and others, 2000). Data are considered acceptable if the standard error (one sigma mean based on the total number of cycles) is better than $\pm 0.05 \%$ for ${ }^{206} \mathrm{~Pb} /{ }^{204} \mathrm{~Pb}$, and better than $\pm 0.02 \%$ for ${ }^{207} \mathrm{~Pb} /{ }^{206} \mathrm{~Pb}$ and ${ }^{208} \mathrm{~Pb} /{ }^{206} \mathrm{~Pb}$ as determined by the on-line data reduction program provided by the manufacturer of the mass spectrometer.

The principal source of analytical uncertainty in mass spectrometric measurements of $\mathrm{Pb}$ isotopes is mass fractionation induced during mass spectrometry. Lighter-mass isotopes are more efficiently evaporated from the filament and transported down the flight tube to the detector. Consequently, the measured isotopic ratio of a heavier mass to a lighter mass (e.g. ${ }^{206} \mathrm{~Pb} /{ }^{204} \mathrm{~Pb}$ ) will generally be slightly lower than the true value. Standards with certified isotopic compositions are run so that mass fractionation effects may be determined. Corrections to the isotopic ratios of the sample data are made based on the amount of mass fractionation determined from the analyses of the standards.

Results for twenty-three analyses of NIST standard SRM 981 are summarized in Table A2-1. Apparent mass fractionation factors are calculated for three isotope ratios, ${ }^{206} \mathrm{~Pb} /{ }^{204} \mathrm{~Pb}$, ${ }^{207} \mathrm{~Pb} /{ }^{206} \mathrm{~Pb}$, and ${ }^{208} \mathrm{~Pb} /{ }^{206} \mathrm{~Pb}$ using a linear mass fractionation law as follows (e.g. Ludwig, 1980):

$$
F_{a}=\left[\left(R_{t} / R_{a}\right)-1\right]{ }^{*} 100 / \Delta M
$$

Where $F_{a}$ is the fractionation factor in percent per AMU for a given isotopic ratio, $R_{a}$ is the measured ratio, $R_{t}$ is the true ratio, and $\Delta M$ is the nominal mass difference between the two isotopes ( 2 for ${ }^{206} \mathrm{~Pb} /{ }^{204} \mathrm{~Pb}$ and ${ }^{208} \mathrm{~Pb} /{ }^{206} \mathrm{~Pb}$, and 1 for ${ }^{207} \mathrm{~Pb} /{ }^{206} \mathrm{~Pb}$ ). The calculated fractionation 
Table A2-1. Lead isotopic analyses of NIST standard SRM 981

\begin{tabular}{|c|c|c|c|c|c|c|c|c|c|c|}
\hline Sample & Temp & ${ }^{206} \mathrm{~Pb} /{ }^{204} \mathrm{~Pb}^{1}$ & $\%$ S.E. & ${ }^{207} \mathrm{~Pb} /{ }^{206} \mathrm{~Pb}^{1}$ & $\%$ S.E. & ${ }^{208} \mathrm{~Pb} /{ }^{206} \mathrm{~Pb}^{1}$ & $\%$ S.E. & $\mathrm{F}^{206} \mathrm{~Pb} /{ }^{204} \mathrm{~Pb}^{2}$ & $\mathrm{~F}^{207} \mathrm{~Pb} /{ }^{206} \mathrm{~Pb}^{2}$ & $\mathrm{~F}^{208} \mathrm{~Pb} /{ }^{206} \mathrm{~Pb}^{2}$ \\
\hline Certified Values $^{3}$ & & 16.9370 & 0.0630 & 0.914640 & 0.0360 & 2.16810 & 0.0370 & & & \\
\hline Redetermined Values ${ }^{4}$ & & 16.9322 & 0.0047 & 0.914561 & 0.0044 & 2.16662 & 0.0060 & & & \\
\hline SRM 981-1 & 1123 & 16.8981 & 0.0018 & 0.913672 & 0.0006 & 2.16241 & 0.0009 & $0.101 \pm 0.001$ & $0.097 \pm 0.001$ & $0.097 \pm 0.000$ \\
\hline SRM 981-2 & 1118 & 16.8994 & 0.0015 & 0.913717 & 0.0021 & 2.16243 & 0.0010 & $0.097 \pm 0.001$ & $0.092 \pm 0.002$ & $0.097 \pm 0.002$ \\
\hline SRM 981-3 & 1218 & 16.9147 & 0.0064 & 0.913891 & 0.0020 & 2.16390 & 0.0039 & $0.052 \pm 0.003$ & $0.073 \pm 0.006$ & $0.063 \pm 0.002$ \\
\hline SRM 981-4 & 1192 & 16.9118 & 0.0022 & 0.914069 & 0.0008 & 2.16418 & 0.0012 & $0.060 \pm 0.001$ & $0.054 \pm 0.001$ & $0.056 \pm 0.001$ \\
\hline SRM 981-5 & 1192 & 16.9051 & 0.0031 & 0.913902 & 0.0009 & 2.16341 & 0.0023 & $0.080 \pm 0.002$ & $0.072 \pm 0.001$ & $0.074 \pm 0.001$ \\
\hline SRM 981-6 & 1190 & 16.9093 & 0.0046 & 0.913942 & 0.0014 & 2.16400 & 0.0033 & $0.068 \pm 0.002$ & $0.068 \pm 0.001$ & $0.061 \pm 0.002$ \\
\hline SRM 981-7 & 1190 & 16.8991 & 0.0028 & 0.913753 & 0.0011 & 2.16281 & 0.0023 & $0.098 \pm 0.001$ & $0.088 \pm 0.001$ & $0.088 \pm 0.001$ \\
\hline SRM 981-8 & 1188 & 16.8988 & 0.0024 & 0.913724 & 0.0007 & 2.16280 & 0.0014 & $0.099 \pm 0.001$ & $0.092 \pm 0.001$ & $0.088 \pm 0.001$ \\
\hline SRM 981-9 & 1163 & 16.9009 & 0.0037 & 0.913732 & 0.0014 & 2.16282 & 0.0031 & $0.093 \pm 0.002$ & $0.091 \pm 0.001$ & $0.088 \pm 0.002$ \\
\hline SRM 981-9 & 1206 & 16.9167 & 0.0044 & 0.914124 & 0.0013 & 2.16495 & 0.0032 & $0.046 \pm 0.002$ & $0.048 \pm 0.001$ & $0.039 \pm 0.002$ \\
\hline SRM 981-10 & 1151 & 16.9007 & 0.0025 & 0.913750 & 0.0008 & 2.16277 & 0.0012 & $0.093 \pm 0.001$ & $0.089 \pm 0.001$ & $0.089 \pm 0.001$ \\
\hline SRM 981-10 & 1210 & 16.9165 & 0.0022 & 0.914118 & 0.0007 & 2.16474 & 0.0013 & $0.046 \pm 0.001$ & $0.048 \pm 0.001$ & $0.043 \pm 0.001$ \\
\hline SRM 981-11 & 1179 & 16.9038 & 0.0021 & 0.913827 & 0.0011 & 2.16320 & 0.0021 & $0.084 \pm 0.001$ & $0.080 \pm 0.001$ & $0.079 \pm 0.001$ \\
\hline SRM 981-11 & 1174 & 16.9045 & 0.0035 & 0.913817 & 0.0008 & 2.16316 & 0.0007 & $0.082 \pm 0.002$ & $0.081 \pm 0.001$ & $0.080 \pm 0.000$ \\
\hline SRM 981-12 & 1186 & 16.9049 & 0.0035 & 0.913808 & 0.0017 & 2.16314 & 0.0033 & $0.081 \pm 0.002$ & $0.082 \pm 0.002$ & $0.080 \pm 0.002$ \\
\hline SRM 981-12 & 1230 & 16.9265 & 0.0045 & 0.914329 & 0.0020 & 2.16580 & 0.0039 & $0.017 \pm 0.002$ & $0.025 \pm 0.002$ & $0.019 \pm 0.002$ \\
\hline SRM $981-13$ & 1113 & 16.8910 & 0.0042 & 0.913649 & 0.0010 & 2.16190 & 0.0013 & $0.122 \pm 0.002$ & $0.100 \pm 0.001$ & $0.109 \pm 0.001$ \\
\hline SRM 981-13 & 1185 & 16.9040 & 0.0032 & 0.913857 & 0.0009 & 2.16322 & 0.0016 & $0.083 \pm 0.002$ & $0.077 \pm 0.001$ & $0.079 \pm 0.001$ \\
\hline SRM 981-14 & 1195 & 16.8919 & 0.0042 & 0.913506 & 0.0017 & 2.16148 & 0.0030 & $0.119 \pm 0.002$ & $0.115 \pm 0.002$ & $0.119 \pm 0.002$ \\
\hline SRM 981-15 & 1136 & 16.8854 & 0.0033 & 0.913242 & 0.0011 & 2.16407 & 0.0017 & $0.139 \pm 0.002$ & $0.144 \pm 0.001$ & $0.059 \pm 0.001$ \\
\hline SRM 981-16 & 1315 & 16.9230 & 0.0089 & 0.914055 & 0.0022 & 2.16517 & 0.0063 & $0.027 \pm 0.004$ & $0.055 \pm 0.002$ & $0.033 \pm 0.003$ \\
\hline SRM 981-17 & 1234 & 16.9185 & 0.0133 & 0.913869 & 0.0036 & 2.16381 & 0.0058 & $0.040 \pm 0.007$ & $0.076 \pm 0.004$ & $0.065 \pm 0.003$ \\
\hline SRM 981-20 & 1238 & 16.9102 & 0.0064 & 0.914049 & 0.0020 & 2.16435 & 0.0046 & $0.065 \pm 0.003$ & $0.056 \pm 0.002$ & $0.052 \pm 0.002$ \\
\hline SRM 981-21 & 1198 & 16.9031 & 0.0028 & 0.913921 & 0.0013 & 2.16343 & 0.0028 & $0.086 \pm 0.001$ & $0.070 \pm 0.001$ & $0.074 \pm 0.001$ \\
\hline SRM 981-22 & 1216 & 16.9034 & 0.0039 & 0.913867 & 0.0017 & 2.16326 & 0.0032 & $0.085 \pm 0.002$ & $0.076 \pm 0.002$ & $0.078 \pm 0.002$ \\
\hline SRM 981-23 & 1212 & 16.9013 & 0.0067 & 0.913771 & 0.0018 & 2.16294 & 0.0034 & $0.091 \pm 0.003$ & $0.086 \pm 0.002$ & $0.085 \pm 0.002$ \\
\hline SRM 981-24 & 1190 & 16.9015 & 0.0023 & 0.913786 & 0.0005 & 2.16302 & 0.0006 & $0.091 \pm 0.001$ & $0.085 \pm 0.001$ & $0.085 \pm 0.001$ \\
\hline SRM 981-25 & 1197 & 16.8954 & 0.0024 & 0.913513 & 0.0010 & 2.16186 & 0.0011 & $0.109 \pm 0.001$ & $0.115 \pm 0.001$ & $0.110 \pm 0.001$ \\
\hline MEAN, ALL $^{5}$ & $\mathrm{~N}=28$ & 16.9048 & 0.0570 & 0.913830 & 0.0230 & 2.16326 & 0.0470 & $0.081 \pm 0.029$ & $0.080 \pm 0.023$ & $0.078 \pm 0.024$ \\
\hline MEAN, T<11405 & $\mathrm{N}=4$ & 16.8935 & 0.0460 & 0.913570 & 0.0250 & 2.16180 & 0.0540 & $0.115 \pm 0.023$ & $0.108 \pm 0.025$ & $0.111 \pm 0.027$ \\
\hline MEAN, T>1220 5 & $\mathrm{~N}=4$ & 16.9200 & 0.0570 & 0.914080 & 0.0280 & 2.16480 & 0.0570 & $0.036 \pm 0.029$ & $0.053 \pm 0.028$ & $0.042 \pm 0.029$ \\
\hline MEAN, $T=1140-1220^{5}$ & $\mathrm{~N}=20$ & 16.9043 & 0.0440 & 0.913833 & 0.0210 & 2.16325 & 0.0420 & $0.083 \pm 0.022$ & $0.080 \pm 0.021$ & $0.078 \pm 0.021$ \\
\hline Correction factors ${ }^{6}$ & & & & & & & & $0.166 \pm 0.044$ & $0.080 \pm 0.021$ & $0.156 \pm 0.042$ \\
\hline MEAN T $=1140-1220^{7}$ & $\mathrm{~N}=20$ & 16.9043 & 0.0440 & 0.913833 & 0.0210 & 2.16325 & 0.0420 & $0.097 \pm 0.022$ & $0.088 \pm 0.021$ & $0.112 \pm 0.021$ \\
\hline \multicolumn{11}{|c|}{ Runs for samples received 04/01-05/01 } \\
\hline 981-24-VB137 & 1190 & 16.9015 & 0.0023 & 0.913786 & 0.0005 & 2.16302 & 0.0006 & $0.091 \pm 0.001$ & $0.085 \pm 0.001$ & $0.083 \pm 0.000$ \\
\hline 981-25-VB139 & 1197 & 16.8954 & 0.0024 & 0.913513 & 0.0010 & 2.16186 & 0.0011 & $0.109 \pm 0.001$ & $0.115 \pm 0.001$ & $0.110 \pm 0.001$ \\
\hline $981-26-V B 140$ & 1168 & 16.9039 & 0.0036 & 0.913899 & 0.0014 & 2.16207 & 0.0141 & $0.084 \pm 0.002$ & $0.072 \pm 0.001$ & $0.105 \pm 0.007$ \\
\hline $981-26-V B 140$ & 1143 & 16.9109 & 0.0038 & 0.914072 & 0.0009 & 2.16425 & 0.0007 & $0.063 \pm 0.002$ & $0.053 \pm 0.001$ & $0.055 \pm 0.000$ \\
\hline 981-27-VB158 & 1145 & 16.9019 & 0.0069 & 0.913814 & 0.0024 & 2.16321 & 0.0049 & $0.090 \pm 0.003$ & $0.082 \pm 0.002$ & $0.079 \pm 0.002$ \\
\hline
\end{tabular}


Table A2-1, Cont'd.

\begin{tabular}{|c|c|c|c|c|c|c|c|c|c|c|}
\hline Sample & Temp & ${ }^{206} \mathrm{~Pb} /{ }^{204} \mathrm{~Pb}^{1}$ & \% S.E. & ${ }^{207} \mathrm{~Pb} /{ }^{206} \mathrm{~Pb}^{1}$ & \% S.E. & ${ }^{208} \mathrm{~Pb} /{ }^{206} \mathrm{~Pb}^{1}$ & \% S.E. & $\mathrm{F}^{206} \mathrm{~Pb}^{204} \mathrm{~Pb}^{2}$ & $\mathrm{~F}^{207} \mathrm{~Pb} /{ }^{206} \mathrm{~Pb}^{2}$ & $\mathrm{~F}^{208} \mathrm{~Pb} /{ }^{206} \mathrm{~Pb}^{2}$ \\
\hline 981-28-VB160 & 1166 & 16.9034 & 0.0022 & 0.913757 & 0.0008 & 2.16302 & 0.0014 & $0.085 \pm 0.001$ & $0.088 \pm 0.001$ & $0.083 \pm 0.001$ \\
\hline 981-29-VB178 & 1091 & 16.9045 & 0.0019 & 0.913759 & 0.0006 & 2.16244 & 0.0009 & $0.082 \pm 0.001$ & $0.088 \pm 0.001$ & $0.097 \pm 0.000$ \\
\hline 981-29-VB178 & 1166 & 16.9106 & 0.0031 & 0.914159 & 0.0016 & 2.16354 & 0.0030 & $0.064 \pm 0.002$ & $0.044 \pm 0.002$ & $0.071 \pm 0.002$ \\
\hline $981-30-V B 180$ & 1157 & 16.9071 & 0.0039 & 0.913788 & 0.0017 & 2.16306 & 0.0031 & $0.074 \pm 0.002$ & $0.085 \pm 0.002$ & $0.082 \pm 0.002$ \\
\hline 981-31-VB190 & 1165 & 16.9114 & 0.0029 & 0.913994 & 0.0006 & 2.16374 & 0.0005 & $0.061 \pm 0.001$ & $0.062 \pm 0.001$ & $0.067 \pm 0.000$ \\
\hline MEAN, ALL $^{5}$ & $\mathrm{~N}=10$ & 16.9051 & 0.0300 & 0.913850 & 0.0200 & 2.16302 & 0.0340 & $0.080 \pm 0.015$ & $0.078 \pm 0.020$ & $0.083 \pm 0.017$ \\
\hline MEAN, $T=1140-1220^{5}$ & $N=9$ & 16.9051 & 0.0310 & 0.913860 & 0.0210 & 2.16309 & 0.0350 & $0.080 \pm 0.016$ & $0.077 \pm 0.021$ & $0.082 \pm 0.018$ \\
\hline Correction factors ${ }^{6}$ & & & & & & & & $0.160 \pm 0.032$ & $0.077 \pm 0.021$ & $0.164 \pm 0.036$ \\
\hline MEAN T $=1140-1220^{7}$ & $\mathrm{~N}=9$ & 16.9051 & 0.0310 & 0.913860 & 0.0210 & 2.16309 & & $0.094 \pm 0.015$ & $0.085 \pm 0.020$ & $0.116 \pm 0.017$ \\
\hline
\end{tabular}

${ }^{1}$ Uncertainties are 1 standard error (1 S.E. $\approx 1$ sigma mean) in percent.

${ }^{2}$ Calculated fractionation factors in percent per AMU for each ratio, uncertainties are at 1 S.E. in percent.

Calculations are relative to the redermined values of Todt and others, 1993, unless otherwise noted.

${ }^{3}$ Certified values from Cantanzaro and others, 1968.

${ }^{4}$ Redetermined values from Todt and others, 1993.

${ }^{5}$ Uncertainties correspond to 1 sigma. Preferred values shown in bold.

${ }^{6}$ mass fractionation correction factors applied to sample isotopic ratios.

${ }^{7}$ Calculated relative to the values of Cantanzaro and others, 1968. Uncertainties are 1 sigma. 
factors also account for small possible differences in collector efficiencies and are therefore calculated separately for each isotope ratio.

The amount of mass fractionation for a given run is a function of several variables including filament thickness; relative amounts of $\mathrm{Pb}$, phosphoric acid, and silica gel; the particle size of the silica gel; and the filament temperature during data acquisition. Although the calculated fractionation factors do appear to vary with temperature (Table A2-1), the relationships are not particularly well correlated $\left(r^{2} \leq 0.6\right)$. Consequently, no attempt was made to "fine tune" the calculations as a function of running temperature. Instead, a temperature interval of approximately $1140^{\circ} \mathrm{C}-1220^{\circ} \mathrm{C}$ was selected to represent acceptable running conditions.

This temperature interval shows reasonably consistent calculated fractionation factors, and encompasses the bulk of the standard runs (mean values in bold type in Table A2-1). Data were accepted for only those samples that were also run within this temperature interval.

Mean calculated fractionation factors are shown relative to both the original certified values for NIST standard SRM-981 (Cantanzaro and others, 1968) and to the more precise redetermined values of Todt and others (1993). The calculated fractionation factors relative to the redetermined standard values are more internally consistent than those relative to the original values. Consequently, the factors calculated relative to the redetermined values were used to correct the sample data.

As a test of the correction procedures, twelve samples of NIST standard SRM-982 were run. Fractionation factors for each isotope ratio for each SRM 982 standard run have been calculated in the manner outlined above. Fractionation factors for the means of the twelve analyses have been calculated relative to both the original certified values (Cantanzaro and others, 1968) and the redetermined values (Todt and others, 1993). The results relative to the original certified values are more internally consistent (bold line in Table A2-2). Agreement between the standards is within $0.011 \%$ per AMU for ${ }^{207} \mathrm{~Pb} /{ }^{206} \mathrm{~Pb}, 0.016 \%$ per $\mathrm{AMU}$ for ${ }^{208} \mathrm{~Pb} /{ }^{206} \mathrm{~Pb}$, and $0.033 \%$ per AMU for ${ }^{206} \mathrm{~Pb} /{ }^{204} \mathrm{~Pb}$.

\section{Data Reduction}

Raw Data are corrected for mass fractionation based on the analyses of the SRM 981 standards (Table A2-1) using the following equation (Ludwig, 1980):

$$
\mathrm{R}_{\mathrm{c}}=\mathrm{R}_{\mathrm{a}}{ }^{*}\left(1+\Delta \mathrm{M} * \mathrm{~F}_{\mathrm{a}} / 100\right)
$$


Table A2-2. Lead isotopic analyses of NIST standard SRM 982

\begin{tabular}{|c|c|c|c|c|c|c|c|c|c|c|}
\hline Sample & Temp & ${ }^{206} \mathrm{~Pb} /{ }^{204} \mathrm{~Pb}^{1}$ & $\%$ S.E. & ${ }^{207} \mathrm{~Pb} /{ }^{206} \mathrm{~Pb}^{1}$ & $\%$ S.E. & ${ }^{208} \mathrm{~Pb} /{ }^{206} \mathrm{~Pb}^{1}$ & $\%$ S.E. & $\mathrm{F}^{206} \mathrm{~Pb} /{ }^{204} \mathrm{~Pb}^{2}$ & $\mathrm{~F}^{206} \mathrm{~Pb} /{ }^{204} \mathrm{~Pb}^{2}$ & $\mathrm{~F}^{206} \mathrm{~Pb} /{ }^{204} \mathrm{~Pb}^{2}$ \\
\hline Certified Values $^{3}$ & & 36.7390 & 0.0990 & 0.467070 & 0.0430 & 1.00016 & 0.0360 & & & \\
\hline Redetermined Values ${ }^{4}$ & & 36.7537 & 0.0027 & 0.467003 & 0.0011 & 1.00016 & $* * 4$ & & & \\
\hline SRM 982-1 & 1144 & 36.6569 & 0.0021 & 0.466533 & 0.0006 & 0.99792 & 0.0011 & $0.112 \pm 0.001$ & $0.115 \pm 0.001$ & $0.112 \pm 0.001$ \\
\hline SRM 982-2 & 1207 & 36.6500 & 0.0041 & 0.466571 & 0.0017 & 0.99793 & 0.0023 & $0.121 \pm 0.002$ & $0.107 \pm 0.002$ & $0.112 \pm 0.001$ \\
\hline SRM 982-3 & 1194 & 36.6676 & 0.0020 & 0.466648 & 0.0006 & 0.99842 & 0.0014 & $0.097 \pm 0.001$ & $0.090 \pm 0.001$ & $0.087 \pm 0.001$ \\
\hline SRM 982-4 & 1166 & 36.6427 & 0.0039 & 0.466530 & 0.0016 & 0.99787 & 0.0036 & $0.131 \pm 0.002$ & $0.116 \pm 0.002$ & $0.115 \pm 0.002$ \\
\hline SRM 982-5 & 1195 & 36.6564 & 0.0050 & 0.466643 & 0.0019 & 0.99833 & 0.0042 & $0.113 \pm 0.003$ & $0.092 \pm 0.002$ & $0.092 \pm 0.002$ \\
\hline SRM 982-6 & 1206 & 36.6668 & 0.0048 & 0.466686 & 0.0018 & 0.99857 & 0.0040 & $0.098 \pm 0.002$ & $0.082 \pm 0.002$ & $0.080 \pm 0.002$ \\
\hline SRM 982-7 & 1192 & 36.6498 & 0.0054 & 0.466658 & 0.0012 & 0.99831 & 0.0020 & $0.122 \pm 0.003$ & $0.088 \pm 0.001$ & $0.093 \pm 0.001$ \\
\hline SRM 982-8 & 1215 & 36.6302 & 0.0106 & 0.466778 & 0.0015 & 0.99855 & 0.0024 & $0.149 \pm 0.005$ & $0.063 \pm 0.002$ & $0.081 \pm 0.001$ \\
\hline SRM 982-9 & 1222 & 36.6699 & 0.0031 & 0.466712 & 0.0013 & 0.99863 & 0.0026 & $0.094 \pm 0.002$ & $0.077 \pm 0.001$ & $0.077 \pm 0.001$ \\
\hline SRM 982-10 & 1193 & 36.6460 & 0.0030 & 0.466624 & 0.0011 & 0.99812 & 0.0021 & $0.127 \pm 0.002$ & $0.096 \pm 0.001$ & $0.102 \pm 0.001$ \\
\hline SRM 982-11 & 1197 & 36.6637 & 0.0028 & 0.466734 & 0.0006 & 0.99863 & 0.0007 & $0.103 \pm 0.001$ & $0.072 \pm 0.001$ & $0.076 \pm 0.000$ \\
\hline SRM 982-12 & 1197 & 36.6457 & 0.0027 & 0.466628 & 0.0011 & 0.99818 & 0.0026 & $0.127 \pm 0.001$ & $0.095 \pm 0.001$ & $0.099 \pm 0.001$ \\
\hline SRM 982-13 & 1165 & 36.6471 & 0.0032 & 0.466542 & 0.0009 & 0.99789 & 0.0021 & $0.125 \pm 0.002$ & $0.113 \pm 0.001$ & $0.114 \pm 0.001$ \\
\hline SRM 982-14 & 1170 & 36.6381 & 0.0028 & 0.466487 & 0.0009 & 0.99759 & 0.0016 & $0.138 \pm 0.001$ & $0.125 \pm 0.001$ & $0.129 \pm 0.001$ \\
\hline SRM 982-15 & 1166 & 36.6660 & 0.0023 & 0.466680 & 0.0010 & 0.99845 & 0.0020 & $0.100 \pm 0.001$ & $0.084 \pm 0.001$ & $0.086 \pm 0.001$ \\
\hline SRM 982-16 & 1150 & 36.6687 & 0.0035 & 0.466653 & 0.0013 & 0.99831 & 0.0027 & $0.096 \pm 0.002$ & $0.089 \pm 0.001$ & $0.093 \pm 0.001$ \\
\hline SRM 982-17 & 1186 & 36.6663 & 0.0031 & 0.466617 & 0.0012 & 0.99824 & 0.0024 & $0.099 \pm 0.002$ & $0.097 \pm 0.001$ & $0.096 \pm 0.001$ \\
\hline Mean $^{5}$ & & 36.6549 & 0.0330 & 0.466631 & 0.0170 & 0.99823 & 0.0320 & $0.115 \pm 0.017$ & $0.094 \pm 0.017$ & $0.097 \pm 0.016$ \\
\hline $\operatorname{Mean}^{6}$ & & 36.6549 & 0.0330 & 0.466631 & 0.0170 & 0.99823 & 0.0320 & $0.135 \pm 0.017$ & $0.080 \pm 0.017$ & $0.097 \pm 0.016$ \\
\hline
\end{tabular}

${ }^{1}$ Uncertainties are 1 standard error (1 S.E. $\approx 1$ sigma mean) in percent.

${ }^{2}$ Calculated fractionation factors in percent per AMU for each ratio, uncertainties are at 1 S.E. in percent.

Calculations are relative to the certified values of Cantanzaro and others, 1968, unless otherwise noted.

${ }^{3}$ Certified values from Cantanzaro and others, 1968.

${ }^{4}$ Redetermined values from Todt and others, 1993. Calculations based on an assumed ${ }^{208} \mathrm{~Pb} /{ }^{206} \mathrm{~Pb}=1.00016$.

${ }^{5}$ Preferred values shown in bold. Uncertainties correspond to 1 sigma.

${ }^{6}$ Calculated relative to the values of Todt and others, 1993. Uncertainties are 1 sigma. 
Where $R_{c}$ is the corrected ratio, $R_{a}$ is the measured ratio, $F_{a}$ is the calculated fractionation factor as defined above, and $\Delta \mathrm{M}$ is the nominal mass difference between the numerator and denominator isotopes. Both the $F_{a}$ values and the correction factors $\left(=\Delta M{ }^{*} F_{a}\right)$ for each isotope ratio are shown in bold type in Table A2-1. Also shown are the 1-sigma uncertainties for both sets of values.

Precision for the mass fractionation-corrected data for individual mass spectrometry runs listed in Table 2 is calculated at the 95\% confidence interval (C.I.) using the equations given by Ludwig $(1980 ; 1994)$ with the following parameters: 3.2 times the measured standard error (based on 4 blocks of data in each run) and the 2.05 times the 1-sigma uncertainty from the average of the SRM-981 standard runs (Table A2-1; based on 20 runs). Weighted means and uncertainties for data from individual samples are then calculated from the data for individual runs also at the $95 \%$ C.I.

\section{Replicate Analyses}

Three types of replicate samples were analyzed. (1) Blind duplicates were submitted by USEPA. (2) Replicate acid-hydrogen peroxide digestions of the same sample were performed in order to evaluate sample homogeneity as well as the reproducibility of the digestion procedure (digestion replicates). These are designated by different suffix letters in Tables 1 and A2-4 (e.g. 642B-A, 642B-B, 642B-C). (3) Replicate loads of the same sample from a single chemical procedure (mass spectrometry replicates) were run in order to evaluate the reproducibility of the mass spectrometric procedures. These replicates are designated by separate entries under a single sample number in Tables 2 and A2-3.

Two sets of blind duplicates were submitted by USEPA. These were the baseline soil, samples 3-15653-B and 3-15654-B (EPA number SC-000650), and high-As-focal samples 3-15650-B and 3-15651-B (EPA number SC-00046). Results for the duplicates of the baseline soil are in reasonably good agreement and in fact the variation between the two samples is less than that found among duplicate acid digestions of sample 3-15654-B (Table 2). Results for the duplicate analyses of the high-As-focal sample are in agreement within analytical uncertainty $\left({ }^{206} \mathrm{~Pb} /{ }^{204} \mathrm{~Pb}=17.801 \pm 0.009\right.$ and $17.789 \pm 0.009$; Table 2).

Samples from most individual acid-digestions were run at least twice under acceptable temperature and beam-intensity conditions outlined above (Table 2). Data were corrected for mass fractionation and a weighted mean and uncertainty were calculated also as outlined above. 
Table A2-3. Lead isotopic compositions from replicate runs of Sample 3-15642-B, Vasquez Blvd.-I70 Project

\begin{tabular}{lcccc}
\hline Sample/Lab No. & Temp & ${ }^{206} \mathrm{~Pb} /{ }^{204} \mathrm{~Pb}^{2}$ & ${ }^{207} \mathrm{~Pb} /{ }^{206} \mathrm{~Pb}^{2}$ & ${ }^{208} \mathrm{~Pb} /{ }^{206} \mathrm{~Pb}^{2}$ \\
\hline 3-15642-B & & & & \\
642B-A & 1078 & $18.1958 \pm 0.0020 \%$ & $0.85370 \pm 0.0006 \%$ & $2.08992 \pm 0.0005 \%$ \\
642B-A & 1188 & $18.2064 \pm 0.0031 \%$ & $0.85404 \pm 0.0014 \%$ & $2.09149 \pm 0.0024 \%$ \\
642B-A & 1167 & $18.2260 \pm 0.0064 \%$ & $0.85436 \pm 0.0023 \%$ & $2.09344 \pm 0.0053 \%$ \\
642B-A & 1194 & $18.2150 \pm 0.0093 \%$ & $0.85402 \pm 0.0025 \%$ & $2.09192 \pm 0.0045 \%$ \\
642B-A & 1273 & $18.1949 \pm 0.0045 \%$ & $0.85359 \pm 0.0010 \%$ & $2.08987 \pm 0.0012 \%$ \\
642B-A & 1213 & $18.2196 \pm 0.0063 \%$ & $0.85400 \pm 0.0025 \%$ & $2.09185 \pm 0.0054 \%$ \\
642B-A & 1191 & $18.2284 \pm 0.0127 \%$ & $0.85371 \pm 0.0028 \%$ & $2.09137 \pm 0.0044 \%$ \\
Mean-All & & $18.212 \pm 0.075 \%$ & $0.85392 \pm 0.031 \%$ & $2.0914 \pm 0.059 \%$ \\
Mean-T=1140-1220 $^{3}$ & & $18.219 \pm 0.049 \%$ & $0.85403 \pm 0.027 \%$ & $2.0920 \pm 0.040 \%$ \\
\hline
\end{tabular}

${ }^{1}$ Data are for separate loads of a single processed aliquot of sample 3-15642-B

${ }^{2}$ Raw data uncorrected for mass fractionation. Corrected data are shown in Table 1. Uncertainties for individual runs are 1 standard error in \% (1 S.E. $\approx 1$ sigma mean)

${ }^{3}$ Uncertainties for means are 1 sigma in percent 
Table A2-4. Lead isotopic data for replicate acid-digestions of selected soils samples from the Vasquez Blvd.-170 Project.

\begin{tabular}{|c|c|c|c|c|c|c|c|}
\hline Sample/Lab No ${ }^{1}$ & $\mathrm{~Pb} \mathrm{ppm^{2 }}$ & Sample wt (g) & ${ }^{206} \mathrm{~Pb} /{ }^{204} \mathrm{~Pb}^{3}$ & ${ }^{207} \mathrm{~Pb} /{ }^{206} \mathrm{~Pb}^{3}$ & ${ }^{208} \mathrm{~Pb} /{ }^{206} \mathrm{~Pb}^{3}$ & ${ }^{207} \mathrm{~Pb} /{ }^{204} \mathrm{~Pb}^{3}$ & ${ }^{208} \mathrm{~Pb} /{ }^{204} \mathrm{~Pb}^{3}$ \\
\hline $\begin{array}{l}\text { 3-15642-B } \\
\text { Mean 642B-A } \\
\text { Mean642B-B } \\
\text { Mean642B-C } \\
\text { Mean 642B A-C }\end{array}$ & 422 & $\begin{array}{l}0.126 \\
0.072 \\
0.092\end{array}$ & $\begin{array}{l}18.249 \pm 0.007 \\
18.219 \pm 0.031 \\
18.243 \pm 0.009 \\
\mathbf{1 8 . 2 4 2} \pm \mathbf{0 . 0 2 9}\end{array}$ & $\begin{array}{c}0.85471 \pm 0.00021 \\
0.85570 \pm 0.00065 \\
0.85511 \pm 0.00021 \\
\mathbf{0 . 8 5 5 1} \pm \mathbf{0 . 0 0 0 9}\end{array}$ & $\begin{array}{l}2.0953 \pm 0.0008 \\
2.0962 \pm 0.0036 \\
2.0960 \pm 0.0010 \\
\mathbf{2 . 0 9 5 6 \pm 0 . 0 0 0 6}\end{array}$ & $\begin{array}{l}15.598 \pm 0.009 \\
15.590 \pm 0.039 \\
15.600 \pm 0.012 \\
\mathbf{1 5 . 5 9 9} \pm \mathbf{0 . 0 0 7}\end{array}$ & $\begin{array}{l}38.237 \pm 0.029 \\
38.191 \pm 0.126 \\
38.237 \pm 0.038 \\
\mathbf{3 8 . 2 3 5} \pm \mathbf{0 . 0 2 3}\end{array}$ \\
\hline $\begin{array}{l}\text { 3-15644-B } \\
\text { Mean 644B-A } \\
\text { 644B-B } \\
\text { 644B-C } \\
\text { Mean 644B A-C }\end{array}$ & 39 & $\begin{array}{l}0.233 \\
0.255 \\
0.191\end{array}$ & $\begin{aligned} 18.452 & \pm 0.012 \\
18.497 & \pm 0.017 \\
18.610 & \pm 0.017 \\
\mathbf{1 8 . 5 2} & \pm \mathbf{0 . 2 0}\end{aligned}$ & 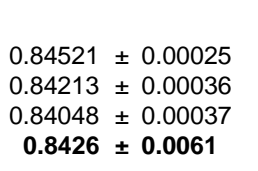 & $\begin{array}{c}2.0963 \pm 0.0013 \\
2.0947 \pm 0.0018 \\
2.1133 \pm 0.0019 \\
\mathbf{2 . 1 0 1} \pm \mathbf{0 . 0 2 3}\end{array}$ & $\begin{array}{l}15.595 \pm 0.014 \\
15.577 \pm 0.021 \\
15.641 \pm 0.021 \\
\mathbf{1 5 . 6 0 4} \pm \mathbf{0 . 0 8 0}\end{array}$ & $\begin{array}{c}38.681 \pm 0.046 \\
38.746 \pm 0.068 \\
39.328 \pm 0.069 \\
\mathbf{3 8 . 9 2} \pm \mathbf{0 . 9 0}\end{array}$ \\
\hline $\begin{array}{l}\text { 3-15654-B } \\
\text { Mean654B-A } \\
654 \mathrm{~B}-\mathrm{B} \\
654 \mathrm{~B}-\mathrm{C} \\
654 \mathrm{~B}-\mathrm{D} \\
654 \mathrm{~B}-\mathrm{E} \\
654 \mathrm{~B}-\mathrm{F} \\
\text { Mean 654B A-F } \\
\text { Mean 654B B-F }\end{array}$ & 101 & $\begin{array}{l}0.254 \\
0.177 \\
0.164 \\
0.078 \\
0.272 \\
0.219\end{array}$ & $\begin{aligned} 18.869 & \pm 0.010 \\
18.459 & \pm 0.017 \\
18.454 & \pm 0.017 \\
18.496 & \pm 0.017 \\
18.385 & \pm 0.017 \\
18.460 & \pm 0.017 \\
18.52 & \pm 0.18 \\
\mathbf{1 8 . 4 5 1} & \pm \mathbf{0 . 0 5 0}\end{aligned}$ & $\begin{array}{c}0.82794 \pm 0.00021 \\
0.84513 \pm 0.00037 \\
0.84637 \pm 0.00037 \\
0.84416 \pm 0.00036 \\
0.84836 \pm 0.00037 \\
0.84481 \pm 0.00036 \\
0.8428 \pm 0.0079 \\
\mathbf{0 . 8 4 5 8} \pm \mathbf{0 . 0 0 2 0}\end{array}$ & $\begin{aligned} 2.0506 & \pm 0.0010 \\
2.0887 & \pm 0.0018 \\
2.0898 & \pm 0.0018 \\
2.0887 & \pm 0.0018 \\
2.0894 & \pm 0.0018 \\
2.0886 & \pm 0.0018 \\
2.083 & \pm 0.016 \\
2.0890 & \pm 0.0008\end{aligned}$ & $\begin{array}{l}15.623 \pm 0.012 \\
15.600 \pm 0.021 \\
15.619 \pm 0.021 \\
15.614 \pm 0.021 \\
15.597 \pm 0.021 \\
15.595 \pm 0.021 \\
15.610 \pm 0.012 \\
\mathbf{1 5 . 6 0 5} \pm \mathbf{0 . 0 0 9}\end{array}$ & $\begin{array}{l}38.693 \pm 0.039 \\
38.556 \pm 0.068 \\
38.564 \pm 0.068 \\
38.633 \pm 0.068 \\
38.414 \pm 0.068 \\
38.554 \pm 0.068 \\
38.571 \pm 0.097 \\
\mathbf{3 8 . 5 4 4} \pm \mathbf{0 . 0 9 6}\end{array}$ \\
\hline $\begin{array}{l}\text { 3-15655-B } \\
\text { Mean 655B-A } \\
\text { 655B-B } \\
\text { Mean 655B A-B }\end{array}$ & 151 & $\begin{array}{l}0.260 \\
0.152\end{array}$ & $\begin{array}{l}18.297 \pm 0.011 \\
18.312 \pm 0.017 \\
\mathbf{1 8 . 3 0 3} \pm \mathbf{0 . 0 7 3}\end{array}$ & $\begin{aligned} 0.85249 & \pm 0.00026 \\
0.85129 & \pm 0.00037 \\
\mathbf{0 . 8 5 1 9} & \pm \mathbf{0 . 0 0 7 3}\end{aligned}$ & $\begin{array}{l}2.0894 \pm 0.0013 \\
2.0865 \pm 0.0018 \\
\mathbf{2 . 0 8 8 0} \pm \mathbf{0 . 0 1 7 3}\end{array}$ & $\begin{array}{l}15.598 \pm 0.014 \\
15.589 \pm 0.021 \\
\mathbf{1 5 . 5 9 5} \pm \mathbf{0 . 0 1 1}\end{array}$ & $\begin{array}{l}38.231 \pm 0.046 \\
38.209 \pm 0.067 \\
\mathbf{3 8 . 2 2 4} \pm \mathbf{0 . 0 3 7}\end{array}$ \\
\hline $\begin{array}{l}\text { 3-15656-B } \\
\text { Mean 656B-A } \\
656 \mathrm{~B}-\mathrm{B} \\
656 \mathrm{~B}-\mathrm{C} \\
656 \mathrm{~B}-\mathrm{D} \\
\text { 656B-E } \\
\text { Mean 656B A-E } \\
\text { Mean 656B A, C-E }\end{array}$ & 175 & $\begin{array}{l}0.208 \\
0.204 \\
0.180 \\
0.524 \\
0.601\end{array}$ & $\begin{array}{c}18.480 \pm 0.010 \\
17.985 \pm 0.016 \\
18.572 \pm 0.017 \\
18.402 \pm 0.017 \\
18.426 \pm 0.017 \\
18.37 \pm 0.28 \\
\mathbf{1 8 . 4 7} \pm \mathbf{0 . 1 2}\end{array}$ & $\begin{aligned} 0.84476 & \pm 0.0002 \\
0.86567 & \pm 0.00037 \\
0.84076 & \pm 0.00037 \\
0.84755 & \pm 0.00037 \\
0.84663 & \pm 0.00037 \\
0.849 & \pm 0.011 \\
\mathbf{0 . 8 4 4 9} & \pm \mathbf{0 . 0 0 4 2 2 5}\end{aligned}$ & $\begin{array}{r}2.0711 \pm 0.0018 \\
2.0975 \pm 0.0018 \\
2.0722 \pm 0.0018 \\
2.0726 \pm 0.0018 \\
2.0705 \pm 0.0018 \\
2.077 \pm 0.014 \\
\mathbf{2 . 0 7 1 4} \pm \mathbf{0 . 0 0 1}\end{array}$ & $\begin{array}{l}15.611 \pm 0.012 \\
15.569 \pm 0.021 \\
15.614 \pm 0.021 \\
15.597 \pm 0.021 \\
15.600 \pm 0.021 \\
15.599 \pm 0.021 \\
\mathbf{1 5 . 6 0 7} \pm \mathbf{0 . 0 0 8}\end{array}$ & $\begin{array}{c}38.274 \pm 0.038 \\
37.722 \pm 0.067 \\
38.483 \pm 0.068 \\
38.140 \pm 0.067 \\
38.151 \pm 0.067 \\
38.16 \pm 0.34 \\
\mathbf{3 8 . 2 6} \pm \mathbf{0 . 2 5}\end{array}$ \\
\hline $\begin{array}{l}\text { 3-15657-B } \\
\text { Mean 657A } \\
\text { 657B-B } \\
\text { Mean 657B A-B }\end{array}$ & 1140 & $\begin{array}{l}0.133 \\
0.199\end{array}$ & $\begin{array}{l}17.900 \pm 0.011 \\
17.894 \pm 0.016 \\
\mathbf{1 7 . 8 9 8} \pm \mathbf{0 . 0 0 9}\end{array}$ & $\begin{array}{c}0.86944 \pm 0.00026 \\
0.87011 \pm 0.00037 \\
\mathbf{0 . 8 6 9 8}\end{array}$ & $\begin{array}{l}2.1125 \pm 0.0013 \\
2.1135 \pm 0.0018 \\
\mathbf{2 . 1 1 2 8} \pm \mathbf{0 . 0 0 1 0}\end{array}$ & $\begin{array}{l}15.563 \pm 0.014 \\
15.570 \pm 0.021 \\
\mathbf{1 5 . 5 6 5} \pm \mathbf{0 . 0 1 1}\end{array}$ & $\begin{array}{l}37.815 \pm 0.045 \\
37.821 \pm 0.067 \\
\mathbf{3 7 . 8 1 7} \pm \mathbf{0 . 0 3 7}\end{array}$ \\
\hline $\begin{array}{l}\text { 3-12152-B } \\
\text { Mean 152A } \\
\text { Mean 152B } \\
\text { Mean 152C } \\
\text { Mean 152A-C } \\
\end{array}$ & 1730 & $\begin{array}{l}1.004 \\
0.269 \\
0.593\end{array}$ & $\begin{aligned} & 17.614 \pm 0.008 \\
& 17.899 \pm 0.008 \\
& 17.786 \pm 0.008 \\
& \mathbf{1 7 . 7 7} \pm \mathbf{0 . 3 6} \\
&\end{aligned}$ & $\begin{array}{c}0.8810 \pm 0.0003 \\
0.8683 \pm 0.0003 \\
0.8736 \pm 0.0003 \\
\mathbf{0 . 8 7 4} \pm \mathbf{0 . 0 1 6} \\
\end{array}$ & $\begin{array}{c}2.1198 \pm 0.0011 \\
2.0997 \pm 0.0010 \\
2.1084 \pm 0.0011 \\
\mathbf{2 . 1 0 9} \pm \mathbf{0 . 0 2 5} \\
\end{array}$ & $\begin{array}{l}15.517 \pm 0.012 \\
15.542 \pm 0.012 \\
15.537 \pm 0.012 \\
\mathbf{1 5 . 5 3 2} \pm \mathbf{0 . 0 3 0} \\
\end{array}$ & $\begin{aligned} & 37.336 \pm 0.035 \\
& 37.582 \pm 0.035 \\
& 37.498 \pm 0.035 \\
& \mathbf{3 7 . 4 7} \pm \mathbf{0 . 3 1} \\
&\end{aligned}$ \\
\hline $\begin{array}{l}1 \text { Separate acid- } \\
\text { mass spectro } \\
\text { Data are corre } \\
2 \mathrm{~Pb} \text { concentrati } \\
3 \text { Uncertainties }\end{array}$ & 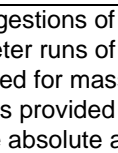 & 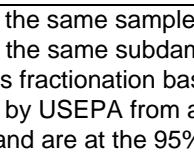 & $\begin{array}{l}\text { on analyses } \\
\text { digestions of } \\
\text { ffidnece leve }\end{array}$ & "-F". Only the mea & lues are shown w & & \\
\hline
\end{tabular}


Seven aliquots of one sample, 642B-A (3-15642-B), were run at a variety of temperatures as shown in Table A2-3. Mean values of all three isotope ratios were calculated for all data and only for those data run between approximately $1140^{\circ} \mathrm{C}$ and $1220^{\circ} \mathrm{C}$ as was done for the SRM 981 standard (Table A2-1). The calculated analytical uncertainties for the mean values are similar to those obtained for to those obtained for the mass fractionation correction factors calculated from analyses of the SRM 981 standard (Table A2-1).

Samples 3-15642-B (422 ppm Pb), 3-15644-B (39 ppm), 3-15654-B (110 ppm) and 3-12152-B (1730 ppm) were acid-digested in triplicate in order to evaluate the overall procedure and sample homogeneity. In addition, duplicate acid-digestions were performed on samples 3-15655-B (151 ppm), 3-15656-B (175 ppm), and 3-15657-B (1140 ppm). Significant isotopic variability was observed among samples 3-15654-B and 3-15656B, so three additional acid digestions of these two samples were performed (Table A2-4).

Two of the samples with moderate to high $\mathrm{Pb}$ content (3-15642-B, and 3-15657-B) show only minor variation in isotopic ratios among the data from replicate acid digestions (Table A2-4). In contrast, there is considerable isotopic variation observed among replicate aciddigestions of sample 3-12152-B.

Significant isotopic variation is observed among most of the samples with $<200$-ppm $\mathrm{Pb}$. Data from one acid digestion of sample 3-15654-B show anomalously radiogenic $\mathrm{Pb}$ isotopic values whereas data for one from sample 3-15656-B show anomalously nonradiogenic values. Data for sample 3-15644-B also show rather large variation $(0.85 \%$ in ${ }^{206} \mathrm{~Pb} /{ }^{204} \mathrm{~Pb}$ ). These variations are not related to mass fractionation corrections, but instead represent real variations induced either by the acid digestion procedures or as a result of sample heterogeneity.

Some isotopic heterogeneity within urban soils is perhaps to be expected. Soils at an individual site may be composed of a variety of natural and man made materials. The isotopic compositions of soils low in $\mathrm{Pb}$ are subject to influence by even small amounts of "exotic" material such as metal, solder, fertilizer, gasoline, etc. Such material may be randomly distributed at a given site and even within a given sample at that site. For example, inclusion of a single 0.0001 gram fragment of lead solder in a 1 gram sample of soil with $100 \mathrm{ppm} \mathrm{Pb}$ would effectively double the lead concentration in that 1-gram sample. The $\mathrm{Pb}$ isotopic composition would also be altered to the approximate average of that in the soil and that in the solder.

Samples higher in lead are generally much less sensitive to the effects of exotic materials. For example, the same $0.0001 \mathrm{gram}$ fragment of solder in a $1 \mathrm{gram}$ sample of soil 3-15657-B (1140 ppm) would alter the apparent $\mathrm{Pb}$ concentration by less than 10 percent 
and would have only about one-fifth the effect on the lead isotopic composition as in the former case. Consequently, the variation in isotopic compositions observed among the replicate acid-digestions of sample 3-12152-B is somewhat more difficult to explain. The results may indicate that the high- $\mathrm{Pb}$ phase in this sample is very heterogeneously distributed within the soil. Alternatively the results may indicate that there is more than one contaminant in the soil and that they are either not uniformly distributed within the soil or that the acid-digestion procedure is not completely dissolving at least one of the contaminants.

The inclusion of small amounts of exotic material appears to be responsible for the atypical isotopic compositions of samples 654B-A (3-15654-B) and 656B-B (3-15656-B). The data for these two fractions is included in $\mathrm{Pb}$ isotopic variation diagrams (Figure 1), but are excluded from the mean calculations for the ${ }^{206} \mathrm{~Pb} /{ }^{204} \mathrm{~Pb}$ vs. $\mathrm{Pb}$ concentration diagram in Figure 2.

\section{Method Determination Limit (Practical Quantitation Limit)}

The method determination limit (MDL) is defined as the lowest analyte concentration that can be determined with a specified relative standard deviation (Vandecasteele and Block, 1993). For concentration measurements, the method determination limit is generally 3 to 5 times the detection limit (Vandecasteele and Block, 1993). EPA often refers to the method determination limit as the practical quantitation limit. In the case of isotopic measurements, where absolute concentrations are not measured, the definition is modified as the lowest ionbeam intensity at which a specified relative standard deviation is obtained. The chemical procedures employed prior to mass spectrometry are designed to produce a purified $\mathrm{Pb}$ fraction and thus to eliminate or at least minimize matrix effects. Consequently, the method determination limit is equivalent to the instrument determination limit. The method determination limit is defined as that intensity for ${ }^{204} \mathrm{~Pb}$ (the least abundant isotope) below which the one-sigma-mean uncertainty in ${ }^{206} \mathrm{~Pb} /{ }^{204} \mathrm{~Pb}$ exceeds $\pm 0.05 \%$.

The method determination limit was determined as follows:

1. Seven aliquots of $\mathrm{Pb}$ standard solution (SRM-981) were loaded into the mass spectrometer and run using the normal software routine, but were repeatedly run at a variety of beam intensities.

2. Mean and standard errors (1 sigma mean) were calculated for the data from the seven runs at discreet beam intensity intervals.

3. The data were then plotted on a graph of relative standard deviation as a function of ${ }^{204} \mathrm{~Pb}$ beam-intensity (Figure A2-1). Best-fit curves were calculated for each of the seven samples and the intensity at which the relative uncertainty equals $0.05 \%$ were calculated. The 
method determination limit was then calculated from the mean of the seven samples as $3.7 \pm$ $0.2 \times 10^{-14}$ amps (Table A2-5, Figure A2-1). Beam intensities for normal running conditions are also shown in Figure A2-1 and are approximately one to two orders of magnitude larger than the MDL $\left(2.5 \times 10^{-13} \mathrm{~A}\right.$ to $\left.2.5 \times 10^{-12} \mathrm{~A}\right)$. 
Table A2-5. Summary of results for determination of the method determination limit (practical quantitation limit).

\begin{tabular}{|c|c|c|c|c|}
\hline Standard Run & coeff. $a^{1}$ & coeff. $b^{1}$ & $r^{2} 2$ & $\begin{array}{l}\text { Minimum } \\
\text { Intensity }^{3}\end{array}$ \\
\hline SRM981-38-00 & -25.595 & -0.86087 & 0.997 & $3.81 \times 10^{-14}$ \\
\hline SRM981-39-00 & -30.038 & -0.87641 & 0.995 & $3.98 \times 10^{-14}$ \\
\hline SRM981-40-00 & -29.891 & -0.87029 & 0.992 & $3.79 \times 10^{-14}$ \\
\hline SRM981-41-00 & -29.364 & -0.85108 & 0.988 & $3.50 \times 10^{-14}$ \\
\hline SRM981-42-00 & -28.378 & -0.81856 & 0.983 & $3.41 \times 10^{-14}$ \\
\hline SRM981-43-00 & -29.213 & -0.84817 & 0.996 & $3.77 \times 10^{-14}$ \\
\hline SRM981-44-00 & -26.309 & -0.75428 & 0.939 & $3.77 \times 10^{-14}$ \\
\hline MEAN = MDL & & & & $3.7 \pm 0.2 \times 10^{-14}$ \\
\hline
\end{tabular}

${ }^{1}$ Equations follow a power law in the form $Y=e^{a *} X^{b}$, where $y$ is relative uncertainty and $\mathrm{x}$ is ${ }^{204} \mathrm{~Pb}$ beam intensity in amps.

${ }^{2} r^{2}$ is the regression correlation coefficient.

${ }^{3}$ The minimum intensity in amps for each standard is calibrated for a 1 S.E. uncertainty of $0.05 \%$. 


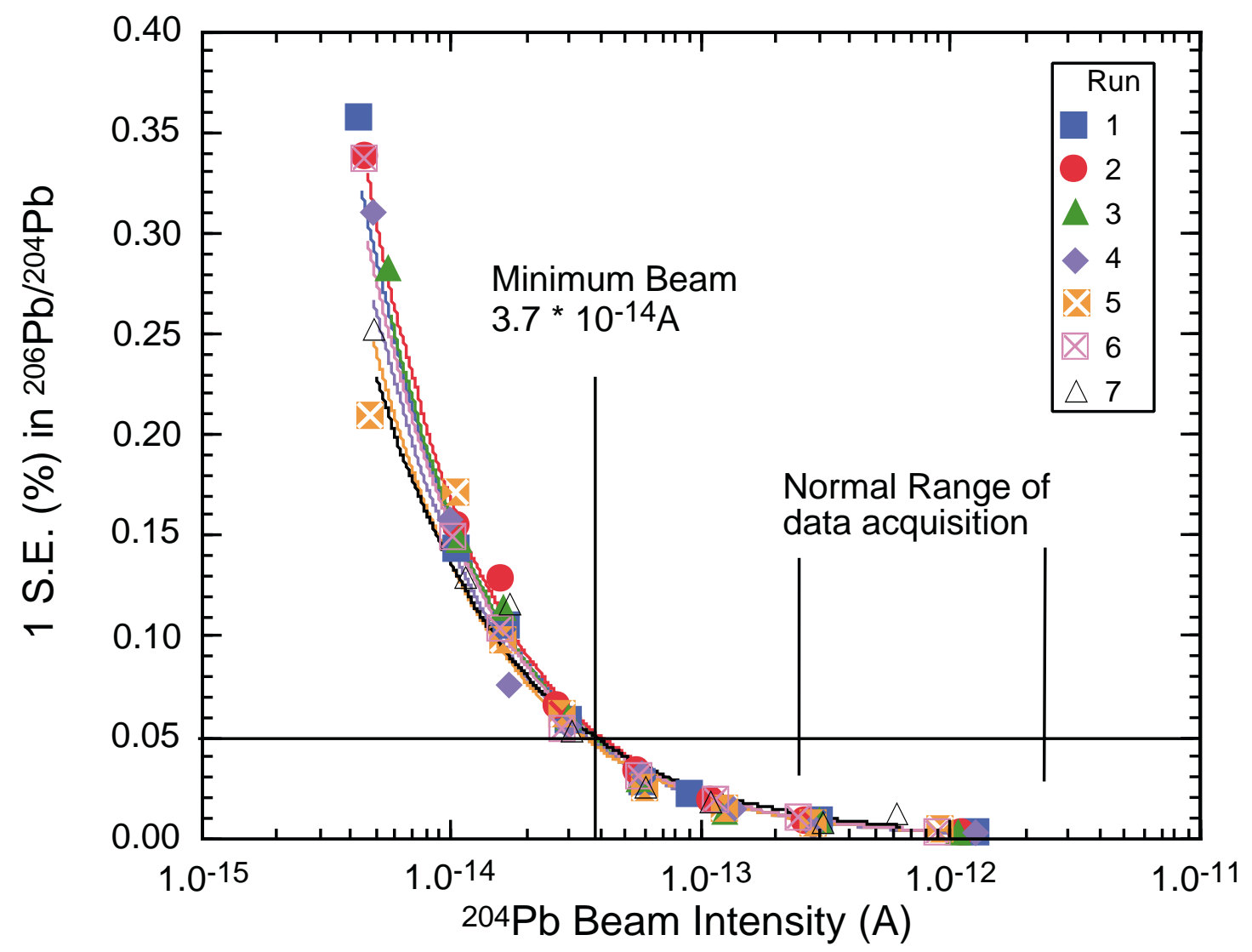

Figure A2-1. Percent Standard Error in ${ }^{206} \mathrm{~Pb} / 204 \mathrm{~Pb}$ vs. ${ }^{204} \mathrm{~Pb}$ beam intensity for seven analyses of NIST standard SRM 981. Seven standards were run at a variety of beam intensities. Best-fit curves (unweighted) through data for each standard are show. The method determination limit (MDL) is defined as that ${ }^{204} \mathrm{~Pb}$ beam intensity below which the 1 S.E. for ${ }^{206} \mathrm{~Pb} / 204 \mathrm{~Pb}$ exceeds $0.05 \%$. 